Florida International University FIU Digital Commons

6-18-2013

\title{
Testing and Expanding an Emotion-Centered Model of Workplace Aggression: The Moderating Effects of Perceived Intensity and Social Support in the Workplace
}

Josh Allen

Florida International University, jalle015@fiu.edu

DOI: $10.25148 /$ etd.FI13120412

Follow this and additional works at: https://digitalcommons.fiu.edu/etd

Part of the Industrial and Organizational Psychology Commons

\section{Recommended Citation}

Allen, Josh, "Testing and Expanding an Emotion-Centered Model of Workplace Aggression: The Moderating Effects of Perceived Intensity and Social Support in the Workplace" (2013). FIU Electronic Theses and Dissertations. 975.

https://digitalcommons.fiu.edu/etd/975 


\section{FLORIDA INTERNATIONAL UNIVERSITY}

Miami, Florida

TESTING AND EXPANDING AN EMOTION-CENTERED MODEL OF WORKPLACE AGGRESSION: THE MODERATING EFFECTS OF PERCEIVED INTENSITY AND SOCIAL SUPPORT IN THE WORKPLACE

A thesis submitted in partial fulfillment of the requirements for the degree of MASTER OF SCIENCE

in

PSYCHOLOGY

by

Josh W. Allen 
To: Dean Kenneth G. Furton

College of Arts and Sciences

This thesis, written by Josh W. Allen and entitled Testing and Expanding an EmotionCentered Model of Workplace Aggression: The Moderating Effects of Perceived Intensity and Social Support in the Workplace having been approved in respect to style and intellectual content, is referred to you for judgment.

We have read this thesis and recommend that it be approved.

Chockalingam Viswesvaran

Jesse S. Michel

Valentina Bruk-Lee, Major Professor

Date of Defense: June 18, 2013

The thesis of Josh W. Allen is approved.

$\begin{array}{r}\begin{array}{r}\text { Dean Kenneth G. Furton } \\ \text { College of Arts and Sciences }\end{array} \\ \hline \begin{array}{r}\text { Dean Lakshimi N. Reddi } \\ \text { University Graduate School }\end{array}\end{array}$

Florida International University, 2013 


\begin{abstract}
OF THE THESIS
TESTING AND EXPANDING AN EMOTION-CENTERED MODEL OF WORKPLACE AGGRESSION: THE MODERATING EFFECTS OF PERCEIVED INTENSITY AND SOCIAL SUPPORT IN THE WORKPLACE
\end{abstract} by Josh W. Allen Florida International University, 2013 Miami, Florida Professor Valentina Bruk-Lee, Major Professor The purpose of this thesis was to examine the mediating effects of job-related negative emotions on the relationship between workplace aggression and outcomes. Additionally, the moderating effects of workplace social support and intensity of workplace aggression are considered. A total 321 of working individuals participated through an online survey. The results of this thesis suggest that job-related negative emotions are a mediator of the relationship between workplace aggression and outcomes, with full and partial mediation supported. Workplace social support was found to be a buffering variable in the relationship between workplace aggression and outcomes, regardless of the source of aggression (supervisor or co-worker) or the source of the social support. Finally, intensity of aggression was found to be a strong moderator of the relationship between workplace aggression and outcomes. 


\section{TABLE OF CONTENTS}

CHAPTER

PAGE

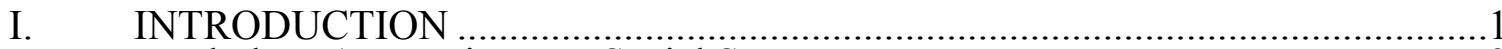

Workplace Aggression as a Social Stressor...................................................

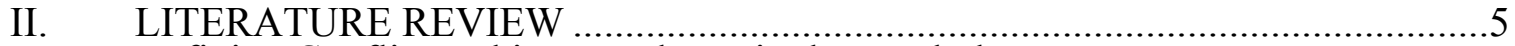

Defining Conflict and its Prevalence in the Workplace .....................................5

Interpersonal Conflict and Job Related Outcomes ...............................................

Defining Abusive Supervision and its Prevalence in the Workplace ........................

Abusive Supervision and Job Related Outcomes ...............................................11

Abusive Supervision and Interpersonal Deviance .............................................11

Workplace Aggression and Employee Health and Well-Being...............................12

The Role of Source of Aggression ................................................................... 15

The Mediating Role of Emotions .................................................................. 18

The Moderating Role of Social Support in the Workplace ................................23

The Moderating Role of Perceived Intensity ...................................................26

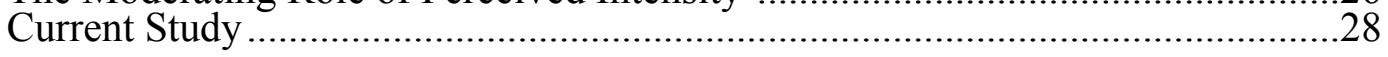

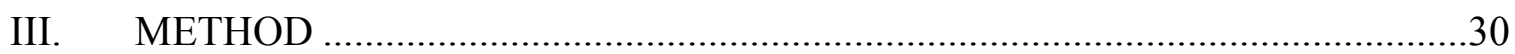

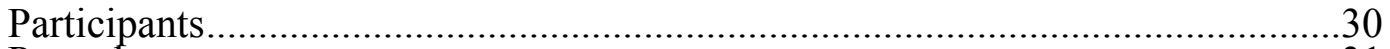



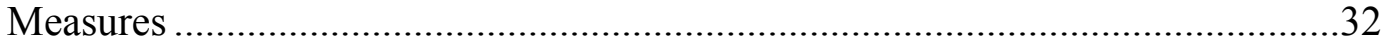

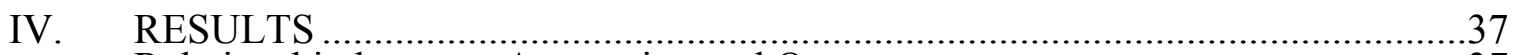

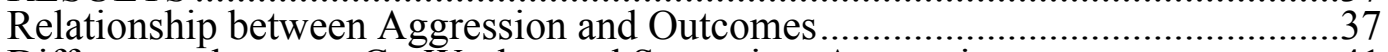

Differences between Co-Worker and Supervisor Aggression ..............................41

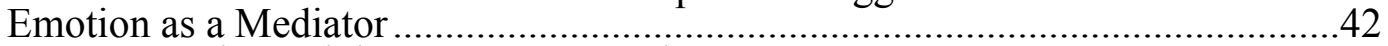

Cross-Domain Social Support as a Moderator...................................................50

Within-Domain Social Support as a Moderator...............................................65

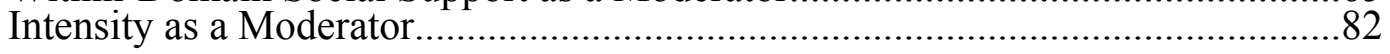

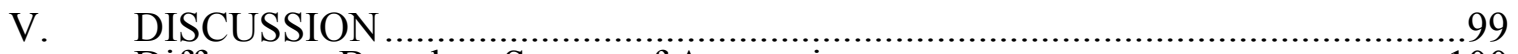

Differences Based on Source of Aggression ................................................100

Emotion as a Mediator .......................................................................... 102

The Moderating Effects of Social Support ......................................................104

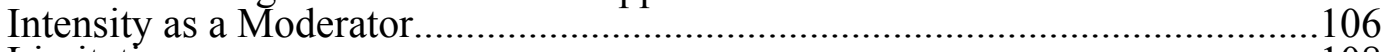

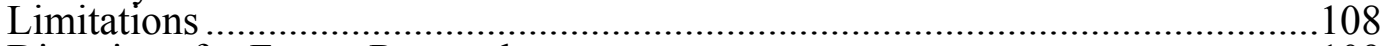

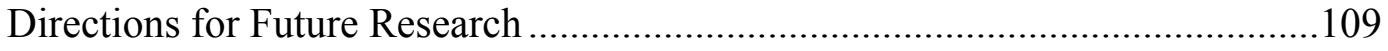

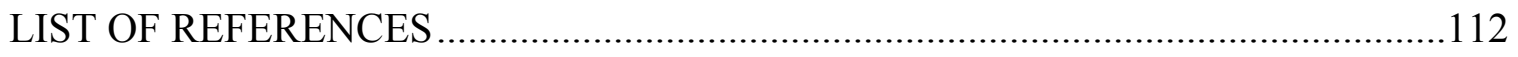

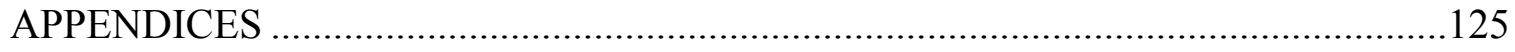




\section{LIST OF TABLES}

TABLE

PAGE

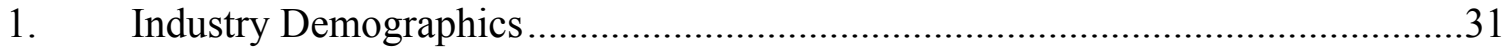

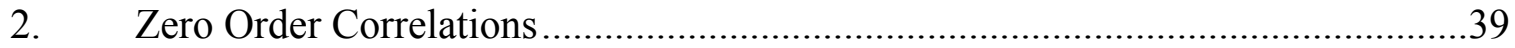

3. Job Related Negative Emotions as a Mediator between Conflict with Supervisors and Job Satisfaction, Turnover Intentions and Affective Commitment

4. Job Related Negative Emotions as a Mediator between Conflict with Supervisors and Perceived Stress, Physical Symptoms and Well-Being

5. Job Related Negative Emotions as a Mediator between Conflict with Supervisors and Depression and Irritation

6. Job Related Negative Emotions as a Mediator between Conflict with Co-Workers and Job Satisfaction, Turnover Intentions and Affective Commitment 46

7. Job Related Negative Emotions as a Mediator between Conflict with Co-Workers and Perceived Stress, Physical Symptoms and Well-Being .46

8. Job Related Negative Emotions as a Mediator between Conflict with Co-Workers and Depression and Irritation.

9. Job Related Negative Emotions as a Mediator between Abusive Supervision and Job Satisfaction, Turnover Intentions and Affective Commitment

10. Job Related Negative Emotions as a Mediator between Abusive Supervision and Perceived Stress, Physical Symptoms and Well-Being....

11. Job Related Negative Emotions as a Mediator between Abusive Supervision and Depression and Irritation

12. Co-Worker Social Support as a Moderator between Conflict with Supervisors and Job Satisfaction, Turnover Intentions and Affective Commitment

13. Co-Worker Social Support as a Moderator between Conflict with Supervisors and Perceived Stress, Physical Symptoms and Well-Being .52

14. Co-Worker Social Support as a Moderator between Conflict with Supervisors and Depression and Irritation

15. Co-Worker Social Support as a Moderator between Abusive Supervision and Job Satisfaction, Turnover Intentions and Affective Commitment 
16. Co-Worker Social Support as a Moderator between Abusive Supervision and Perceived Stress, Physical Symptoms and Well-Being.... .54

17. Co-Worker Social Support as a Moderator in the Relationship between Abusive Supervision and Depression and Irritation .54

18. Supervisor Social Support as a Moderator between Conflict with Co-Workers and Job Satisfaction, Turnover Intentions and Affective Commitment

19. Supervisor Social Support as a Moderator between Conflict with Co-Workers and Perceived Stress, Physical Symptoms and Well-Being .63

20. Supervisor Social Support as a Moderator between Conflict with Co-Workers and Depression and Irritation

21. Supervisor Social Support as a Moderator between Conflict with Supervisors and Job Satisfaction, Turnover Intentions and Affective Commitment

22. Supervisor Social Support as a Moderator between Conflict with Supervisors and Perceived Stress, Physical Symptoms and Well-Being .68

23. Supervisor Social Support as a Moderator Conflict with Supervisors and Depression and Irritation

24. Supervisor Social Support as a Moderator between Abusive Supervision and Job Satisfaction, Turnover Intentions and Affective Commitment

25. Supervisor Social Support as a Moderator between Abusive Supervision and Perceived Stress, Physical Symptoms and Well-Being .70

26. Supervisor Social Support as a Moderator between Abusive Supervision and

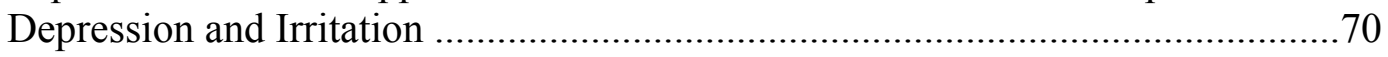

27. Co-Worker Social Support as a Moderator between Conflict with Co-Workers and Job Satisfaction, Turnover Intentions and Affective Commitment .77

28. Co-Worker Social Support as a Moderator between Conflict with Co-Workers and Perceived Stress, Physical Symptoms and Well-Being..... .78

29. Co-Worker Social Support as a Moderator between Conflict with Co-Workers and Depression and Irritation .78

30. Intensity as a Moderator between Conflict with Supervisors and Turnover Intentions, Job Satisfaction and Affective Commitment .83

31. Intensity as a Moderator between Conflict with Supervisors and Perceived Stress, Physical Symptoms and Well-Being .84 
32. Intensity as a Moderator between Conflict with Supervisors and Depression and Irritation .84

33. Intensity as a Moderator between Conflict with Co-Workers and Turnover Intentions, Job Satisfaction and Affective Commitment ......................................89

34. Intensity as a Moderator between Conflict with Co-Workers and Perceived Stress, Physical Symptoms and Well-Being .90

35. Intensity as a Moderator between Conflict with Co-Workers and Depression and Irritation

36. Intensity as a Moderator between Abusive Supervision and Turnover Intentions, Job Satisfaction and Affective Commitment .....................................................96

37. Intensity as a Moderator between Abusive Supervision and Perceived Stress, Physical Symptoms and Well-Being .97

38. Intensity as a Moderator between Abusive Supervision and Depression and Irritation 


\section{LIST OF FIGURES}

FIGURE

PAGE

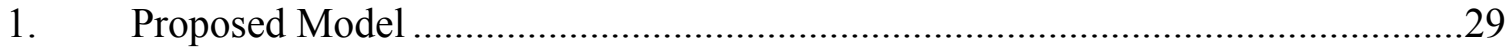

2. Co-Worker Support as a Moderator between Conflict with Supervisors and Turnover Intentions................................................................................56

3. Co-Worker Support as a Moderator between Conflict with Supervisors and Physical Symptoms.

4. Co-Worker Support as a Moderator between Conflict with Supervisors and

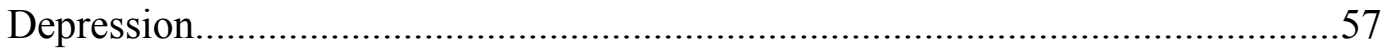

5. Co-Worker Support as a Moderator between Conflict with Supervisors and

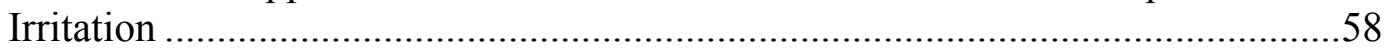

6. Co-Worker Support as a Moderator between Abusive Supervision and Turnover Intentions

7. Co-Worker Support as a Moderator between Abusive Supervision and Affective

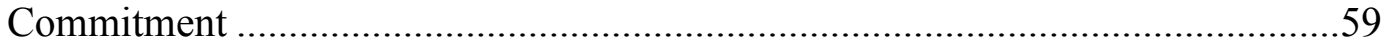

8. Co-Worker Support as a Moderator between Abusive Supervision and Physical Symptoms

9. Co-Worker Support as a Moderator between Abusive Supervision and Depression .60

10. Co-Worker Support as a Moderator between Abusive Supervision and Irritation

11. Supervisor Social Support as a Moderator between Conflict with Co-Workers and Physical Symptoms.

12. Supervisor Social Support as a Moderator between Conflict with Co-Workers and Irritation

13. Supervisor Social Support as a Moderator between Conflict with Supervisors and Job Satisfaction...

14. Supervisor Social Support as a Moderator Conflict with Supervisors and Affective Commitment 
15. Supervisor Social Support as a Moderator between Conflict with Supervisors and Perceived Stress

16. Supervisor Social Support as a Moderator between Conflict with Supervisors and Irritation

17. Supervisor Social Support as a Moderator between Abusive Supervision and Affective Commitment

18. Supervisor Social Support as a Moderator between Abusive Supervision and Perceived Stress .75

19. Supervisor Social Support as a Moderator between Abusive Supervision and Irritation .75

20. Co-Worker Social Support as a Moderator between Conflict with Co-Workers and Affective Commitment 80

21. Co-Worker Social Support as a Moderator between Conflict with Co-Workers and Perceived Stress .80

22. Co-Worker Social Support as a Moderator between Conflict with Co-Workers and Physical Symptoms. .81

23. Co-Worker Social Support as a Moderator between Conflict with Co-Workers and Depression .81

24. Co-Worker Social Support as a Moderator between Conflict with Co-Workers and Irritation .82

25. Intensity as a Moderator between Conflict with Supervisors and Turnover Intentions .86

26. Intensity as a Moderator between Conflict with Supervisors and Job Satisfaction .86

27. Intensity as a Moderator between Conflict with Supervisors and Affective Commitment .87

28. Intensity as a Moderator between Conflict with Supervisors and Well-Being......87

29. Intensity as a Moderator between Conflict with Supervisors and Depression .....88

30. Intensity as a Moderator between Conflict with Supervisors and Irritation ...........88

31. Intensity as a Moderator between Conflict with Co-Workers and Job Satisfaction 
32. Intensity as a Moderator between Conflict with Co-Workers and Affective

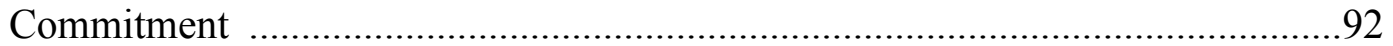

33. Intensity as a Moderator between Conflict with Co-Workers and Perceived Stress



34. Intensity as a Moderator between Conflict with Co-Workers and Physical Symptoms .93

35. Intensity as a Moderator Conflict with Co-Workers and Well-Being .94

36. Intensity as a Moderator between Conflict with Co-Workers and Depression .....94

37. Intensity as a Moderator between Conflict with Co-Workers and Irritation ........95

38. Intensity as a Moderator Abusive Supervision and Job Satisfaction....................98 


\section{CHAPTER I. INTRODUCTION}

Aggression in the workplace is a rapidly expanding area of research that is reported to have a serious impact on individual employee outcomes, as well as a number of important organizational outcomes. For instance, workplace aggression has been found to be significantly related to decreases in job satisfaction, lower performance, greater physical health symptoms, and higher turnover intentions (Frone, 2000; Nixon, 2011; Thomas, Bliese \& Jex, 2005; Tucker, Sinclair \& Thomas, 2005). Workplace aggression can be defined as behavior that causes, or threatens to cause, harm to others in the workplace (e.g., Loeber \& Hay, 1997).

Workplace aggression can take the form of physical or psychological abuse, although psychological aggression is much more prevalent than physical aggression (Baron \& Neuman, 1996; Gerberich, Church, McGovern, Hansen, Nachreiner, Geisser, Ryan, \& Mongin, 2004; LeBlanc \& Kelloway, 2002; U.S. Postal Service Commission, 2000). Psychological aggression refers to verbal aggression, such as yelling, and nonverbal aggression, such as threatening postures or looks (Schat \& Kelloway, 2003). Workplace aggression has a broad definition that encompasses many different subtypes including interpersonal conflict, hostility, harassment, bullying, mobbing, abusive supervision, incivility and social undermining (Hershcovis, 2011; Raver \& Barling, 2008).

A study conducted by Northwestern National Life Insurance Company estimated that there were 16 million workplace psychological aggression incidents in 1993 (see VandenBos \& Bulatao, 1996). In a survey of 4918 nurses across Minnesota, $13 \%$ of 
nurses reported experiencing physical aggression at work in the past year and 38\% reported experiencing psychological aggression (Gerberich et al., 2004). In a diary study evaluating stressors in work and non-work settings, psychological aggression was identified as the most upsetting stressor (Bolger, DeLongis, Kessler, \& Schilling, 1989). Similarly, in a survey of 600 people from three different organizations Smith and Sulsky (1995) found that almost $25 \%$ of respondents chose interpersonal issues as most troubling job stressor. Finally, in an employee survey given by Schwartz and Stone (1993) employees indicated that three-fourths of detrimental work experiences a consequence of workplace aggression.

Interpersonal conflict and abusive supervision both represent poor interpersonal relations at work and fall under the larger umbrella of workplace aggression. Metaanalytic evidence with regards to interpersonal conflict has displayed a negative relationship with job satisfaction, job performance, organizational commitment, psychological and physical well-being (De Dreu \& Weingart, 2003; de Wit, Greer \& Jehn, 2012; Hershcovis, 2011; Nixon, Mazzola, Bauer, Krueger, \& Spector, 2011; Spector \& Jex, 1998). Abusive supervision has been found to impact many of the same employee outcomes as interpersonal conflict, including turnover intentions, psychological wellbeing, affective commitment and job satisfaction (Aryee, Chen, Sun, \& Debrah, 2007; Hershcovis, 2011; Tepper, 2000). Despite the inherent similarities between abusive supervision and interpersonal conflict, the two areas are rarely measured together with just one published empirical study to date exploring a relationship between the two areas (Tepper, Moss \& Duffy, 2011). 


\section{Workplace Aggression as a Social Stressor}

The occupational stress literature can help to provide the framework as to how the process of workplace aggression impacts employee health and wellbeing, as well as organizational outcomes. The classic transactional model defines the stress process by two elements: stressors and strains (Lazuras \& Folkman, 1984). Stressors are situational stimuli that are perceived as challenging or threatening and require adaptive responses from individuals (Lazuras \& Folkman, 1984). Strains refer to the negative responses employees may experience when faced with a stressor and may be categorized as affective, physical, or behavioral (Jex \& Beehr, 1991). Stressors require energy and effort to cope with demands which often invokes emotional-related strains such as anger, anxiety, frustration and emotional exhaustion (Cartwright \& Cooper, 1997; Lazuras \& Folkman, 1984; Spector \& Bruk-Lee, 2008). Psychological strains refer to emotional responses to stressors, such as anxiety or anger, as well as attitudinal responses to stress, such as job dissatisfaction, higher intentions to quit and lower organizational commitment.

Poor workplace interpersonal relations can be conceptualized as social stressors. Much of workplace mistreatment research (e.g., Barling, 1996; LeBlanc \& Kelloway, 2002; Spector \& Bruk-Lee, 2008) has drawn on a stressor-strain model to argue that workplace aggression is a stressor that negatively relates to a range of outcomes. A social stressor is defined as "an incident when individuals or parties experience a negative response to disagreements, threats, or interference to a party's needs or goals" (Spector \& Bruk-Lee, 2008, p. 268). Social stressors have been shown to have a detrimental impact on the physical and psychological well-being of employees, as well as a direct 
relationship with outcomes of organizational importance such as job performance and commitment (Bowling \& Beehr, 2006; De Dreu \& Weingart, 2003; Hershcovis, 2011; Jex \& Beehr, 1991). Barling (1996) applied this stressor model to the experience of workplace aggression, suggesting that exposure to aggression is a workplace stressor that leads to direct outcomes such as fear, and subsequently to psychological, physical, and behavioral outcomes. The relationship between workplace stressors and strains has been well documented (Jex \& Beehr, 1991; Spector \& Bruk-Lee, 2008), but our understanding of the mediating and moderating processes through which work stressors affect strains is limited (Allen, Wittgenstein, Harari \& Bruk-Lee, 2012; Beehr, 1994; Hershcovis, 2011).

My research study focuses on interpersonal conflict at work and abusive supervision conceptualized as social stressors. Currently, much of the research in the workplace aggression subtypes has been concerned with distinguishing one subtype from another (Tepper \& Henle, 2011). However, recently there has been a call to unify workplace aggression research and identify similarities among the various subtypes instead of pointing out the differences (Hershcovis, 2011; Nixon, 2011; Raver \& Barling, 2008). Specifically, researchers urge for a refined model of workplace aggression that seeks to identify universal mediators and moderators common to all areas of workplace aggression (Hershcovis, 2011). The primary purpose of this research is to explore the common processes by which conflict and abusive supervision relate to strains by exploring both mediating (negative emotions) and moderating variables (social support and perceived intensity). 


\section{CHAPTER II. LITERATURE REVIEW}

The present section will identify the current research with regards to interpersonal conflict and abusive supervision. I will clarify the relationships between these two subtypes of aggression with several job and health related outcomes. First, I will examine the literature on interpersonal conflict and relevant job related outcomes. Next, I will review the literature examining the effect of abusive supervision on relevant job related outcomes. I will then focus specifically on the impact of interpersonal conflict and abusive supervision on employee health and well-being. Following, I will examine the role of the source of conflict (co-worker and supervisor) on the relationship between interpersonal conflict and outcomes. Additionally, I will discuss the role of emotion as a mediator between the two subtypes of workplace aggression (interpersonal conflict and abusive supervision) and job and health related outcomes. Finally, I will examine the moderating influences of workplace social support and the perceived intensity of workplace aggression on the relationship between workplace aggression and job and health related outcomes.

\section{Defining Conflict and its Prevalence in the Workplace}

Conflict is defined from a social psychology perspective as the perceived incompatibilities by parties of the views, wishes, and desires that each holds (Jehn, 1995). Interpersonal conflict at work is routinely broken down into two different types: task conflict and relationship conflict (Jehn, 1995). Relationship conflict, also referred to as emotional conflict, is personal in nature and involves incompatibilities among group members, or simply the extent to which tension or friction characterizes group members' 
interactions (Pondy, 1969). Relationship conflicts can involve disagreements over personal tastes, political preferences, values and style (Jehn, 1995; De Dreu \& Weingart, 2003). Specifically, relationship conflicts result from personal differences that are not directly related to the job being performed. Conversely, task conflict refers to disagreements or differing points of views that revolve around the completion or implementation of a task (Jehn, 1995). Specifically, task conflicts are defined as conflicts about the distribution of resources, procedures and policies, and disagreements about how to perform a job (De Dreu \& Weingart, 2003). Although task performance is generally believed to be less detrimental to a group, task conflict is still found to negatively impact satisfaction and performance (De Dreu \& Weingart, 2003).

Until recently the study of workplace interpersonal conflict has been largely overlooked (de Jonge, Reuvers, Houtman, \& Kompier, 2000). There has been a plethora of studies showing that conflict at work is one of the most common sources of stress in the workplace and is therefore an important topic across occupations, which has in turn renewed interest in the construct (Bolger et al., 1989; Keenan \& Newton, 1985; Narayanan, Menon, \& Spector, 1999; Smith \& Sulsky, 1993). In a study of full-time workers across a variety of occupations, Hahn (2000) found respondents reported experiencing interpersonal conflict in half of their work days. Keenan and Newton (1985) found $74 \%$ of stressful events were social in nature, with conflict at work being reported as a major stressor in a study of young engineers. In a study of 227 Department of Transportation agents, researchers found that interpersonal conflict was a relatively frequent event with nearly four verbal confrontations occurring per day (Brondolo, Masheb, Stores, Stockhammer, Tunick, Melhado, Karlin, Schwartz, Harburg, \& 
Contrada, 1998). Furthermore, these researchers found a significant variability on the amount of conflict experienced with about one third (34\%) of respondents reporting not experiencing a conflict on the previous workday, while $37 \%$ reported experiencing three or more conflicts. Narayanan and colleagues (1999) found that interpersonal conflict was the third most cited stressor in a US population.

\section{Interpersonal Conflict and Job Related Outcomes}

Research supports the notion that both task and relationship conflict can be detrimental to job satisfaction (e.g., De Dreu \& Weingart, 2003; Duffy, Shaw \& Stark, 2000; Frone, 1998; Guerra, Martinez, Munduate, \& Medina, 2005; Liu, Spector \& Shi, 2005; Medina, Munduate, Dorado, Martinez, \& Guerra, 2005; Spector, 1987). In a study of military personnel, Tucker and colleagues (2005) found interpersonal conflict was negatively related to job satisfaction $(\mathrm{r}=-.30)$. Penney and Spector (2005) found that interpersonal conflict rated by self-ratings and peer-ratings were negatively correlated to employee's job satisfaction. Similarly, in a study of members of a nonprofit sports board, interpersonal conflict was negatively related to job satisfaction $(r=-.48)$ (Hamm-Kerwin \& Doherty, 2010). Frone (2000) found that employees who perceived more conflict with supervisors also reported lower levels of overall satisfaction with their jobs $(r=-.44)$. A meta-analysis of 10 studies showed that the Interpersonal Conflict at Work Scale (ICAWS) correlated negatively $(r=-.32)$ with job satisfaction (Spector \& Jex, 1998).

Additionally, support is found cross-culturally for the impact of interpersonal conflict on job satisfaction in a study of white collar workers in Japan (Nakata, Haratani, Takahashi, Kawakami, Arito, Kobayashi, \& Araki, 2004). 
Likewise, interpersonal conflict is found to have a negative relationship with affective commitment (e.g., Chen, Sharma, Edinger, Shapiro, \& Farh, 2011; De Dreu \& Beersma, 2005; Frone, 2000; Janssen, 2004; Thomas, Bliese \& Jex, 2005). Affective commitment is referred to as "emotional attachment to, identification with, and involvement in the organization" (Meyer \& Allen, 1991, p.67). Affective commitment is differentiated from continuance or normative commitment because it involves an emotional connection with the organization. Affective commitment implies that employees want to be working in the organization (Meyer \& Allen, 1991). Employee commitment is extremely important as low employee commitment is often cited as a precursor to employee turnover and poor employee performance (Thomas et al., 2005). Other areas of workplace aggression have shown a similar relationship with affective commitment including studies of workplace violence (Marrs, 1999), mobbing (Cantisano, Dominguez \& Galan, 2006), and incivility (Spence Laschinger, Leiter, Day \& Gilin, 2009). Furthermore, meta-analytic research supports a negative relationship between workplace aggression and organizational commitment (e.g., Bowling \& Beehr, 2006; de Wit et al., 2012; Hershcovis, 2011). Additionally, support is found cross-culturally for the negative impact of interpersonal conflict on organizational commitment in a study of working professionals in China (Li, Ahlstrom, \& Ashkanasy, 2010).

Finally, both task and relationship conflict are consistently found to have a positive relationship with employee turnover intentions (e.g., Bruk-Lee \& Spector, 2006; Hershcovis, 2011; Medina et al., 2005; Nixon, 2011; Tucker et al., 2005). The more conflict an employee faces, the more likely they will leave, or make plans to leave the company (Chen et al., 2011). In studies focused on conflict in student work teams, 
researchers discovered that conflict leads to an increase in the intent to leave the team (e.g. Bayazit \& Mannix, 2003; Jehn, 1995; Jehn, Northcraft \& Neale, 1999). In a study of young employees, Frone (2000) found that employees who reported more conflict with supervisors indicated higher intentions of quitting. Additionally, Chen and Spector (1992) found a moderate positive correlation $(r=.39)$ between interpersonal conflict and intentions to quit in a large sample of employees from a variety of occupations. Given the positive relationship between turnover intentions and actual turnover, self-reports of intentions to quit are a good indicator of actual turnover (Carsten \& Spector, 1987) and the impact of interpersonal conflict on employee turnover intentions likely leads to more turnover.

Hypothesis 1: Interpersonal conflict will be negatively related to affective commitment and job satisfaction and positively related to turnover intentions.

\section{Defining Abusive Supervision and its Prevalence in the Workplace}

Abusive supervision has been identified as a major problem for organizations and is a quickly expanding field of research. Estimates suggest that more than $13 \%$ percent of the working population become the target of abusive supervision, or non-violent hostility instigated by their superior (Schat, Frone, \& Kelloway, 2006). The cost of abusive supervision to organizations is estimated to be into the billions of dollars per year with an increase in employee health care costs and turnover, and a decrease in employee performance (Tepper, Duffy, Henle \& Lambert, 2006). Abusive supervision is characterized as "subordinate's perceptions of the extent to which supervisors engage in sustained display of hostile verbal and non-verbal behavior, excluding physical contact" 
(Tepper, 2000, p.178). The concept of abusive supervision is subjective as the same behavior by a supervisor may be perceived differently by two different employees. Additionally, a behavior in one context may be believed to be abusive, but the same behavior in a different context may not. Although abusive supervision relates to other supervisory behaviors (e.g., petty tyranny, supervisor aggression and workplace bullying), it is identified by being downward directed, excluding physical violence, and not encompassing behaviors other than hostility (Tepper, 2007).

Abusive supervision can be identified by public criticism, loud and angry tantrums, rudeness, inconsiderate actions, taking undue credit, invasion of privacy, and coercion (Bies 2000; Tepper et al., 2006). Traditionally, abusive supervision researchers have relied on different forms of justice (i.e., procedural justice, organizational justice) as a potential mediator and moderator between abusive supervision and job outcomes (Allen et al., 2012; Hershcovis, 2011; Tepper, 2000; Tepper, et al., 2006). Procedural injustice is also found to be an antecedent of abusive supervision (Aryee et al., 2007; Tepper et al., 2006). The belief is that supervisors who feel wronged by their boss or organizations will take their feelings of injustice out on their employees, and an employee's sense of organizational justice will determine how much the abusive supervision affects outcomes (Aryee et al., 2007; Tepper et al., 2006). Although injustice has been shown to be both an effective mediator and moderator of abusive supervision and job outcomes relationships, researchers propose it is time to explore other potential universal mediating and moderating variables (Allen et al., 2012; Hershcovis, 2011). For example, in a quantitative review of the workplace aggression literature, Hershcovis (2011) points out a number of possible moderating variables of the workplace aggression and outcomes 
relationship that have been understudied (i.e., negative emotion, relationship power, and intensity). Furthermore, in a qualitative review of workplace aggression Allen and colleagues (2012) found that only $41 \%$ of studies meeting the inclusion criteria tested a mediating variable and $61 \%$ of studies tested a moderating variable.

\section{Abusive Supervision and Job Related Outcomes}

Given abusive supervision's similarity to interpersonal conflict as a workplace stressor, I believe that the process (e.g., mediating and moderating variables) and outcomes (both job related and health related) should be similar to interpersonal conflict as well. Abusive supervision has been found to be negatively related to job satisfaction (Tepper et al., 2004; Tepper et al., 2009), organizational commitment (Aryee et al., 2007; Duffy \& Ferrier, 2003; Tepper, Henle, Lambert, Giacalone, \& Duffy, 2008), and positively related to turnover intentions (Aryee et al., 2007; Duffy, Ganster, \& Pagon, 2002; Tepper, Duffy, Hoobler \& Ensley, 2004). In a meta-analysis of workplace aggression the negative outcomes of abusive supervision appear to parallel the negative outcomes of interpersonal conflict, specifically psychological distress, organizational commitment, and job satisfaction (Hershcovis, 2011).

Hypothesis 2: Abusive supervision will be negatively related to job satisfaction and affective commitment and will be positively related to turnover intentions.

\section{Abusive Supervision and Interpersonal Deviance}

Sustained exposure to abusive supervision is associated with serious negative outcomes for victims and employers, including aggression directed against a victim's supervisor (Dupre, Inness, Connelly, Barling, \& Hoption, 2006; Inness, Barling \& 
Turner, 2005), and family (Hoobler \& Brass, 2006). A person is more likely to be aggressive or hostile after abusive supervision but given a supervisor's control over subordinates, the aggression or hostility may be taken out on other co-workers (Burton, Hoobler \& Scheur, 2011). Aquino, Tripp, and Bies (2001) found that victims were less likely to seek revenge against higher status aggressors, reasoning that victims feared retaliation. Abusive supervision may lead employees to take their aggression out on other employees resulting in more negative interpersonal relations (Bamberger \& Bacharach, 2006; Lian, Ferris \& Brown, 2012; Mitchell \& Ambrose, 2007; Tepper, 2007). Further evidence of the link between deviance and abusive supervision is provided by Mitchell and Ambrose (2007) where researchers found that abusive supervision was positively related to interpersonal deviance, (e.g., playing mean pranks on each other, gossiping, and saying hurtful things about each other). Additionally, research suggests that abusive supervision results in more interpersonal deviance, supervisor directed deviance and organizational deviance (e.g., Lian et al., 2012; Liu, Kwan, Wu \& Wu, 2010; Mitchell \& Ambrose, 2007; Tepper, Henle, Lambert, Giacalone \& Duffy, 2008). In a qualitative review of abusive supervision literature Allen and colleagues (2012) concluded that deviance was the most commonly studied outcome with regards to abusive supervision.

Hypothesis 3: Abusive supervision will be positively related to interpersonal conflict.

\section{Workplace Aggression and Employee Health and Well-Being}

Perhaps the worst outcome of workplace aggression is the detriment to employee health that it seems to inflict. Evidence suggests that negative interactions, such as 
interpersonal conflicts, have a stronger effect than positive events with regards to impact on individual well-being (Guerra et al., 2005; Rook, 2001; Taylor, 1991). Interpersonal conflict has been linked to depression, negative emotional states, psychosomatic complaints, life dissatisfaction, burnout, and psychiatric morbidity (Dormann \& Zapf, 1999; Frone, 1998, 2000; Lubbers, Loughlin \& Zweig, 2005). Self-reported physical symptoms are particularly useful as they are often indicators of short and long-term health (Benyamini \& Idler, 1999).

Using anecdotal case studies, Adams (1992) concluded that workplace aggression presents high costs to an organization through damage to the psychological well-being of employees. In a meta-analysis of working employees, Spector and Jex (1998) found interpersonal conflict was positively correlated with anxiety and depression. In a study of 1,489 members of the US military, Tucker and colleagues (2005) found interpersonal conflict was negatively related to global well-being $(r=-.35)$, and positively related to depression $(r=.33)$. Dormann and Zapf (1999) found that increased conflict led to higher levels of depressive symptoms in employees. Furthermore, in a study of 276 female health care workers, researchers found that interpersonal conflict at work was significantly correlated with psychological distress (Klainin, 2009). Additionally, in a study of employed adolescents researchers found interpersonal conflict significantly impacted employee depression and even on the job drug use (Frone, 1998). Bruk-Lee and Nixon (2011) surveyed 260 adult workers in a variety of occupations and found relationship conflict was significantly negatively related to depression $(r=.32)$. Finally, in a meta-analysis workplace aggression was positively related to anxiety (mean $r=.25$ ), 
depression (mean $r=.28$ ), and frustration/irritation (mean $r=.30$; Bowling \& Beehr, 2006).

The negative impact of interpersonal conflict is not only limited to individual psychological well-being as the impact is also found on physical symptoms reported by the individuals (Bruk-Lee, 2006; Frone, 2000; Hahn, 2000; Lubbers et al., 2005). Data from a diary study of working undergraduates conducted by Hahn (2000) showed that participants reported more health symptoms following a conflict. Spector and Jex (1998) reported a significant correlation between the Physical Symptoms Inventory (PSI) and a measure of interpersonal conflict at work $(r=.26)$. Bruk-Lee (2006) found that interpersonal relationship conflict was significantly related to psychosomatic symptoms $(r=.29)$. Meta-analytic evidence from Nixon and colleagues (2011) found interpersonal conflict was positively related to backaches, headaches, eye strain, sleep disturbances, dizziness, fatigue, appetite and gastrointestinal problems. Additionally there is some evidence suggesting that the positive relationship between workplace aggression and physical symptoms persists in longitudinal contexts (Spector, Chen, \& O`Connell, 2000). Furthermore, interpersonal conflict has been linked to increased cardiovascular activity, and even the greater risk of heart attack, with the risk even greater in women and people with lower social support (Lavoie, Miller, Conway, \& Fleet, 2001; Piferi \& Lawler, 2000; Steptoe, 2000).

A poor relationship with one's supervisor is believed to be a major source of stress for employees (Tepper, 2000). Abusive supervision has been linked to anxiety and depression (Tepper, 2000), well-being (Hobman, Restubog, Bordia \& Tang, 2008; Tepper, 2000; Yagil, 2006) and burnout (Grandey, Kern, \& Frone, 2007; Yagil, 2006). A 
study by Rafferty, Restubog and Jimmieson (2010) found that abusive supervision was positively related to psychological distress and insomnia. In a study of 131 students in the Philippines, abusive supervision was negatively related to psychological well-being and positively related to project anxiety (Hobman, Restubog, Bordia \& Tang, 2009). Furthermore, researchers also found that this relationship was moderated by social support where team member support had a buffering effect, and supervisor support exacerbated the relationship. Meta-analytic evidence has displayed a negative relationship between abusive supervision and psychological health $(r=-.31$; Hershcovis, 2011). Additionally, supervisor initiated aggression displayed a negative effect on both psychological and physical health $(r=-.30$ and $r=-.15$, respectively), (Hershcovis, 2011). Despite the apparent relationship between abusive supervision and psychological distress in subordinates, the relationship between abusive supervision and physical symptoms has yet to be explored (Allen et al., 2012; Nixon, 2011).

Hypothesis 4: Interpersonal conflict will be negatively related to well-being and positively related to perceived stress, physical symptoms, psychological distress (depression and irritation) and job related negative affect.

Hypothesis 5: Abusive supervision will be negatively related to well-being and positively related to perceived stress, physical symptoms, psychological distress (depression and irritation) and job related negative affect.

\section{The Role of the Source of Aggression}

Recently, researchers have started to explore the source of conflict (e.g., coworkers or supervisors) to determine if there is a difference in outcomes based on the 
source (e.g., Bruk-Lee \& Spector, 2006; Frone, 2000). One reason for this distinction is because supervisors are believed to represent an organization; therefore conflict with a supervisor should have more influence on organizational outcomes (i.e., commitment, job satisfaction and turnover; Frone, 2000). Conflict with co-workers is believed to affect more personal outcomes like depression and somatic symptoms (Frone, 2000). Metaanalytic evidence shows that supervisor aggression has stronger adverse relationships than co-worker aggression with job satisfaction, affective commitment, turnover intent, general health and organizational deviance (Hershcovis \& Barling, 2010). Furthermore, both coworker and supervisor aggression were more strongly related to employee outcomes than outsider aggression, suggesting the importance of interpersonal relations with others in the workplace (Hershcovis \& Barling, 2010). Researchers did find a slightly higher negative relation with physical well-being with regards to coworker aggression over supervisor aggression, as previously suggested (e.g., Frone, 2000; Hershcovis, 2010). However, psychological distress was significantly worse when supervisors perpetrated the aggression. In a study of nurses, workplace aggression with someone who holds high relationship power was significantly related to organizational attitudes, including decreased job satisfaction (Nixon, 2011). Differentiating between sources of conflict can help researchers identify moderators or mediators that may be specific to one source of conflict (Hershcovis \& Barling, 2010).

Aggression initiated by someone with formal power may signal to the victims that they do not matter, and that their position within the company is in jeopardy which could adversely impact employee attitudes and behaviors (Kivimaki, Ferrie, Brunner, Head, Shipley, Vahtera, et al., 2005). Coworkers possess social power and are able to affect the 
presence and quality of social relationships within the group. Social exclusion is powerful and is associated with anxiety and depression, as well as aggressive tendencies (Baumeister \& Tice, 1990; Twenge, Baumeister, Tice, \& Stucke, 2001). The manner in which co-workers treat an employee may indicate their status within the group (Aquino, Douglas, \& Martinko, 2004; Bies, 1999). The recipients of abusive supervision are also more likely to reciprocate with supervisor-targeted aggression and deviance (Inness et al., 2005; Mitchell \& Ambrose, 2007), and less likely to reciprocate with organizational citizenship behaviors (Aryee et al., 2007; Harris, Harvey \& Kacmar, 2011).

The nature of how the source of conflict affects somatic symptoms is an area that needs further exploration (Frone, 2000; Hershcovis, 2011; Nixon, 2011). In a study of 195 student workers, Lubbers and colleagues (2005) found that interpersonal conflict was negatively related to psychological and physical health but only for conflict with supervisor; conflict with co-workers were not significantly related to either psychological or physical health. Furthermore, researchers found that job-related affect partially mediated the relationship between interpersonal conflict and psychological and physical health (Lubbers et al., 2005). Conversely, Frone (2000) found that when employees reported experiencing more conflict with their co-workers, they also reported higher levels of somatic symptoms. A goal of this thesis is to further explore the differential impact that the source of aggression may have on the criteria of interest.

Hypothesis 6a: Supervisor initiated aggression (abusive supervision and conflict with supervisors) will be more strongly related to organizational outcomes (job satisfaction, affective commitment and turnover intentions) than co-worker initiated aggression (conflict with co-workers). 
Hypothesis 6b: Co-worker initiated aggression (conflict with co-workers) will be more strongly related to individual health outcomes (perceived stress, well-being, psychological distress, and physical symptoms) than supervisor initiated aggression (abusive supervision and conflict with supervisors).

\section{Negative Emotion as a Mediator between Workplace Aggression and Outcomes}

The role of negative emotions (i.e., negative affect) is recognized as an important variable that is being increasingly studied in workplace aggression research, particularly with regards to research on employee health and well-being. Affect can be thought of as an umbrella term that encompasses a broad range of feelings that individuals experience which are in the moment, short-range affective reactions (Watson \& Clark, 1984). Affect is considered to be state dependent and can fluctuate depending on the environment (Watson \& Clark, 1984). Affectivity on the other hand describes a more stable personality characteristic that frames how the world is perceived by the individual. Negative affectivity reflects pervasive individual differences in negative emotionality and self-concept (Watson \& Clark, 1984). The role of emotion as a mediator is crucial to the emotion-centered model of social stressors (Spector 1998; Spector \& Bruk-Lee, 2008). It is proposed that perceived stressors lead to an emotional response which in turn leads to a strain response (Spector \& Bruk-Lee, 2008). The strain experienced may be behavioral, physical or psychological.

In some areas of workplace aggression the negative affectivity of an individual is treated as a nuisance and controlled for (see Brief, Burke, George, Robinson \& Webster, 1998) but there is convincing theoretical and empirical evidence that supports workplace 
negative affect as an effective mediator between work environments and employee outcomes (Brief \& Weiss, 2002; Bruk-Lee \& Spector, 2006; Hershcovis, 2011; Lubbers et al., 2005; Penney \& Spector, 2005; Spector, 1998; Spector \& Bruk-Lee, 2008; Spector, Zapf, Chen \& Frese, 2000 ). Emotion as a mediator is also congruent with the Affect Event Theory (AET) which posits that characteristics of the work environment predispose the occurrence of certain work events leading to specific emotions (affective reactions), which in turn shape work attitudes and behaviors (Weiss \& Cropanzano, 1996).

Fisher (2000) showed support for the AET where, using the Job Emotions Scale (JES), researchers found that frequency and intensity of emotion at work related to global satisfaction. Additionally, support is found for the mediation quality of negative affect where researchers found that job related affect mediated the relationship between interpersonal conflict and health outcomes (Lubbers, et al., 2005). Affective responses have helped predict job outcomes like job satisfaction (Ilies \& Judge, 2002) and organizational citizenship behavior (Ilies, Scott, \& Judge, 2006). Through epidemiological evidence researchers found support for the role of affect as a mediator of physical illness (Leventhal \& Patrick-Miller, 2000). Grandey, Tam, and Brauburger (2002) reported that negative emotions at work predicted lower job satisfaction and higher turnover intentions among young workers.

Researchers suggests that negative interpersonal relations at work can result in anger (Frone, 2000; Spector \& Jex, 1998), which can spiral over time into overt hostility and aggression (Andersson \& Pearson, 1999; Cortina, Magley, Williams, \& Langhout, 2001). Anger refers to a physiological state of arousal that creates a tendency to attack or 
confront the source of the event and occurs when one perceives that he or she has been treated unfairly or unjustly by another (Andersson \& Pearson, 1999; Averill, 1982; Smith \& Ellsworth, 1985). Considering research linking the experience and expression of anger to cardiovascular disease (Greenglass, 1996; Julkunen, 1996), the emotional reactions coming from conflicts in the workplace may be crucial to employee health. Furthermore, the experience of negative emotional states has been shown to negatively impact immune system functioning (O’Leary, 1990). In addition, self-reported interpersonal conflict has correlated moderately with negative emotions (e.g., state anxiety and frustration) and with symptoms of depression (Frone, 2000; Lubbers et al., 2005; Spector \& Jex, 1998).

Several studies indicate daily conflict is associated with increased same-day negative affect (Bolger, et al., 1989; Stone, 1987; Vittengl \& Holt, 1998; Zohar, 1999). Van Katwyk, Fox, Spector, and Kelloway (2000) found interpersonal conflict with coworkers to be negatively associated with job-related affect. Barki \& Hartwick (2001) propose that both task and relationship conflict consist of three overlapping properties, which include negative emotion, disagreement and interference. Keenan and Newton (1985) reported that anger, annoyance, and frustration were the most frequently cited emotions reported by their sample of engineers, who ranked interpersonal conflicts as one of the most commonly experienced work stressors. Similarly, Narayanan and colleagues (1999) found that social stressors, including interpersonal conflicts at work, were associated with anger, annoyance, and frustration across occupations. Bolger and colleagues (1989) concluded that interpersonal conflicts accounted for more than $80 \%$ of the variance in daily mood, which was assessed by a measure of anxiety, hostility, and depression. Furthermore, these researchers identified interpersonal conflict as the most 
important stressor influencing psychological distress. Potter, Smith, Strobel and Zautra (2002) were able to predict negative affect using workplace stressors, demonstrating the link between stressors and affect. In a longitudinal study of 82 unionized university employees, interpersonal conflict was associated with higher negative affect, where interpersonal conflict alone explained $23 \%$ of the intraindividual variance in negative affect (Ilies, Johnson, Judge, \& Keeney, 2011). Affective responses are considered the principle indicator of mental health (Warr, 1998). Watson (1988), in a within-individual analysis, specifically linked negative affect with the stress response and found that negative affect was strongly correlated with a measure of perceived distress. In a study of young workers, Grandey and colleagues (2002) reported that negative emotions at work predicted lower job satisfaction and higher turnover intentions. Affect directly impacts health through physiological responses that elevate blood pressure and heart rate, and increase vulnerability to cardiovascular disease, myocardial infarction, and cancer (Lubbers et al., 2005). Brief and Weiss (2002) suggest several links between affect and work performance among adults, including withdrawal behaviors (e.g., absenteeism, turnover intentions), creativity in problem solving, quality of decision making, prosocial helping behavior, and general job performance.

Research relating affect and abusive supervision has typically looked at the trait of negative affectivity, whereas individuals high in negative affectivity report higher levels of abusive supervision (Tepper, Duffy, Henle, \& Lambert, 2006). Abusive supervision research often discards negative affectivity by controlling for the effects, rather than examining emotionality as an important individual difference. In a recent review of workplace aggression literature, researchers found that $25 \%$ of the included 
abusive supervision articles controlled for negative affectivity, whereas no study tested negative affectivity (NA) as potential moderator (Allen et al., 2012). Aquino, Grover, Bradfield and Allen (1999) argued high NA persons present themselves as anxious, distressed, and dissatisfied, potential abusers may see them as ripe targets for exploitation. Olweus (1978) refers to these types of individuals as "submissive victims" because they behave in ways (e.g., anxious, insecure) that makes them appear less likely to defend themselves. Abusing subordinates who are perceived to be vulnerable may be a means by which supervisors who feel they are treated unjustly can displace their anger against a safe target (Spector, 1978).

Research on job-related affective states with regards to abusive supervision is lacking with no study to date testing negative emotion as a mediator between the abusive supervision-outcomes relationship (Allen et al., 2012). Ignoring the negative emotion inflicted by abusive supervision may be possibly overlooking an important intervening variable. As mentioned previously, other areas of workplace aggression (i.e., interpersonal conflict) have found that negative emotion is an effective mediator of the relationship between workplace aggression and outcomes (e.g., Ilies et al., 2011; Lubbers et al., 2005). Given the mediating role of negative emotions proposed by the emotion centered model of social stressors and the similarities between abusive supervision and interpersonal conflict, it is hypothesized that:

Hypothesis 7: Job related negative affect will mediate the relationship between workplace aggression (abusive supervision and interpersonal conflict) and job and health related outcomes. 


\section{The Moderating Role of Social Support in the Workplace}

One potential moderator of the relationship between the negative emotions caused by social stressors and outcomes is social support experienced by the individual. Social support has been defined broadly as "the availability of helping relationships and the quality of those relationships" (Leavy, 1983, p.5). Many researchers have examined the role of social support in promoting the psychological well-being of employees (e.g., Beehr, Farmer, Glazer, Gudanowski, \& Nair, 2003; Mendelson, Catano, \& Kelloway, 2000). Social support may be defined as behaviors that are intended to assist others and sources of support may include a variety of people (e.g., spouse, sibling, friend, team member or supervisor).

In the past three decades, researchers have amassed a considerable amount of research highlighting the impact of social support at work (Dormann \& Zapf, 1999; Etzion, 1984; Evans \& Steptoe, 2001; Halbesleben, 2006; Peeters, Buunk \& Schaufeli, 1995; Thomas et al., 2005; Viswesvaran, Sanchez, \& Fisher, 1999). Social support has been shown to reduce a number of negative outcomes including increases in cardiovascular symptoms and negative affect (Buunk \& Verhoeven, 1991; Evans \& Steptoe, 2001; Halbesleben, 2006; Peeters et al., 1995). In a qualitative study, Nelson and Friedlander (2001) found that students experiencing conflict with their supervisors often turned to peers for support. Peeters and colleagues (1995) used a longitudinal design to measure female secretaries' stressful events, perceived social support, and negative affect over a one-week period and found within-and between-person buffering effects of task related social support. 
Meta-analytic research has found that social support helped to moderate the stressor-strain relationship, although researchers concluded that more work needs to be done to guide how different sources of support can be matched to different stressors and stains (Viswesvaran et al., 1999). The research on social support in the workplace and its relationship between interpersonal conflict and employee outcomes is lacking. Addressing this problem, a recent publication on social support in the workplace found that social support helps to mitigate the distress associated with interpersonal conflict, specifically that receiving social support on the job can help to buffer negative consequences of conflict (Ilies et al., 2011). It is suggested that social support at work is an important resource, and a meta-analytic review has found that a lack of social support in the workplace was associated with emotional exhaustion (Lee \& Ashforth, 1996).

Social contacts can attenuate the negative impact of interpersonal conflict by freeing personal resources that can be used to deal directly with the problem. According to the "undoing hypothesis"' (Fredrickson \& Levenson, 1998), positive emotions caused by social support may speed the process of recovery from negative events. The "reverse buffering effect" posits that social support helps to buffer the effects of stressors and negative outcomes (Beehr et al., 2003; Hobman, et al., 2009). It is hypothesized that workers experiencing negative affect will actively seek support (Peeters et al., 1995).

What if the stressor and the social support come from the same source? The within-domain-stress-buffering hypothesis posits that social support from the same source as the stressors serves to exacerbate the negative effects of the stressor (Duffy, Ganster \& Pagon, 2002; Hobman et al., 2009). The cross-domain-stress-buffering hypothesis posits that social support outside the source of the stressor will serve to buffer 
the negative effects of the stressor (Hobman et al., 2009). The cross-domain-stressbuffering hypothesis is consistent with Blau's (1981) argument that support needs to come from a different source other than the stressor to be effective. Support is found for this hypothesis in an experiment where researchers discovered that in conditions of abusive supervision, high team member social support ameliorated anxiety (Hobman et al., 2009). Furthermore, in support of the stress exacerbation hypothesis, when there was high advisor support, there was a significant relationship between abusive supervision and anxiety and psychological well-being. Duffy and colleagues (2002) found support for the within-domain exacerbation proposition, supervisor support magnified the associations between supervisor social undermining and all outcome variables (i.e., less organizational commitment and more somatic complaints) whereas team member support buffered the negative effect of supervisor undermining on somatic complaints.

Hypothesis 8a: Cross-domain social support in the workplace will act to buffer the relationship between supervisor initiated aggression (abusive supervision and conflict with supervisors) and outcomes, such that when social support from coworkers is high (low), the relationship between supervisor initiated aggression and outcomes will be weakened (strengthened).

Hypothesis 8b: Cross-domain social support in the workplace will act to buffer the relationship between co-worker initiated aggression (conflict with coworkers) and outcomes, such that when social support from supervisors is high (low), the relationship between conflict with co-workers and employee outcomes will be weakened (strengthened). 
Hypothesis 8c: Within-domain social support in the workplace will exacerbate the relationship between supervisor initiated aggression (abusive supervision and conflict with supervisors) and outcomes, such that, when social support from supervisors is high (low), the relationship between supervisor initiated aggression and outcomes will be strengthened (weakened).

Hypothesis 8d: Within-domain social support in the workplace will exacerbate the relationship between co-worker initiated aggression (conflict with co-workers) and outcomes, such that, when social support from co-workers is high (low), the relationship between conflict with co-workers and outcomes will be strengthened (weakened).

\section{The Moderating Role of Perceived Intensity}

The most commonly used scales of conflict and abusive supervision measure the frequency of the action, excluding any mention of intensity of the action (Jehn, 1995; Spector and Jex, 1998; Tepper, 2000). These scales are typically rated on a five point scale with responses ranging from $1=$ none or very little to $5=$ always or very often. Frequency scaling raises an important question of whether all instances of social stressors are the same or there are some instances where the intensity of the social stressor is more indicative of outcomes than the frequency. Research on intensity of workplace abuse is severely lacking but there has been a call for researchers to explore intensity as an important moderator of the stressor-strain relationship (Hershcovis, 2011). Different areas of workplace aggression are believed to have greater intensity than others. Abusive 
supervision is believed to represent high intensity and interpersonal conflict could fall anywhere from low to high on intensity.

Intensity refers to the level of perceived severity the target of an aggressive behavior attributes to that behavior (e.g., Barling, 1996). It has been assumed that the intensity of the aggressive behaviors will affect the impact of those behaviors on outcomes such that higher intensity will lead to more negative outcomes (e.g., Andersson \& Pearson, 1999; Barling, 1996; Hershcovis, 2011). There is limited empirical evidence about the effects of intensity on workplace aggression and employee outcomes, but in an unpublished dissertation support was found for the moderation effects of intensity (Nixon, 2011). Perceived intensity of workplace aggression was related to nurse's organizational attitudes, including decreased job satisfaction and organizational commitment, as well as increased turnover intentions. Intensity was found to moderate the relationships between workplace aggression and both depression and musculoskeletal injuries. Specifically, nurses who reported high intensity workplace aggression also experienced more depression and musculoskeletal injuries, particularly when workplace aggression was frequent, compared to nurses who experienced low intensity aggression. This finding provides evidence that perceived intensity exacerbates workplace aggression-strain relationships. Intensity was related to psychological and physical strains, such that workplace aggression that was perceived to be intense was related to increased depression, anxiety, irritation, and physical symptoms for nurses (Nixon, 2011).

Hypothesis 9: Perceived intensity of workplace aggression will moderate the relationship between workplace aggression and outcomes, such that when 
perceived intensity is high (low), the relationship between workplace aggression and outcomes will be strengthened (weakened).

\section{Current Study}

The purpose of my research will be to refine and expand the emotion-centered model of workplace aggression using two subtypes of workplace aggression: abusive supervision and interpersonal conflict. Interpersonal conflict will also be explored by differentiating the source of conflict (conflict with supervisor and conflict with coworker). One unique contribution of my work will be to extend the emotion-centered model of the stressor-strain relationship beyond interpersonal relationship conflict, where it has typically been applied.

Furthermore, my research will expand the literature on the impact of social support in the workplace with regards to the stressor-strain relationship. Until recently, research concerning the impact of social support on interpersonal stressors and strains has been lacking. By testing multiple types of workplace aggression, I will be able to compare the impact of social support in the workplace on the different types of workplace aggression. Additionally, because I will be looking at the source of stressor (supervisor vs. co-worker) I will be able to explore within-domain and cross-domain social support to determine the impact of receiving support from the same source, or different source, than the source of stress. Finally, intensity has also been overlooked by traditional social stressor research and my research will help to explore the impact of perceived intensity on the stressor-strain relationship. Considering that different types of workplace stressors are being measured, this research can help to expand knowledge of intensity by 
determining if certain types of stressors are perceived as more intense (abusive supervision and conflict with different sources).

Figure 1. Proposed Model

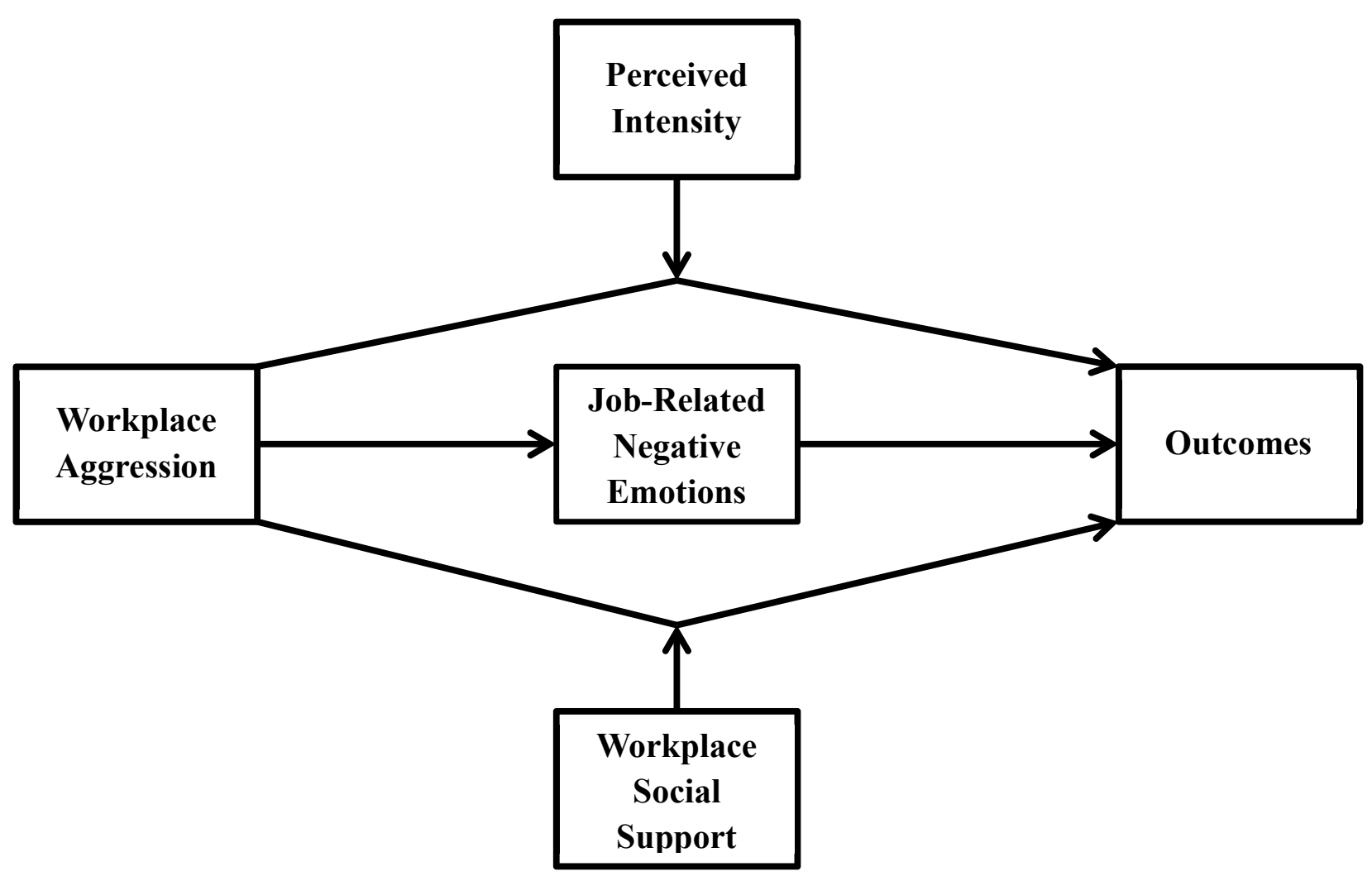




\section{CHAPTER III. METHOD}

\section{Participants}

The study used a snowball recruitment technique where personal contacts of the primary researcher were provided a survey invitation and encouraged to reach out to coworkers and other contacts in the professional community. Participation in the study was completely voluntary, confidential, and anonymous. All of the standards set by the Institutional Review Board (IRB) were followed. A copy of the IRB approval form is presented in Appendix A.

My study included 321 working individuals. The mean age of participants was 34.70. The participants were predominately female (54.1\%). The participants were $73.2 \%$ White/Caucasian, 9.3\% Hispanic, 6.9\% Asian, 4.7\% African American, 2.2\% Native American, $1.9 \%$ other and $.9 \%$ Pacific Islander. The majority of the participants worked full time (83.5\%), for an average of 39.22 hours per week and were employed at their current companies for an average of 6.59 years. Additional industry and position related demographic information can be found in Table 1. 
Table 1. Industry Demographics

\begin{tabular}{ll}
\hline \multicolumn{1}{c}{ Industry } & Percentage \\
\hline Trades/Skilled Labor & $4.4 \%$ \\
Education/Academia & $16.9 \%$ \\
Management, Professional & $26.3 \%$ \\
and Related & \\
Technical & $9.7 \%$ \\
Service & $11.6 \%$ \\
Health/Medical Care & $16.9 \%$ \\
Government & $2.8 \%$ \\
Other & $11.6 \%$ \\
\hline \multicolumn{1}{c}{ Job } & Percentage \\
\hline Sales & $6.9 \%$ \\
Customer Service & $12.1 \%$ \\
Technical & $11.2 \%$ \\
Clerical & $2.8 \%$ \\
Managerial & $18.1 \%$ \\
Training & $3.4 \%$ \\
Professional & $33.0 \%$ \\
Other & $12.5 \%$
\end{tabular}

\section{Procedure}

Participants were sent a link through electronic mail with access to the questionnaire that measured workplace aggression, negative emotions, social support, health and job related outcomes and demographic information. Participants were also recruited using popular social media websites (LinkedIn, Twitter and Facebook). The questionnaire was administered through Qualtrics systems. The system restricted participants from completing the survey more than one time. Participants were first required to acknowledge informed consent in order to begin the survey. Confidentiality and anonymity of the participants was maintained throughout the study by the use of identification numbers. Participants were given $\$ 10$ electronic gift cards to Amazon.com for successful completion of the survey. Participation in the study was completely 
voluntary and participants were made aware that they could stop at any point during the process. Once all of the questionnaires were completed, the measures were scored and the data were entered into SPSS for analysis. A total of 438 individuals started the survey. The survey included ten dummy questions (i.e., please select answer choice never) to ensure participants were accurately reading and responding to each item in the survey. Any participants who responded incorrectly to more than $20 \%$ of dummy questions were excluded from further analysis. Additionally, any participant that completed the survey in less than five minutes was excluded. After screening the data there were 321 surveys deemed suitable for analysis $(73 \%)$.

\section{Measures}

Abusive supervision. Abusive supervision was measured using Mitchell and Ambrose (2007) five item adaptation of the Tepper (2000) abusive supervision scale. The five item scale reflects active forms of abusive supervision. Sample items include "My supervisor tells me my thoughts and feelings are stupid." Respondents answered on a five point scale with $1=$ "I cannot remember him/her using this behavior with me" to $5=$ "He/She uses this behavior very often with me." This scale displayed acceptable internal reliability $(\alpha=.90)$.

Conflict at work. Conflict at work was measured using Frone's (2000) modified version of the Interpersonal Conflict at Work Scale (ICAWS; Spector \& Jex, 1998). The scale measures conflict with supervisor and conflict with co-workers, with each subscale consisting of four items. For example, to assess conflict with one's supervisor, the general question "How often do you get into arguments with others at work?" was changed to 
"How often do you get into arguments with your supervisor?" A similar change was made to assess conflict with co-workers. Each item was rated on a five point response scale ranging from $1=$ "never" to $5=$ "all of the time." The scale displayed an acceptable internal reliability ( $\alpha=.84$ conflict with supervisors, $\alpha=.84$ conflict with co-workers).

Perceived Intensity. Consistent with the method employed in other research measuring intensity, (e.g., Nixon, 2011) after each of the conflict and abusive supervision questions participants were instructed if the behavior is present, to indicate how much the behavior upset them. Responses were measured on a five point scale with $1=$ "not at all" and $5=$ "greatly." The intensity scale consisted of 13 questions: 5 for abusive supervision, and 8 for conflict ( 4 co-worker, 4 supervisor). The scale displayed acceptable internal reliability ( $\alpha=.88$ intensity of conflict with supervisors, $\alpha=.73$ intensity of conflict with co-workers, and $\alpha=.79$ intensity of abusive supervision).

Job Satisfaction. Job satisfaction was measured using the three-item Cammann, Fichman, Jenkins, and Klesh (1979) job satisfaction measure from the Michigan Organizational Assessment Scale. A sample item includes "All in all I am satisfied with my current job." Each item was rated on a five point scale with $1=$ "strongly disagree" to $5=$ "strongly agree." The scale displayed acceptable internal reliability $(\alpha=.92)$.

Organizational Commitment. Organizational commitment was measured using the six item affective organizational commitment scale by Meyer, Allen and Smith (1993). Sample items are "I really feel as if this organization's problems are my own" and "This organization has a great deal of personal meaning for me." Participants 
answered using a five point scale with $1=$ "strongly disagree" to $5=$ "strongly agree." The scale displayed acceptable internal reliability $(\alpha=.88)$.

Turnover Intentions. Turnover intentions were assessed using three items adapted from Spector, Dwyer and Jex (1988) and Cammann, Fichman, Jenkins, and Klesh (1979). A sample item is "I am seriously thinking about quitting my job." Each item used a five point response scale that ranged from $1=$ "strongly disagree" to $5=$ "strongly agree." The scale displayed acceptable internal reliability $(\alpha=.79)$.

General Well-Being. General well-being was measured with the 12-item General Health Questionnaire (GHQ-12) developed by Goldberg (1978). Respondents were asked the extent to which they have experienced things in the past month on a four point scale ranging from $1=$ "not at all" to 4 = "very often." Sample items include, "Rate the extent you have been able to concentrate on whatever you're doing" or "lost much sleep over worry" (reverse coded). Higher scores indicate better general well-being. The scale displayed an acceptable internal reliability $(\alpha=.82)$.

Psychological Strains. Psychological distress was measured with the WorkRelated Depression and Irritation Scale (Caplan, Cobb, French, Harrison, \& Pinneau, 1980). Subscales include depression (6 items), and irritation (3 items) as aspects of psychological well-being. A sample item for depression is "I am unhappy", and a sample item for the irritation scale is "I get aggravated." Participants answered using a four-point scale with $1=$ "never" and $4=$ "most of the time." Higher scores indicate higher psychological strain. The scale has shown an acceptable internal reliability $(\alpha=.85$ for depression, and $\alpha=.83$ for irritation). 
Physical Symptoms. Physical symptoms were measured using the 18 item Physical Symptoms Inventory (PSI; Spector and Jex, 1998). The PSI was designed to assess somatic symptoms of which a person would be aware (i.e., discomfort, headache, upset stomach), with each item corresponding to a symptom. Respondents are asked to indicate how often in the past 30 days they have experienced the symptom. Participants answered on a seven-point response scale with $1=$ "not at all" and $7=$ "several times a day." The scale displayed acceptable internal consistency $(\alpha=.88)$.

Negative Emotions. The Job-Related Affect Well-Being Scale was used to measure negative affect at work (JAWS; Van Katwyk, Fox, Spector, \& Kelloway, 2000). Respondents rated how their jobs made them feel each of 10 negative emotions in the past 30 days (e.g., "My job made me feel angry"). Each item was rated on a 5-point scale ranging from $1=$ "never" to 5 = "extremely often." The scale displayed an acceptable internal reliability $(\alpha=.89)$.

Social Support. Social support was measured using a 12 item measure adapted from Hobman et al. (2009) and Spooner-Lane (2004) which measures social support from source (supervisor and co-workers). The scale was comprised of items tapping into both instrumental (provision of services and assistance) and emotional support (provision of understanding and caring behaviors; Cohen \& Wills, 1985). Example items of supervisor support include, "My supervisor helps me figure out how to solve problems" and "My supervisor is understanding and sympathetic." Co-worker support was the same six items as the supervisor scale but the word "supervisor" was replaced with "coworker." Respondents answered on a five-point scale with $1=$ "strongly disagree" to $5=$ 
"strongly agree." The scale displayed acceptable internal reliability $(\alpha=.92$ for coworker support and $\alpha=.90$ for supervisor support). 


\section{CHAPTER IV. RESULTS}

Means, standard deviations, correlations and reliabilities were calculated for all variables and can be found in Table 2. The first five hypotheses were tested using correlational analysis and the results are as follows.

\section{Relationship between Aggression and Outcomes}

Conflict with supervisors was negatively related to job satisfaction $(r=-.38, p<$ $.001)$ and affective commitment $(r=-.19, p<.01)$ and positively related to turnover intentions $(r=.26, p<.001)$. Conflict with co-workers was negatively related to job satisfaction $(r=-.20, p<.01)$ and positively related to turnover intentions $(r=.14, p<$ .05). However, conflict with co-workers was not significantly related to affective commitment $(r=.01, n s)$. Therefore, partial support was found for hypothesis 1 , which predicted that interpersonal conflict would be negatively related to job satisfaction and affective commitment and positively related to turnover intentions.

Abusive supervision was negatively related to job satisfaction $(r=-.34, p<.001)$ and affective commitment $(r=-.27, p<.001)$ and positively related to turnover intentions $(r=.27, p<.001)$. Thus, lending support for hypothesis 2 . Abusive supervision was positively related to conflict with supervisors $(r=.80, p<.001)$ and conflict with coworkers $(r=.63, p<.001)$. These correlational findings provide support for hypothesis 3 , which predicted that abusive supervision would be positively related to interpersonal conflict.

Conflict with supervisors was negatively related to general well-being $(r=-.47, p$ $<.001)$ and positively related to perceived stress $(r=.33, p<.001)$, physical symptoms $(r$ 
$=.34, p<.001)$, psychological distress $(r=.41, p<.001$ for depression, $r=.39, p<.001$ for irritation) and job-related negative emotions $(r=.46, p<.001)$. Conflict with coworkers was negatively related to general well-being $(r=-.33, p<.001)$, and positively related to perceived stress $(r=.30, p<.001)$, physical symptoms $(r=.28, p<$ $.001)$, psychological distress $(r=.29, p<.001$ for depression, $r=.24, p<.001$ for irritation) and job related negative affect $(r=.25, p<.001)$. Therefore, support was found for hypothesis 4 , which predicted that interpersonal conflict would be negatively related to general well-being and positively related to strain criteria.

Abusive supervision was found to be negatively related to general well-being $(r=$ $-.41, p<.001)$ and positively related to perceived stress $(r=.28, p<.001)$, physical symptoms $(r=.36, p<.001)$, and psychological distress $(r=.36, p<.001$ for depression, $r=.45, p<.001$ for irritation) and job-related negative emotions $(r=.44, p<.001)$. Thus, support was found for hypothesis 5 which predicted that abusive supervision would be negatively related to general well-being and positively related to physical symptoms, psychological distress and job-related negative affect. 
Table 2. Zero Order Correlations

1 Gender

\section{Age}

3 Tenure

4 Conflict w/ Supervisor

5 Conflict w/ Supervisor Intensity

6 Conflict w/ Co-Workers

7 Conflict w/ Co-Workers Intensity

8 Abusive Supervision

9 Abusive Supervision Intensity

10 JAWS-Negative Emotion

11 Co-Worker Support

12 Supervisor Support

13 Turnover Intentions

14 Job Satisfaction

15 Affective Commitment

16 PSS

17 PSI

$18 \mathrm{GHQ}-12$

19 Depression

20 Irritation

Mean
SD
$\mathrm{N}$

N

$-.06$

$-.07 \quad .63 * * *$

$\begin{array}{llll}-.23 * * * & -.15 * * & -.05 & (.84)\end{array}$

$\begin{array}{lllll}.20 * * & -.10 & -.04 & .36 * * * & (.88)\end{array}$

$\begin{array}{lllll}-.19 * * & -.15 * * & -.06 & .69 * * * & .01\end{array}$

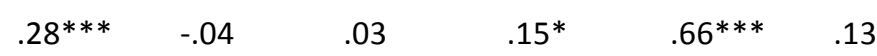

$\begin{array}{llllllll}-.19 * * & -.12 * & -.06 & .80 * * * & .31 * * * & .63 * * * & .18^{* *} & (.90)\end{array}$

$\begin{array}{lllllllll}.29 * * * & -.09 & -.19 * & .10 & .65 * * * & -.26 * * * & .58 * * * & .20 * * & (.79)\end{array}$

$\begin{array}{llllllllll}.07 & -.22 * * * & -.12 * & .46 * * * & .42 * * * & .26 * * * & .24 * * * & .44 * * * & .48 * * * & (.89)\end{array}$

$\begin{array}{llllllllll}.20 * * & .07 & -.02 & -.35 * * * & -.09 & -.34 * * * & -.06 & -.29 * * * & -.11 & -.39 * * *\end{array}$

$\begin{array}{llllllllll}.11 * & .18 * * & .11 & -.58 * * * & -.38 * * * & -.25 * * * & -.12 & -.49 * * * & -.32 * * * & -.51 * * *\end{array}$

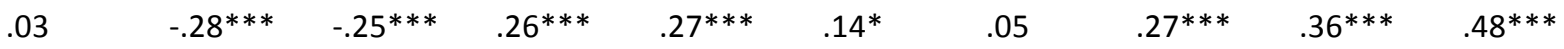

$\begin{array}{llllllllll}-.04 & .18 * * & .12 * & -.38 * * * & -.28 * * * & -.20 * * & -.01 & -.34 * * * & -.35 * * * & -.65 * * *\end{array}$

$\begin{array}{llllllllll}-.08 & .17^{* *} & .17^{* *} & -.19 * * & -.29 * * * & .01 & -.13 & -.27^{* * *} & -.51^{* * *} & -.53^{* * *}\end{array}$

$\begin{array}{llllllllll}-.06 & -.21 * * & -.05 & .33 * * * & .25 * * & .30 * * * & .14 * & .28 * * * & .23 * * & .52 * * *\end{array}$

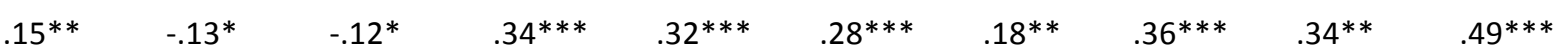

$\begin{array}{llllllllll}15 * & .16 * * & .03 & -.47 * * * & -.23 * * & -.33 * * * & -.03 & -.41 * * * & -.14 & -.53 * * *\end{array}$

$\begin{array}{llllllllll}-.01 & -.15 * * & -.09 & .41 * * * & .19 * * & .29 * * * & .12 & .36 * * * & .26 * * & .57^{* * *}\end{array}$

$\begin{array}{llllllllll}.01 & -.13^{*} & -.1 & .39 * * * & .39 * * * & .24 * * * & .28 * * * & .45^{* * *} & .38^{* * *} & .58^{* * *}\end{array}$

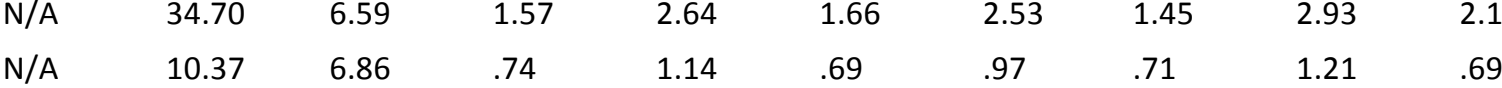

$\begin{array}{llllllllll}320 & 321 & 285 & 312 & 181 & 314 & 219 & 311 & 148 & 307\end{array}$


Table 2. Cont.

$\begin{array}{llllllllll}11 & 12 & 13 & 14 & 15 & 16 & 17 & 18 & 19 & 20\end{array}$

11 Co-Worker Support

12 Supervisor Support

13 Turnover Intentions

14 Job Satisfaction

15 Affective Commitment

16 PSS

$17 \mathrm{PSI}$

$18 \mathrm{GHQ}-12$

19 Depression

20 Irritation

Mean

SD

$\mathrm{N}$

(.92)

$$
\begin{array}{ll}
.43^{* * *} & (.90) \\
-.23 * * * & -.31 * * *
\end{array}
$$$$
\begin{array}{llll}
.46 * * * & .53 * * * \quad-.58 * * * \quad(.92)
\end{array}
$$$$
\begin{array}{lllll}
.35 * * * \quad .41 * * * & -.60 * * * \quad .66 * * * \quad(.88)
\end{array}
$$$$
\begin{array}{llll}
-.41 * * * & -.32 * * * \quad .13 * & -.39 * * * & -.15 * *
\end{array}
$$$$
\begin{array}{llllll}
-.28 * * * & -.25 * * * & .25 * * * & -.39 * * * & -.24 * * * & .40 * * *
\end{array}
$$

$50 * * * \quad .40 * * * \quad-20 * * *-.50 * * *-31 * * *$

$-.69 * * *-.40 * * * \quad(.82$

$\begin{array}{lllllllll}-.51 * * * & -.36 * * * & .22 * * * & -.48 * * * & -.30 * * * & .65 * * * & .44 * * * & -.67 * * * & (.85)\end{array}$

$\begin{array}{lllllllll}-.37 * * * & -.38 * * * & .24 * * * & -.43 * * * & -.34 * * * & .40 * * * & .44 * * * & -.42 * * * & .54 * * *\end{array}$

$\begin{array}{lll}4.00 & 3.83 \quad 2.79 \\ .69 & .94\end{array}$

$\begin{array}{lll}.69 & .84 & .94\end{array}$

2.793 .89

313

.96

.91

$3.50 \quad 2.59$

$2.59-1.65$

$\begin{array}{llll}1.65 & 3.63 & 2.13 & 1.94\end{array}$

308

$.56 \quad .58$

309

.50

315

.53

Note $* p<.05, * * p<.01, * * * p<.001$. Due to the high intercorrelations among some variables several confirmatory factor analyses were performed and can be found in Appendix O. The CFA results generally supported the hypothesized factor structures. 


\section{Differences between Co-Worker and Supervisor Aggression}

Hypothesis 6 was concerned with differences derived from the source of aggression (supervisor vs. co-worker) in relationship to outcomes (organizational vs. individual) and was tested using a series of Hotelling-Williams t-test for dependent correlations (Williams, 1959). Conflict with supervisors and conflict with co-workers displayed significant differences with their relationships to job satisfaction $(t=3.066, p<$ $.005)$, turnover intentions $(t=-1.809, p<.05)$, and affective commitment $(t=21.312, p<$ .005). Likewise, abusive supervision and conflict with co-workers displayed significant differences with their relationship to job satisfaction $(t=2.315, p<.05)$, turnover intentions $(t=-2.014, p<.05)$ and affective commitment $(t=8.701, p<.005)$. These results support hypothesis $6 \mathrm{a}$ which predicted that supervisor initiated aggression would be more strongly related to organizational outcomes (job satisfaction, turnover intentions and affective commitment) than co-worker initiated aggression.

Hypothesis $6 \mathrm{~b}$ posited that co-worker initiated aggression would be more strongly related to individual outcomes than supervisor initiated aggression. Conflict with supervisors and conflict with co-workers displayed significant differences with their relationships to well-being $(t=1.880, p<.05)$, and irritation $(t=-1.960, p<.05)$ but not with their relationships to perceived stress $(t=-.393, n s)$, physical symptoms $(t=-.0788$, $n s)$ or depression $(t=1.520, n s)$. Similarly, abusive supervision and conflict with coworkers displayed significant differences with their relationships to irritation $(t=-2.700$, $p<.005)$ but not with perceived stress $(t=.27, n s)$, well-being $(t=1.071, n s)$, physical symptoms $(t=-1.060, n s)$ or depression $(t=-.923, n s)$. However, contrary to hypothesis 
$6 \mathrm{~b}$, the outcomes that did display a significant difference by source were more strongly related to supervisor initiated aggression than co-worker initiated aggression. Thus, hypothesis $6 \mathrm{~b}$ was not supported.

\section{Emotion as a Mediator}

Hypothesis 7 stated that job-related negative emotions would mediate the relationships between workplace aggression and all outcomes. This hypothesis was tested using the Baron and Kenny (1986) test for mediation using a hierarchical linear regression. Three demographic variables (age, gender, and tenure) were entered in Step 1 as control variables, consistent with the methodology employed in other workplace aggression research (e.g., Aquino \& Bradfield, 2000; Aryee et al., 2007). In the second step the workplace aggression variable was entered (conflict with supervisor, conflict with co-workers, or abusive supervision) and in the last step job-related negative emotion was entered. If the beta weight for the workplace aggression variable dropped but remained significant, partial mediation was said to occur. Alternatively, if the workplace aggression predictor beta weight was no longer significant, a pattern for full mediation was supported. All related information can be found in Tables 3 through 11. The results are as follows.

Conflict with supervisors was found to be a significant predictor of turnover intentions $(\beta=.25, p<.001)$ and affective commitment $(\beta=-.20, p<.01)$, however when job-related negative emotions were added to the regression, the beta weights for turnover intentions $(\beta=.04, n s)$ and affective commitment $(\beta=.07, n s)$ became non-significant, as found in Table 3. Conflict with supervisors was found to be a significant predictor of job 
satisfaction $(\beta=-.41, p<.001)$, perceived stress $(\beta=.25, p<.001)$, physical symptoms $(\beta=.30, p<.001)$, well-being $(\beta=-.28, p<.001)$, depression $(\beta=.42, p<.001)$ and irritation $(\beta=.40, p<.001)$, as found in Tables 3 through 5. When job-related negative emotions were added to the regression the beta weight dropped for job satisfaction $(\beta=$ $.12, p<.05)$, perceived stress $(\beta=.13, p<.05)$, physical symptoms $(\beta=.20, p<.001)$, well-being $(\beta=-.15, p<.01)$, depression $(\beta=-.16, p<.01)$, and irritation $(\beta=-.14, p<$ $.05)$, however all remained significant. Thus, a pattern of full mediation was found for job-related negative emotions in the relationships between conflict with supervisors and 1) turnover intentions and 2) affective commitment. Similarly, partial mediation was found for 1) job satisfaction, 2) perceived stress, 3) well-being, 4) physical symptoms, 5) depression and 6) irritation.

Table 3. Job Related Negative Emotions as a Mediator between Conflict with Supervisors and Job Satisfaction, Turnover Intentions and Affective Commitment

\begin{tabular}{|c|c|c|c|c|c|c|c|c|c|}
\hline & \multicolumn{3}{|c|}{ Turnover Intentions } & \multicolumn{3}{|c|}{ Job Satisfaction } & \multicolumn{3}{|c|}{ Affective Commitment } \\
\hline & $\begin{array}{c}\text { Step } 1 \\
\beta \\
\end{array}$ & $\begin{array}{c}\text { Step } 2 \\
\beta \\
\end{array}$ & $\begin{array}{c}\text { Step } 3 \\
\beta\end{array}$ & $\begin{array}{c}\text { Step } 1 \\
\beta \\
\end{array}$ & $\begin{array}{c}\text { Step } 2 \\
\beta \\
\end{array}$ & $\begin{array}{c}\text { Step } 3 \\
\beta \\
\end{array}$ & $\begin{array}{c}\text { Step } 1 \\
\beta \\
\end{array}$ & $\begin{array}{c}\text { Step } 2 \\
\beta\end{array}$ & $\begin{array}{c}\text { Step } 3 \\
\beta \\
\end{array}$ \\
\hline Age & $-.23 * *$ & $-.18 *$ & -.11 & $.20 * *$ & .11 & .02 & $.16^{*}$ & .12 & .03 \\
\hline Gender & .01 & .07 & -.01 & -.02 & $-.12 *$ & -.01 & -.04 & -.09 & .01 \\
\hline Tenure & -.11 & -.13 & $-.13 *$ & .00 & .02 & .03 & .07 & .08 & .09 \\
\hline $\begin{array}{l}\text { Conflict } \\
\text { With } \\
\text { Supervisor }\end{array}$ & -- & $.25 * * *$ & .04 & -- & $-.41 * * *$ & $-.12 *$ & -- & $-.20 * *$ & .07 \\
\hline $\begin{array}{l}\text { Job- } \\
\text { Related } \\
\text { Negative } \\
\text { Emotions }\end{array}$ & -- & -- & $.43 * * *$ & -- & -- & $-.60 * * *$ & -- & -- & $-.56 * * *$ \\
\hline$R^{2}$ & $\begin{array}{c}.097 * * \\
*\end{array}$ & $.155^{*} * *$ & $.284 * * *$ & $.041 *$ & $.195 * * *$ & $.455 * * *$ & $.045 * *$ & $.081 * * *$ & $.303 * * *$ \\
\hline$\Delta R^{2}$ & -- & $.058 * * *$ & $.130 * * *$ & -- & $.154 * * *$ & $.260 * * *$ & -- & $.036 * *$ & $.222 * * *$ \\
\hline
\end{tabular}


Table 4. Job Related Negative Emotions as a Mediator between Conflict with Supervisors and Perceived Stress, Physical Symptoms and Well-Being

\begin{tabular}{|c|c|c|c|c|c|c|c|c|c|}
\hline & \multicolumn{3}{|c|}{ Perceived Stress } & \multicolumn{3}{|c|}{ Physical Symptoms } & \multicolumn{3}{|c|}{ Well-Being } \\
\hline & $\begin{array}{c}\text { Step } 1 \\
\beta\end{array}$ & $\begin{array}{c}\text { Step } 2 \\
\beta\end{array}$ & $\begin{array}{c}\text { Step } 3 \\
\beta\end{array}$ & $\begin{array}{c}\text { Step } 1 \\
\beta\end{array}$ & $\begin{array}{c}\text { Step } 2 \\
\beta\end{array}$ & $\begin{array}{c}\text { Step } 3 \\
\beta\end{array}$ & $\begin{array}{c}\text { Step } 1 \\
\beta\end{array}$ & $\begin{array}{c}\text { Step } 2 \\
\beta\end{array}$ & $\begin{array}{c}\text { Step } 3 \\
\beta\end{array}$ \\
\hline Age & $-.28 * * *$ & $-.23^{* *}$ & -.13 & -.13 & -.07 & .02 & $.23 * *$ & $.17^{*}$ & .06 \\
\hline Gender & -.09 & -.04 & -.10 & $.14^{*}$ & $.20 * *$ & $.15 * *$ & $.20 * *$ & $.15^{*}$ & $.21 * * *$ \\
\hline Tenure & .11 & .10 & .08 & -.03 & -.05 & -.06 & -.10 & -.08 & -.07 \\
\hline $\begin{array}{l}\text { Conflict } \\
\text { with } \\
\text { Supervisors }\end{array}$ & -- & $.25 * * *$ & $.13 *$ & -- & $.30 * * *$ & $.20 * * *$ & -- & $-.28 * * *$ & $-.15^{* *}$ \\
\hline $\begin{array}{l}\text { Job-Related } \\
\text { Negative } \\
\text { Emotions }\end{array}$ & -- & -- &. $.48 * * *$ & -- & -- & $.43 * * *$ & -- & -- & $-.51 * * *$ \\
\hline$R^{2}$ & $.060 * *$ & $117 * * *$ & $.320^{* * *}$ & $.046^{* *}$ & $.132 * * *$ & $294 * * *$ & $.075^{* * *}$ & $.147 * * *$ & $.374 * * *$ \\
\hline$\Delta R^{2}$ & -- & $.057 * * *$ & $.203^{* * *}$ & -- & $.086 * * *$ & $.162 * * *$ & -- & $.072 * * *$ & $.226 * * *$ \\
\hline
\end{tabular}

Table 5. Job Related Negative Emotions as a Mediator between Conflict with Supervisors and Depression and Irritation

Age

\begin{tabular}{cccccc}
\multicolumn{3}{c}{ Depression } & \multicolumn{3}{c}{ Irritation } \\
\hline $\begin{array}{c}\text { Step 1 } \\
\beta\end{array}$ & $\begin{array}{c}\text { Step 2 } \\
\beta\end{array}$ & Step 3 & Step 1 & Step 2 & Step 3 \\
\hline$-.17^{* *}$ & -.08 &. .00 & -.14 & -.06 & .03
\end{tabular}

Gender

$\begin{array}{llllll}-.05 & .04 & -.05 & -.01 & .08 & -.02\end{array}$

Tenure

.05

.02

.02

.02

$-.01$

$-.02$

Conflict With Supervisor

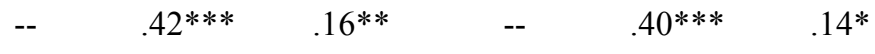

Job-Related Negative Emotions

$\begin{array}{llllll}- & - & .54 * * & - & - & .5\end{array}$

\begin{tabular}{lcccccc}
\hline$R^{2}$ & .024 & $.182^{* * *}$ & $.389^{* * *}$ & .018 & $.165^{* * *}$ & $.374^{* * *}$ \\
\hline$\Delta R^{2}$ & -- & $.158^{* * *}$ & $.207^{* * *}$ & -- & $.147^{* * *}$ & $.209^{* * *}$ \\
\hline
\end{tabular}

Note $\mathrm{N}=270 * p<.05 * * p<.01 * * * p<.001$

As found in Table 6, conflict with co-workers was not found to be a significant predictor of turnover intentions $(\beta=.10, n s)$ or affective commitment $(\beta=.03, n s)$, 
therefore mediation could not be tested. Conflict with co-workers was found to be a significant predictor of job satisfaction $(\beta=-.18, p<.01)$ and irritation $(\beta=.22, p<.01)$, however when job-related negative emotions were added to the regression, the beta weights for job satisfaction $(\beta=0.02, n s)$ and irritation $(\beta=0.07, n s)$ became nonsignificant, as found in Tables 6 through 8 . Conflict with co-workers was found to be a significant predictor of perceived stress $(\beta=.25, p<.001)$, physical symptoms $(\beta=.30, p$ $<.001)$, well-being $(\beta=-.28, p<.001)$, and depression $(\beta=.27, p<.001)$, as found in Tables 7 and 8 . When job-related negative emotions was added to the regression the beta weight dropped for perceived stress $(\beta=.13, p<.05)$, physical symptoms $(\beta=.20, p<$ $.001)$, well-being $(\beta=-.15, p<.01)$ and depression $(\beta=.13, p<.05)$, however all outcomes remained significant. Thus a pattern of full mediation was found for job-related negative emotions in the relationships between conflict with co-workers and 1) job satisfaction and 2) irritation. Similarly, partial mediation was found for 1) perceived stress, 2) physical symptoms, 3) well-being and 4) depression. 
Table 6. Job Related Negative Emotions as a Mediator between Conflict with CoWorkers and Job Satisfaction, Turnover Intentions and Affective Commitment

\begin{tabular}{|c|c|c|c|c|c|c|c|c|c|}
\hline & \multicolumn{3}{|c|}{ Turnover Intentions } & \multicolumn{3}{|c|}{ Job Satisfaction } & \multicolumn{3}{|c|}{ Affective Commitment } \\
\hline & $\begin{array}{c}\text { Step } 1 \\
\beta\end{array}$ & $\begin{array}{c}\text { Step } 2 \\
\beta\end{array}$ & $\begin{array}{c}\text { Step } 3 \\
\beta\end{array}$ & $\begin{array}{c}\text { Step } \\
1 \\
\beta \\
\end{array}$ & $\begin{array}{c}\text { Step } \\
2 \\
\beta \\
\end{array}$ & $\begin{array}{c}\text { Step } \\
3 \\
\beta \\
\end{array}$ & $\begin{array}{c}\text { Step } 1 \\
\beta\end{array}$ & $\begin{array}{c}\text { Step } 2 \\
\beta\end{array}$ & $\begin{array}{c}\text { Step } 3 \\
\beta\end{array}$ \\
\hline Age & $-.23 * *$ & $-.21 * *$ & -.11 & $.20 * *$ & $.17^{*}$ & .03 & $.16^{*}$ & $.17^{*}$ & .05 \\
\hline Gender & .01 & .03 & -.02 & -.02 & -.05 & .02 & -.04 & -.04 & .03 \\
\hline Tenure & -.11 & -.12 & $-.13^{*}$ & .00 & .01 & .03 & .07 & .07 & .08 \\
\hline $\begin{array}{l}\text { Conflict } \\
\text { With Co- } \\
\text { Workers }\end{array}$ & -- & .10 & -.01 & -- & $.18^{* *}$ & -.02 & -- & .03 & $.18 * *$ \\
\hline $\begin{array}{l}\text { Job-Related } \\
\text { Negative } \\
\text { Emotions }\end{array}$ & -- & -- & $.45 * * *$ & -- & -- & $\begin{array}{c}- \\
65^{* *} \\
*\end{array}$ & -- & -- & $-.57 * *$ \\
\hline$R^{2}$ & $.097 * * *$ & $.107 * * *$ & $.283 * * *$ & $.041 *$ & $\begin{array}{c}.071 * \\
*\end{array}$ & $\begin{array}{c}.446^{*} \\
* *\end{array}$ & $.045 * *$ & $.047^{*}$ & $.326 * * *$ \\
\hline$\Delta R^{2}$ & -- & .010 & $.176^{* *}$ & -- & $\begin{array}{c}.031 * \\
*\end{array}$ & $\begin{array}{c}.374^{*} \\
*\end{array}$ & -- & .001 & $.280 * *$ \\
\hline
\end{tabular}

Note $\mathrm{N}=270 * p<.05 * * p<.01 * * * p<.001$

Table 7. Job Related Negative Emotions as a Mediator between Conflict with CoWorkers and Perceived Stress, Physical Symptoms and Well-Being

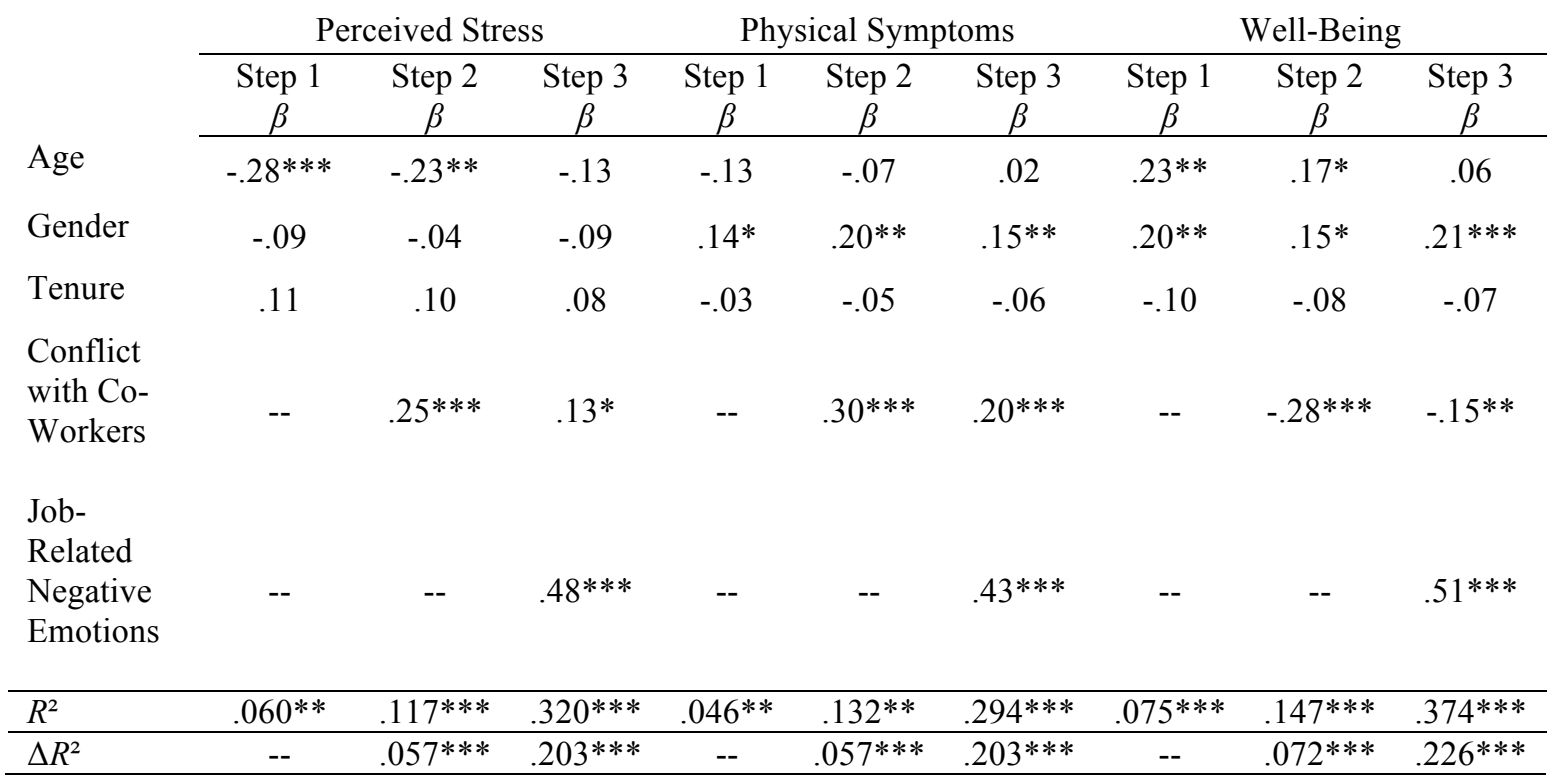

Note $\mathrm{N}=270 * p<.05 * * p<.01 * * * p<.001$ 
Table 8. Job Related Negative Emotions as a Mediator between Conflict with CoWorkers and Depression and Irritation

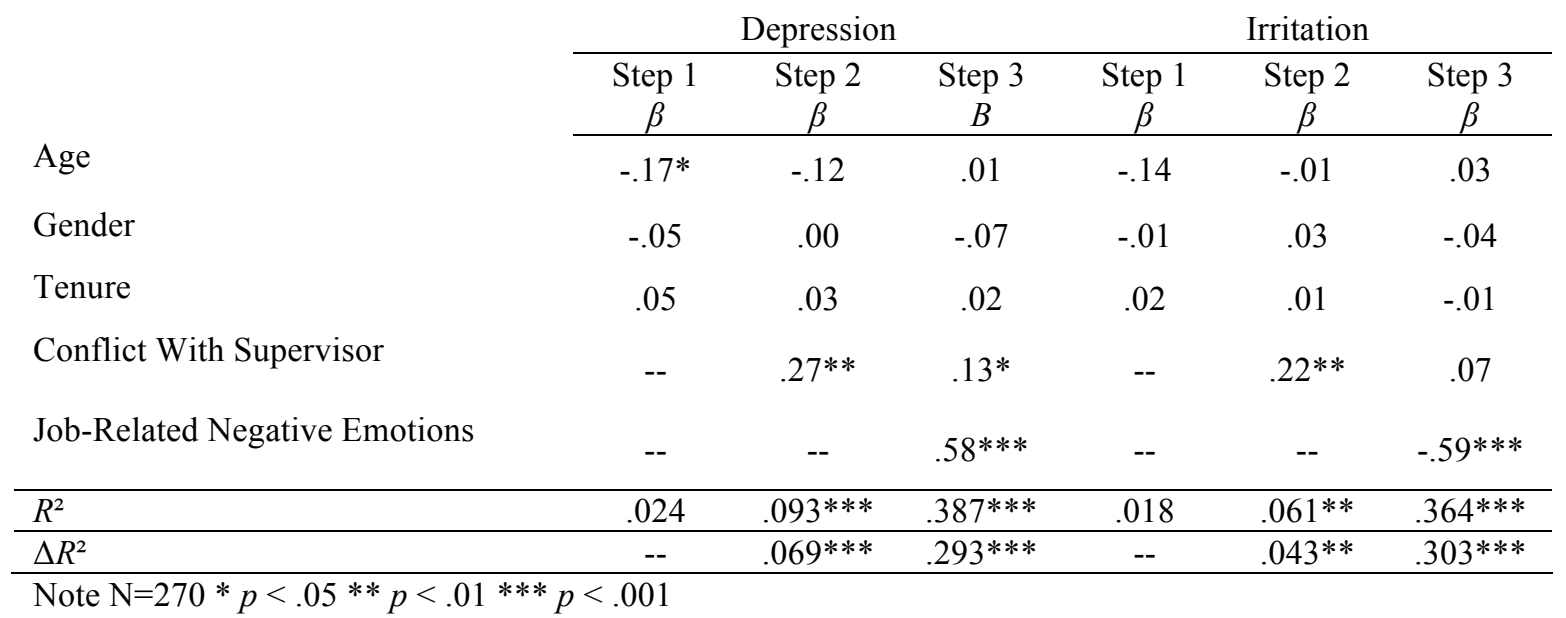

As found in Table 9 and Table 10, abusive supervision was found to be a significant predictor of turnover intentions $(\beta=.27, p<.001)$ affective commitment $(\beta=$ $-.27, p<.001)$, and perceived stress $(\beta=.26, p<.001)$, however when job-related negative emotions was added to the regression the beta weights for turnover intentions ( $\beta$ $=.08, n s)$ affective commitment $(\beta=-.04, n s)$, and perceived stress $(\beta=.04, n s)$ became non-significant. As found in Table 9 though Table 11, abusive supervision was found to be a significant predictor of job satisfaction $(\beta=-.38, p<.001)$, physical symptoms $(\beta=$ $.41, p<.001)$, well-being $(\beta=-.40, p<.001)$, depression $(\beta=.39, p<.001)$, and irritation $(\beta=.48, p<.001)$. When job-related negative emotions was added to the regression, the beta weights for job satisfaction $(\beta=-.12, p<.05)$, physical symptoms $(\beta$ $=.24, p<.001)$, well-being $(\beta=-.20, p<.001)$, depression $(\beta=.15, p<.01)$, and 
irritation ( $\beta=.27, p<.001)$ dropped but remained significant. Thus, a pattern of full mediation was found for job-related negative emotions in the relationships between abusive supervision and 1) turnover intentions, 2) affective commitment and 3) perceived stress. Similarly, job-related negative emotions partially mediated the relationships between abusive supervision and 1) job satisfaction, 2) physical symptoms, 3) well-being, 4) depression and 5) irritation.

Table 9. Job Related Negative Emotions as a Mediator between Abusive Supervision and Job Satisfaction, Turnover Intentions and Affective Commitment

\begin{tabular}{lccccccccc} 
& \multicolumn{3}{c}{ Turnover Intentions } & \multicolumn{3}{c}{ Job Satisfaction } & \multicolumn{3}{c}{ Affective Commitment } \\
\cline { 2 - 9 } & Step 1 & Step 2 & Step 3 & Step 1 & Step 2 & Step 3 & Step 1 & Step 2 & Step 3 \\
Age & $\beta$ & $B$ & $\beta$ & $\beta$ & $\beta$ & $\beta$ & $\beta$ & $\beta$ & $\beta$ \\
\cline { 2 - 10 } Gender & $-.23^{* *}$ & $-.19^{* *}$ & -.11 & $.20^{* *}$ & $.14^{*}$ & .02 & $.16^{*}$ & .12 & .02 \\
Tenure & .01 & .06 & .00 & -.02 & -.09 & .00 & -.04 & -.09 & -.02 \\
Abusive & -.11 & -.12 & $-.13^{*}$ & .00 & .01 & .03 & .07 & .08 & .09 \\
Supervision & -- & $.27^{* * *}$ & .08 & -- & $-.38^{* * *}$ & $-.12^{*}$ & -- & $-.27^{* * *}$ & -.04 \\
Job-Related & & & & & & & & & \\
Negative & -- & -- & $.41^{* * *}$ & -- & -- & $-.61^{* * *}$ & -- & -- & $-.50^{* * *}$ \\
Emotions & & & & & & & & & \\
\hline$R^{2}$ & $.097^{* * *}$ & $.163^{* * *}$ & $.288^{* * *}$ & $.041^{*}$ & $.179^{* * *}$ & $.456^{* * *}$ & $.045^{* *}$ & $.112^{* * *}$ & $.301^{* * *}$ \\
\hline$\Delta R^{2}$ & -- & $.066^{* * *}$ & $.125^{* * *}$ & -- & $.139^{* * *}$ & $.276^{* * *}$ & -- & $.067^{* * *}$ & $.188^{* * *}$ \\
\hline
\end{tabular}

Note $\mathrm{N}=270 * p<.05 * * p<.01 * * * p<.001$ 
Table 10. Job Related Negative Emotions as a Mediator between Abusive Supervision and Perceived Stress, Physical Symptoms and Well-Being

\begin{tabular}{|c|c|c|c|c|c|c|c|c|c|}
\hline & \multicolumn{3}{|c|}{ Perceived Stress } & \multicolumn{3}{|c|}{ Physical Symptoms } & \multicolumn{3}{|c|}{ Well-Being } \\
\hline & $\begin{array}{c}\text { Step } 1 \\
\beta\end{array}$ & $\begin{array}{c}\text { Step } 2 \\
\beta\end{array}$ & $\begin{array}{c}\text { Step } 3 \\
\beta\end{array}$ & $\begin{array}{c}\text { Step } 1 \\
\beta\end{array}$ & $\begin{array}{c}\text { Step } 2 \\
\beta\end{array}$ & $\begin{array}{c}\text { Step } 3 \\
\beta\end{array}$ & $\begin{array}{c}\text { Step } 1 \\
\beta\end{array}$ & $\begin{array}{c}\text { Step } 2 \\
\beta\end{array}$ & $\begin{array}{c}\text { Step } 3 \\
\beta\end{array}$ \\
\hline Age & $-.28 * * *$ & $-.24 * *$ & $-.14^{*}$ & -.13 & -.07 & .01 & $.23^{* *}$ & $.16^{*}$ & .07 \\
\hline Gender & -.09 & -.04 & $-.11 *$ & $.14 *$ & $.22 * * *$ & $.16^{* *}$ & $.20 * *$ & $.13 *$ & $.20 * * *$ \\
\hline Tenure & .11 & .10 & .09 & -.03 & -.04 & -.06 & -.10 & -.08 & -.07 \\
\hline $\begin{array}{l}\text { Abusive } \\
\text { Supervision }\end{array}$ & -- & $.26 * * *$ & .04 & -- & $.41 * * *$ & $.24 * * *$ & -- & $-.40 * * *$ & $-.20 * * *$ \\
\hline $\begin{array}{l}\text { Job Related } \\
\text { Negative } \\
\text { Emotions }\end{array}$ & -- & -- & $.50 * * *$ & -- & -- & $.37 * * *$ & -- & -- & $-.46^{* * *}$ \\
\hline$R^{2}$ & $.060 * *$ & $.122 * * *$ & $.294 * * *$ & $.046^{* *}$ & $203 * * *$ & $.306 * * *$ & $.075^{* * *}$ & $.227 * * *$ & $.384 * * *$ \\
\hline$\Delta R^{2}$ & -- & $.062 * * *$ & $.185^{* * *}$ & -- & $.157 * * *$ & $.103 * * *$ & -- & $.152 * * *$ & $.157 * * *$ \\
\hline
\end{tabular}

Table 11. Job Related Negative Emotions as a Mediator between Abusive Supervision and Depression and Irritation

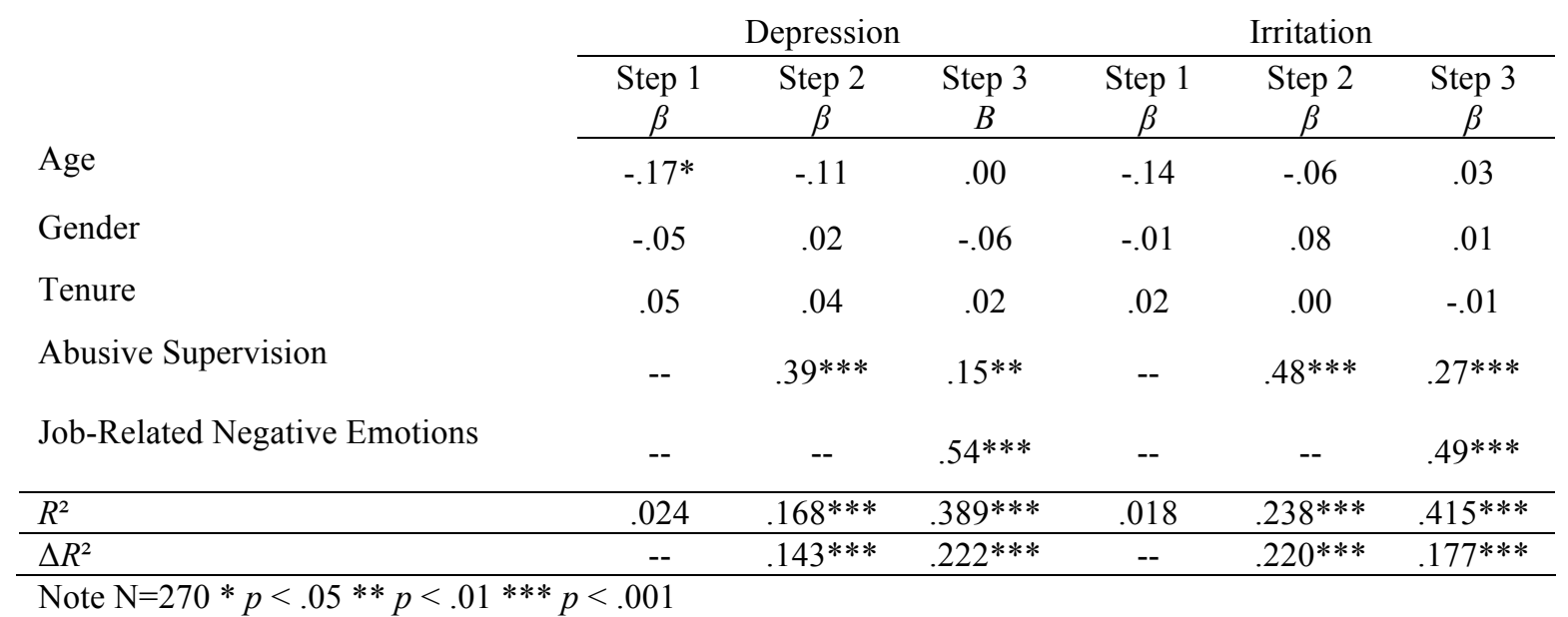


Taken as a whole, support was found for hypothesis 7 which predicted that jobrelated negative emotions would act as a mediator between workplace aggression and outcomes, with full and partial mediation found.

\section{Cross-Domain Social Support as a Moderator}

Hypothesis 8a stated that co-worker social support would act to buffer the negative outcomes of supervisor initiated aggression. Following the suggestions of Aiken \& West (1991) the interaction term was created from the cross-product of the centered variables. Hypothesis 8 a was tested using a set of hierarchical linear regressions where demographic variables (age, gender and tenure) were entered in the first step as control variables, the supervisor aggression and co-worker support variables were entered in the second step and the interaction between supervisor aggression and co-worker social support were entered in the third step. All related information can be found in Table 12 through Table 17. Results are as follows.

As found in Table 12 though Table 14, the interaction term between conflict with supervisor and co-worker social support accounted for a significant increase of the variance explained for turnover intentions $\left(\Delta R^{2}=.018, F(1,267)=6.00, p<.05\right)$, physical symptoms $\left(\Delta R^{2}=.174, F(1,267)=31.79, p<.001\right)$, depression $\left(\Delta R^{2}=.056, F\right.$ $(1,267)=24.70, p<.001)$, and irritation $\left(\Delta R^{2}=.058, F(1,267)=21.63, p<.001\right)$. The interaction term did not result in a significant increase in variance explained for job satisfaction $\left(\Delta R^{2}=.000, F(1,267)=.03, n s\right)$, affective commitment $\left(\Delta R^{2}=.003, F(1,267)\right.$ $=.83, n s)$, perceived stress $\left(\Delta R^{2}=.001, F(1,267)=.34, n s\right)$, or well-being $\left(\Delta R^{2}=.002, F\right.$ $(1,267)=.81, n s)$. 
The increase in the variances explained in turnover intentions $\left(\Delta R^{2}=.024, F\right.$ $(1,267)=8.16, p<.01)$, affective commitment $\left(\Delta R^{2}=.015, F(1,267)=5.36, p<.05\right)$, physical symptoms $\left(\Delta R^{2}=.050, F(1,267)=19.30, p<.001\right)$, depression $\left(\Delta R^{2}=.051, F\right.$ $(1,267)=22.08, p<.001)$, and irritation $\left(\Delta R^{2}=.028, F(1,267)=10.95, p<.01\right)$, were significant when the interaction term for abusive supervision and co-worker social support was entered into the regression, found in Tables 15 through 17. The interaction term did not explain additional variance in job satisfaction $\left(\Delta R^{2}=.001, F(1,267)=.45\right.$, $n s)$, perceived stress $\left(\Delta R^{2}=.000, F(1,267)=.08, n s\right)$, or well-being $\left(\Delta R^{2}=.001, F(1,267)\right.$ $=.26, n s)$.

Table 12. Co-Worker Social Support as a Moderator between Conflict with Supervisors and Job Satisfaction, Turnover Intentions and Affective Commitment

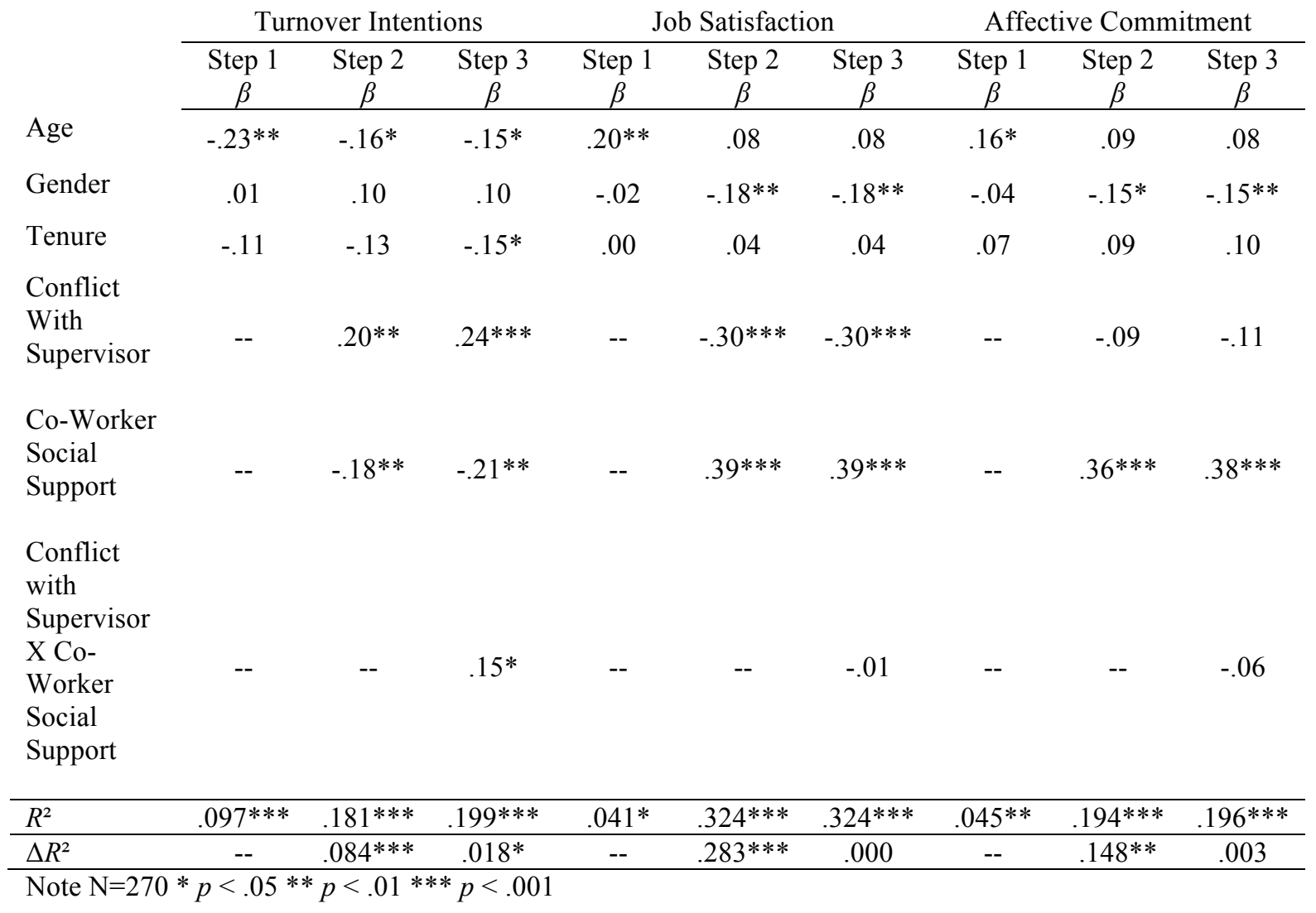


Table 13. Co-Worker Social Support as a Moderator between Conflict with Supervisors and Perceived Stress, Physical Symptoms and Well-Being

\begin{tabular}{|c|c|c|c|c|c|c|c|c|c|}
\hline & \multicolumn{3}{|c|}{ Perceived Stress } & \multicolumn{3}{|c|}{ Physical Symptoms } & \multicolumn{3}{|c|}{ Well-Being } \\
\hline & $\begin{array}{c}\text { Step } 1 \\
\beta\end{array}$ & $\begin{array}{c}\text { Step } 2 \\
\beta\end{array}$ & $\begin{array}{c}\text { Step } 3 \\
\beta\end{array}$ & $\begin{array}{c}\text { Step } 1 \\
\beta\end{array}$ & $\begin{array}{c}\text { Step } 2 \\
\beta\end{array}$ & $\begin{array}{c}\text { Step } 3 \\
B\end{array}$ & $\begin{array}{c}\text { Step } 1 \\
\beta\end{array}$ & $\begin{array}{c}\text { Step } 2 \\
\beta\end{array}$ & $\begin{array}{c}\text { Step } 3 \\
\beta\end{array}$ \\
\hline Age & $-.28 * *$ & $-.19 * *$ & $-.19 * *$ & -.13 & -.03 & -.07 & $.23 * *$ & .10 & .11 \\
\hline Gender & -.09 & .04 & .04 & $.14^{*}$ & $.27 * * *$ & $.27^{* * *}$ & $.20 * *$ & .04 & .04 \\
\hline Tenure & .11 & .08 & .08 & -.03 & -.06 & -.03 & -.10 & -.06 & -.06 \\
\hline $\begin{array}{l}\text { Conflict } \\
\text { With } \\
\text { Supervisors }\end{array}$ & -- & $.20^{* *}$ & $.19 * *$ & -- & $.30 * * *$ & $.21 * *$ & -- & $-.33 * * *$ & $-.32 * * *$ \\
\hline $\begin{array}{l}\text { Co-Worker } \\
\text { Social } \\
\text { Support }\end{array}$ & -- & $-.32 * * *$ & $-.31 * *$ & -- & $-.24 * * *$ & $-.16^{* *}$ & -- & $.36 * * *$ & $.34 * * *$ \\
\hline $\begin{array}{l}\text { Conflict } \\
\text { with } \\
\text { Supervisors } \\
\text { X Co- } \\
\text { Worker } \\
\text { Social } \\
\text { Support }\end{array}$ & -- & -- & -.04 & -- & -- & $-.32 * * *$ & -- & -- & .05 \\
\hline$R^{2}$ & $.060 * *$ & $.224 * * *$ & $.224 * * *$ & $.046 * *$ & $.220 * * *$ & $.303 * * *$ & $.075^{* * *}$ & $.354 * * *$ & $.356^{* * *}$ \\
\hline$\Delta R^{2}$ & -- & $.164 * * *$ & .001 & -- & $.174 * * *$ & $.083 * * *$ & -- & $.278 * * *$ & .002 \\
\hline
\end{tabular}


Table 14. Co-Worker Social Support as a Moderator between Conflict with Supervisors and Depression and Irritation

Age

Gender

Tenure

Conflict With Supervisors

Co-Worker Social Support

Conflict with Supervisors X Co-

Worker Social Support

\begin{tabular}{cccccc} 
& Depression & \multicolumn{3}{c}{ Irritation } \\
\hline Step 1 & Step 2 & Step 3 & Step 1 & Step 2 & Step 3 \\
$\beta$ & $\beta$ & $B$ & $\beta$ & $\beta$ & $\beta$ \\
\hline$-.17^{*}$ & -.05 & -.07 & -.14 & -.03 & -.06
\end{tabular}

\begin{tabular}{lcccccc}
\hline$R^{2}$ & .024 & $.333 * * *$ & $.390^{* * *}$ & .018 & $.226^{* * *}$ & $.284 * * *$ \\
\hline$\Delta R^{2}$ & -- & $.309 * * *$ & $.056^{* * *}$ & -- & $.208^{* * *}$ & $.058^{* * *}$ \\
\hline
\end{tabular}

Note $\mathrm{N}=270 * p<.05 * * p<.01 * * * p<.001$

Table 15. Co-Worker Social Support as a Moderator between Abusive Supervision and Job Satisfaction, Turnover Intentions and Affective Commitment

\begin{tabular}{|c|c|c|c|c|c|c|c|c|c|}
\hline & \multicolumn{3}{|c|}{ Turnover Intentions } & \multicolumn{3}{|c|}{ Job Satisfaction } & \multicolumn{3}{|c|}{ Affective Commitment } \\
\hline & $\begin{array}{c}\text { Step } 1 \\
\beta \\
\end{array}$ & $\begin{array}{c}\text { Step } 2 \\
\beta \\
\end{array}$ & $\begin{array}{c}\text { Step } 3 \\
\beta\end{array}$ & $\begin{array}{c}\text { Step } 1 \\
\beta \\
\end{array}$ & $\begin{array}{c}\text { Step } 2 \\
\beta \\
\end{array}$ & $\begin{array}{c}\text { Step } 3 \\
\beta \\
\end{array}$ & $\begin{array}{c}\text { Step } 1 \\
\beta \\
\end{array}$ & $\begin{array}{c}\text { Step } 2 \\
\beta \\
\end{array}$ & $\begin{array}{c}\text { Step } 3 \\
\beta \\
\end{array}$ \\
\hline Age & $-.23 * *$ & $-.17 *$ & $-.15^{*}$ & $.20 * *$ & .10 & .09 & $.16^{*}$ & .08 & .07 \\
\hline Gender & .01 & .09 & .10 & -.02 & $-.17 * *$ & $-.17 * *$ & -.04 & $-.16^{*}$ & $-.16^{* *}$ \\
\hline Tenure & -.11 & -.13 & $-.14 *$ & .00 & .03 & .03 & .07 & .09 & .10 \\
\hline $\begin{array}{l}\text { Abusive } \\
\text { Supervision }\end{array}$ & -- & $.22 * * *$ & $.29 * * *$ & -- & $-.28 * * *$ & $-.30 * * *$ & -- & $-.18 * *$ & $-.23 * * *$ \\
\hline $\begin{array}{l}\text { Co-Worker } \\
\text { Social } \\
\text { Support }\end{array}$ & -- & $-.18 * *$ & $-.22 * * *$ & -- & $.40 * * *$ & $.41 * * *$ & -- & $.34 * * *$ & $.37 * * *$ \\
\hline
\end{tabular}

Abusive

Supervision

$\mathrm{X}$ Co-

Worker

Social

Support

\begin{tabular}{lccccccccc}
\hline$R^{2}$ & $.097 * * *$ & $.191 * * *$ & $.215^{* * *}$ & $.041^{*}$ & $.321 * * *$ & $.322 * * *$ & $.045^{* *}$ & $.215 * * *$ & $.231 * * *$ \\
\hline$\Delta R^{2}$ & -- & $.094 * * *$ & $.024 * *$ & -- & $.280 * * *$ & .001 & -- & $.170 * * *$ & $.015 *$ \\
\hline
\end{tabular}

Note $\mathrm{N}=270-271 * p<.05 * * p<.01 * * * p<.001$ 
Table 16. Co-Worker Social Support as a Moderator between Abusive Supervision and Perceived Stress, Physical Symptoms and Well-Being

\begin{tabular}{|c|c|c|c|c|c|c|c|c|c|}
\hline & \multicolumn{3}{|c|}{ Perceived Stress } & \multicolumn{3}{|c|}{ Physical Symptoms } & \multicolumn{3}{|c|}{ Well-Being } \\
\hline & $\begin{array}{c}\text { Step } 1 \\
\beta \\
\end{array}$ & $\begin{array}{c}\text { Step } 2 \\
\beta\end{array}$ & $\begin{array}{c}\text { Step } 3 \\
\beta \\
\end{array}$ & $\begin{array}{c}\text { Step } 1 \\
\beta \\
\end{array}$ & $\begin{array}{c}\text { Step } 2 \\
\beta\end{array}$ & $\begin{array}{c}\text { Step } 3 \\
\beta\end{array}$ & $\begin{array}{c}\text { Step } 1 \\
\beta \\
\end{array}$ & $\begin{array}{c}\text { Step } 2 \\
\beta\end{array}$ & $\begin{array}{c}\text { Step } 3 \\
\beta \\
\end{array}$ \\
\hline Age & $-.28 * * *$ & $-.20 * *$ & $-.20 * *$ & -.13 & -.04 & -.06 & $.23^{* *}$ & .12 & $.12 *$ \\
\hline Gender & -.09 & .03 & .03 & $.15^{*}$ & $.27 * * *$ & $.27 * * *$ & $.20 * *$ & .06 & .06 \\
\hline Tenure & .11 & .09 & .09 & -.04 & -.06 & -.04 & -.10 & -.07 & -.07 \\
\hline $\begin{array}{l}\text { Abusive } \\
\text { Supervision }\end{array}$ & -- & $.17^{* *}$ & $.17^{* *}$ & -- & $.35 * * *$ & $.25 * * *$ & -- & $-.31 * * *$ & $-.30 * * *$ \\
\hline $\begin{array}{l}\text { Co-Worker } \\
\text { Social } \\
\text { Support }\end{array}$ & -- & $-.33 * * *$ & $-.33 * * *$ & -- & $-.24 * * *$ & $-.18 * *$ & -- & $.37 * * *$ & $.36 * * *$ \\
\hline $\begin{array}{l}\text { Abusive } \\
\text { Supervision } \\
\text { X Co- } \\
\text { Worker } \\
\text { Social } \\
\text { Support }\end{array}$ & -- & -- & -.02 & -- & -- & $-.25 * * *$ & -- & -- & .03 \\
\hline$R^{2}$ & $.060 * *$ & $.217 * * *$ & $.218 * * *$ & $.047^{* *}$ & $.251 * * *$ & $.301 * * *$ & $.075 * * *$ & $.347 * * *$ & $.347 * * *$ \\
\hline$\Delta R^{2}$ & -- & $.157 * * *$ & .000 & -- & $.204 * * *$ & $.050 * * *$ & -- & $.272 * * *$ & .001 \\
\hline
\end{tabular}

Table 17. Co-Worker Social Support as a Moderator between Abusive Supervision and Depression and Irritation

Age

Gender

Tenure

Abusive Supervision

Co-Worker Social Support

Abusive Supervision X Co-Worker Social Support

\begin{tabular}{cccccc}
\multicolumn{3}{c}{ Depression } & \multicolumn{3}{c}{ Irritation } \\
\hline Step 1 & Step 2 & Step 3 & Step 1 & Step 2 & Step 3 \\
$\beta$ & $\beta$ & $B$ & $\beta$ & $\beta$ & $\beta$ \\
\hline$-.17^{*}$ & -.06 & -.08 & -.14 & -.04 & -.05
\end{tabular}

\begin{tabular}{lcccccc}
\hline$R^{2}$ & .024 & $.331 * * *$ & $.382 * * *$ & .018 & $.294 * * *$ & $.322 * * *$ \\
\hline$\Delta R^{2}$ & -- & $.307 * * *$ & $.051 * * *$ & -- & $.276 * * *$ & $.028^{* *}$ \\
\hline
\end{tabular}

Note $\mathrm{N}=270 * p<.05 * * p<.01 * * * p<.001$ 
The moderation effects are illustrated in Figure 1 through Figure 10. With regards to conflict with supervisors, support is found for hypothesis $8 \mathrm{a}$ in the relationships with physical symptoms $\left(b=.36, \mathrm{SE}_{b}=.04, p<.001\right)$, depression $\left(b=.27, \mathrm{SE}_{b}=.03, p<.001\right)$ and irritation $\left(b=.33, \mathrm{SE}_{b=} .04, p<.001\right)$ where when co-worker social support is low ($1 \mathrm{SD})$ the relationship between conflict with supervisors and outcomes is strengthened, depicted in Figures 3 through 5. In participants indicating high co-worker social support $(+1 \mathrm{SD})$ there is not a significant relationship between conflict with supervisors and physical symptoms $\left(b=-.06, \mathrm{SE}_{b}=.04, n s\right)$, depression $\left(b=.00, \mathrm{SE}_{b}=.03, n s\right)$ and

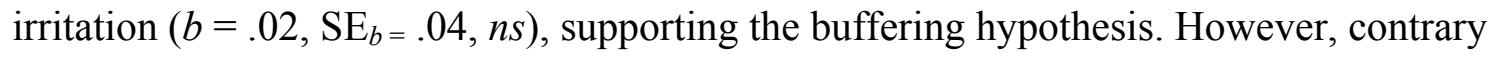
to hypothesis $8 \mathrm{a}$ the relationship between conflict with supervisors and turnover intentions is strengthened when co-worker support is high and there are also high levels of conflict with supervisors $\left(b=.46, \mathrm{SE}_{b}=.08, p<.001\right)$, depicted in figure 2 .

In support of hypothesis $8 \mathrm{a}$, the relationships between abusive supervision and physical symptoms $\left(b=.37, \mathrm{SE}_{b=.05, p}<.001\right)$, depression $\left(b=.26, \mathrm{SE}_{b}=.04, p<.001\right)$ and irritation $\left(b=.37, \mathrm{SE}_{b=.04, p<.001)}\right.$ are strengthened in conditions of low coworker social support, depicted in figures 8 through 10. Additionally, the relationships between abusive supervision and physical symptoms $\left(b=.04, \mathrm{SE}_{b}=.05, n s\right)$, depression $\left(b=-.01, \mathrm{SE}_{b}=.04, n s\right)$ and irritation $\left(b=.14, \mathrm{SE}_{b}=.04, p<.001\right)$ are not significant with high co-worker support, providing evidence for the buffering hypothesis. Contrary to hypothesis $8 \mathrm{a}$, as abusive supervision increases, employees reporting a high level of coworker support indicated greater turnover intentions $\left(b=.56, \mathrm{SE}_{b=.08, p<.001)}\right.$ and lower affective commitment $\left(b=-.44, \mathrm{SE}_{b}=.08, p<.001\right)$ than those with low levels of 
support, as illustrated by Figures 6 and 7. Given the results, partial support is found for hypothesis 8 a which predicted that co-worker social support would buffer relationship between supervisor aggression and outcomes.

Figure 2. Co-Worker Support as a Moderator between Conflict with Supervisors and Turnover Intentions

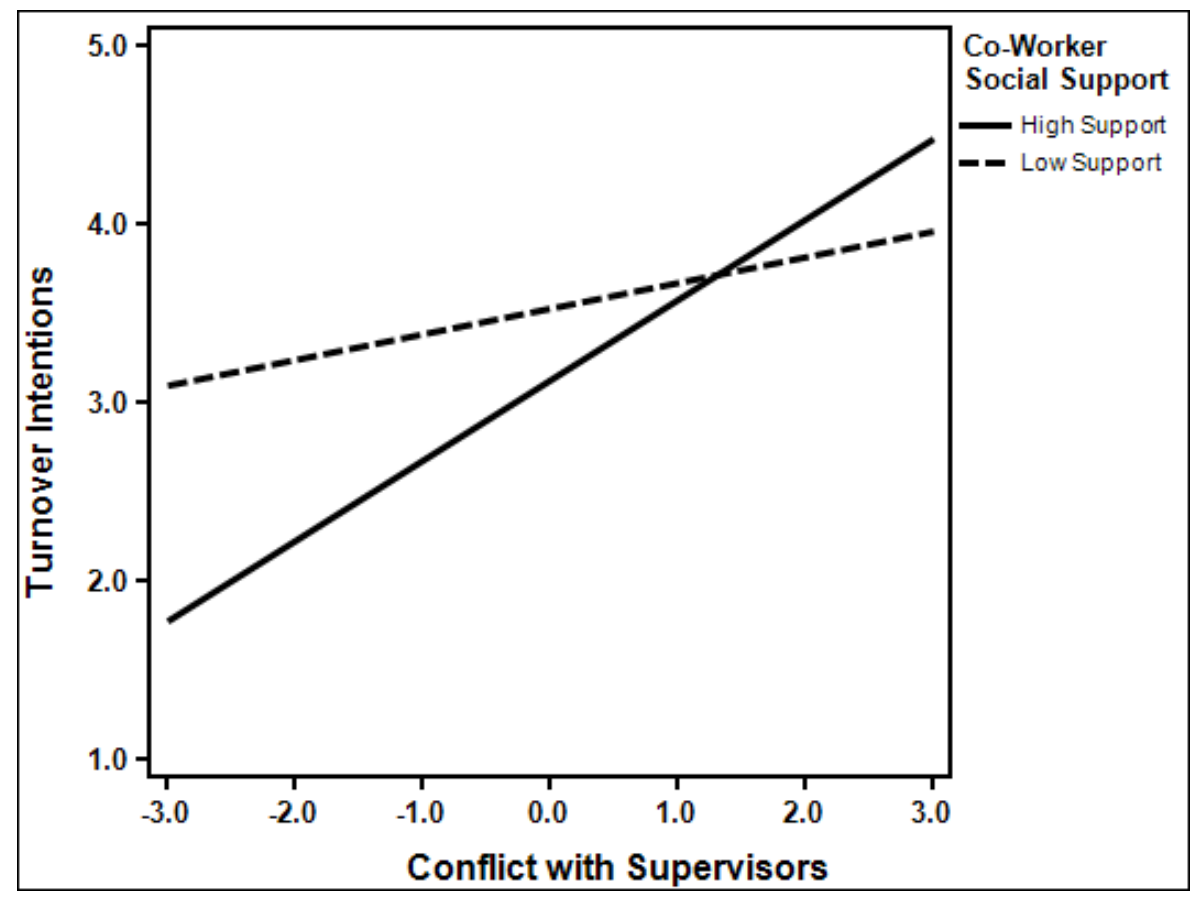


Figure 3. Co-Worker Support as a Moderator between Conflict with Supervisors and Physical Symptoms

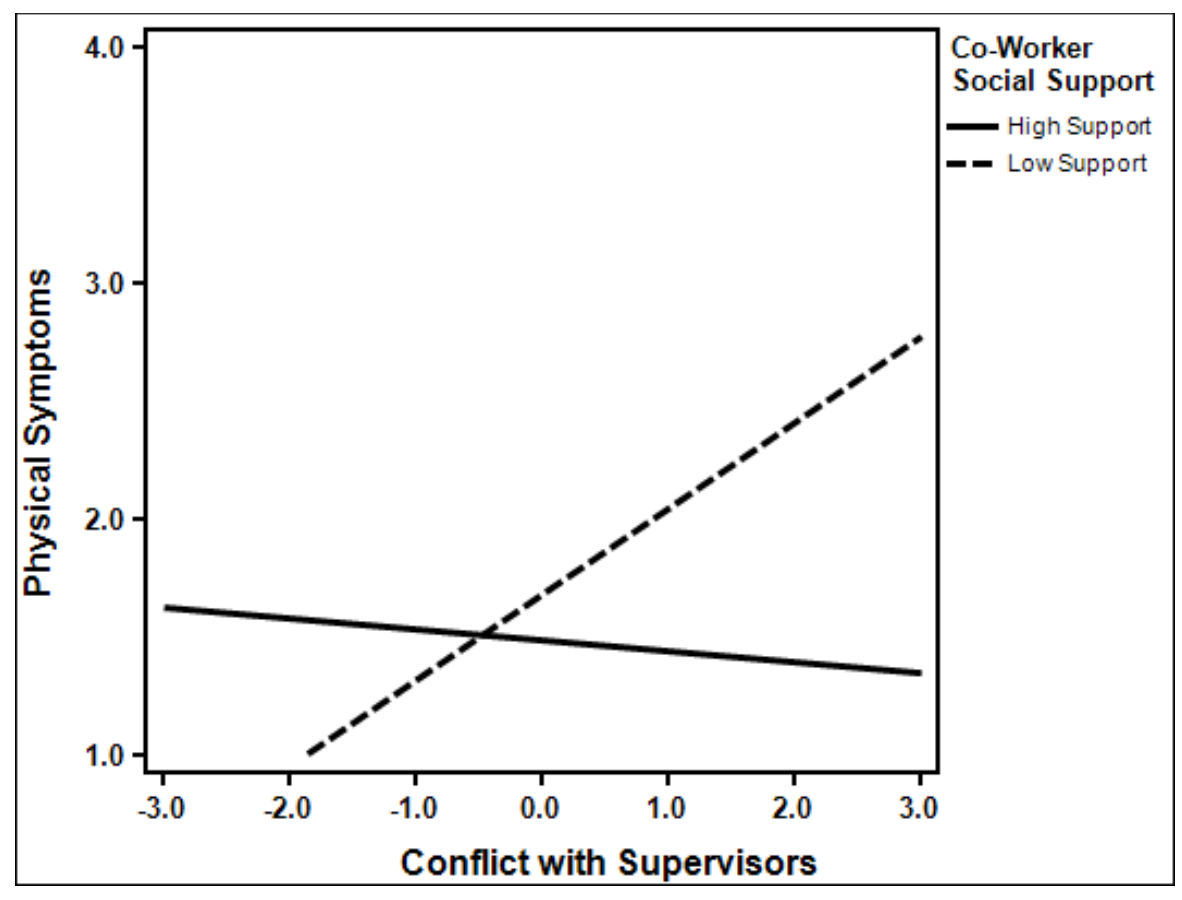

Figure 4. Co-Worker Support as a Moderator between Conflict with Supervisors and Depression

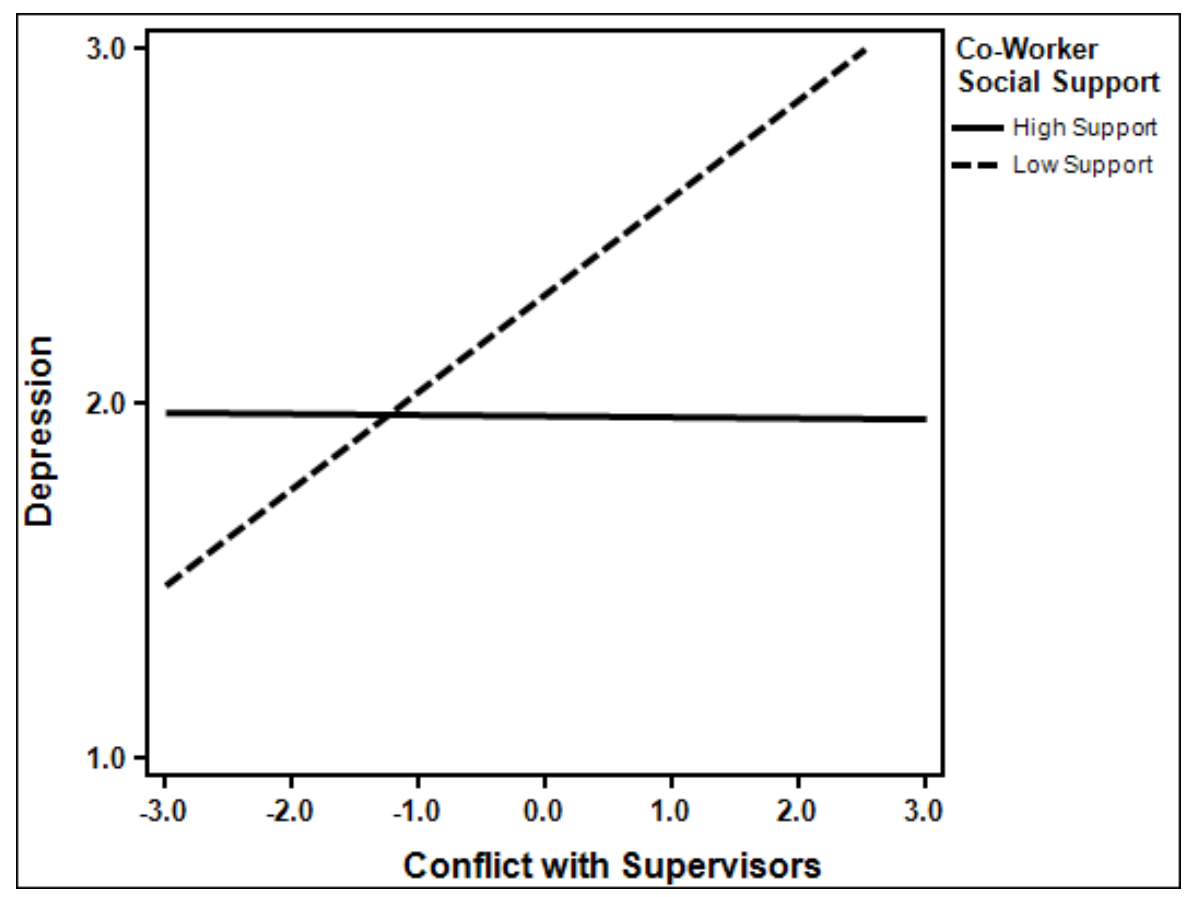


Figure 5. Co-Worker Support as a Moderator between Conflict with Supervisors and Irritation



Figure 6. Co-Worker Support as a Moderator between Abusive Supervision and Turnover Intentions

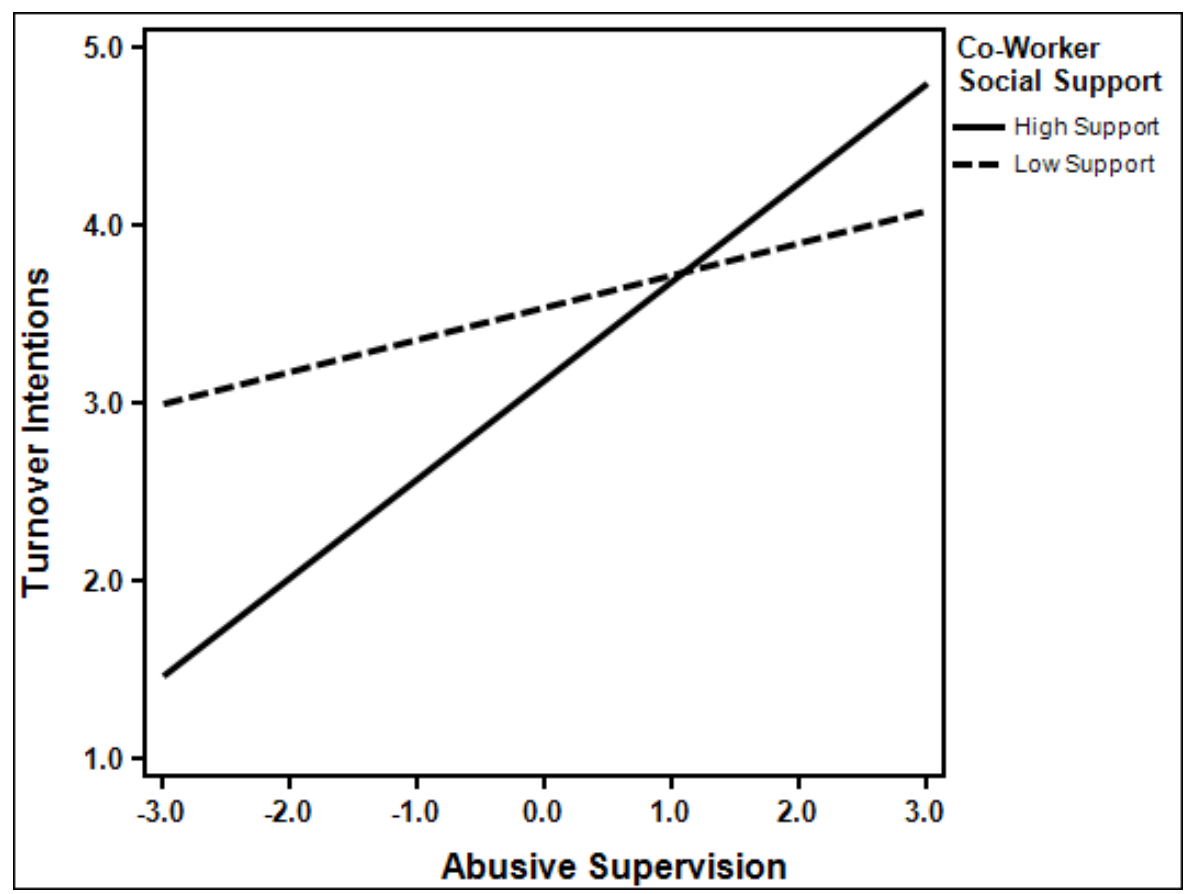


Figure 7. Co-Worker Support as a Moderator between Abusive Supervision and Affective Commitment

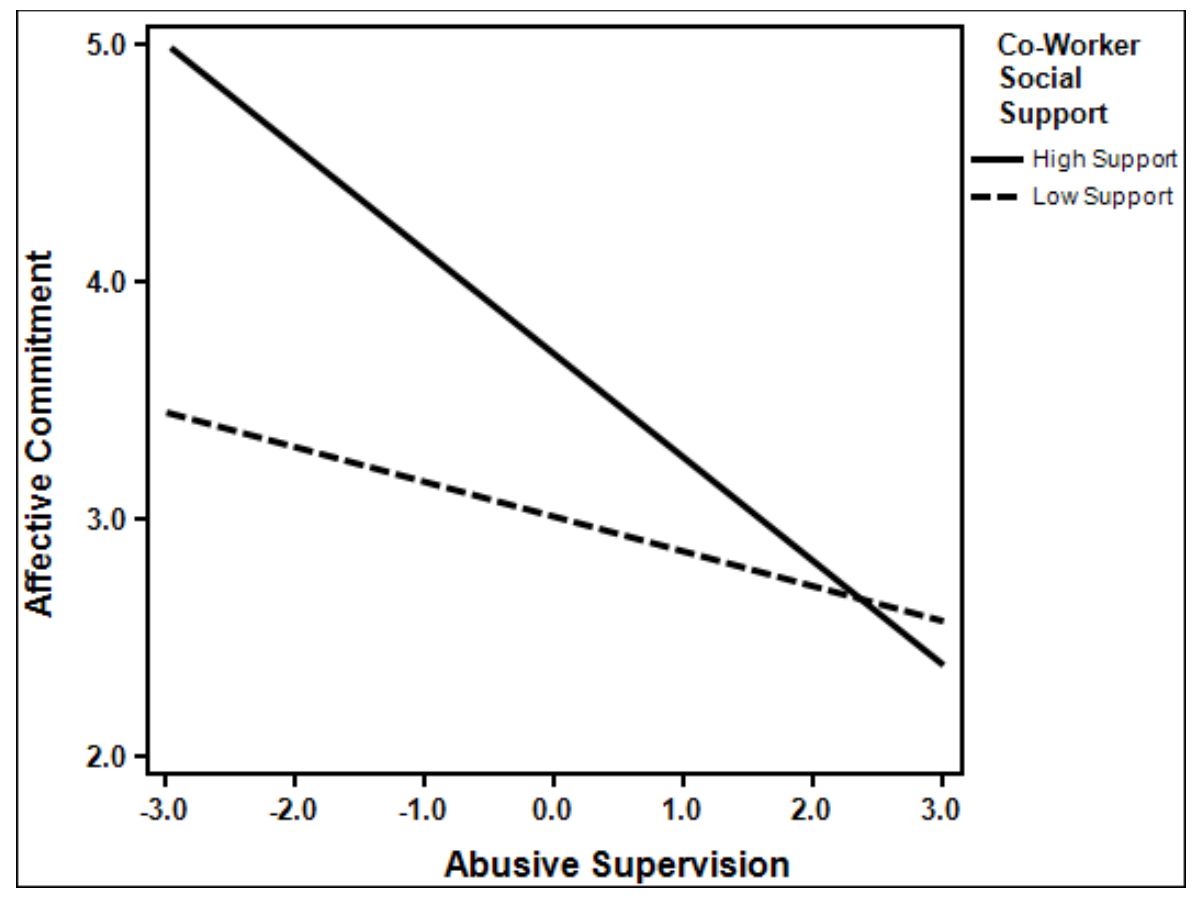

Figure 8. Co-Worker Support as a Moderator between Abusive Supervision and Physical Symptoms




Figure 9. Co-Worker Support as a Moderator Abusive Supervision and Depression

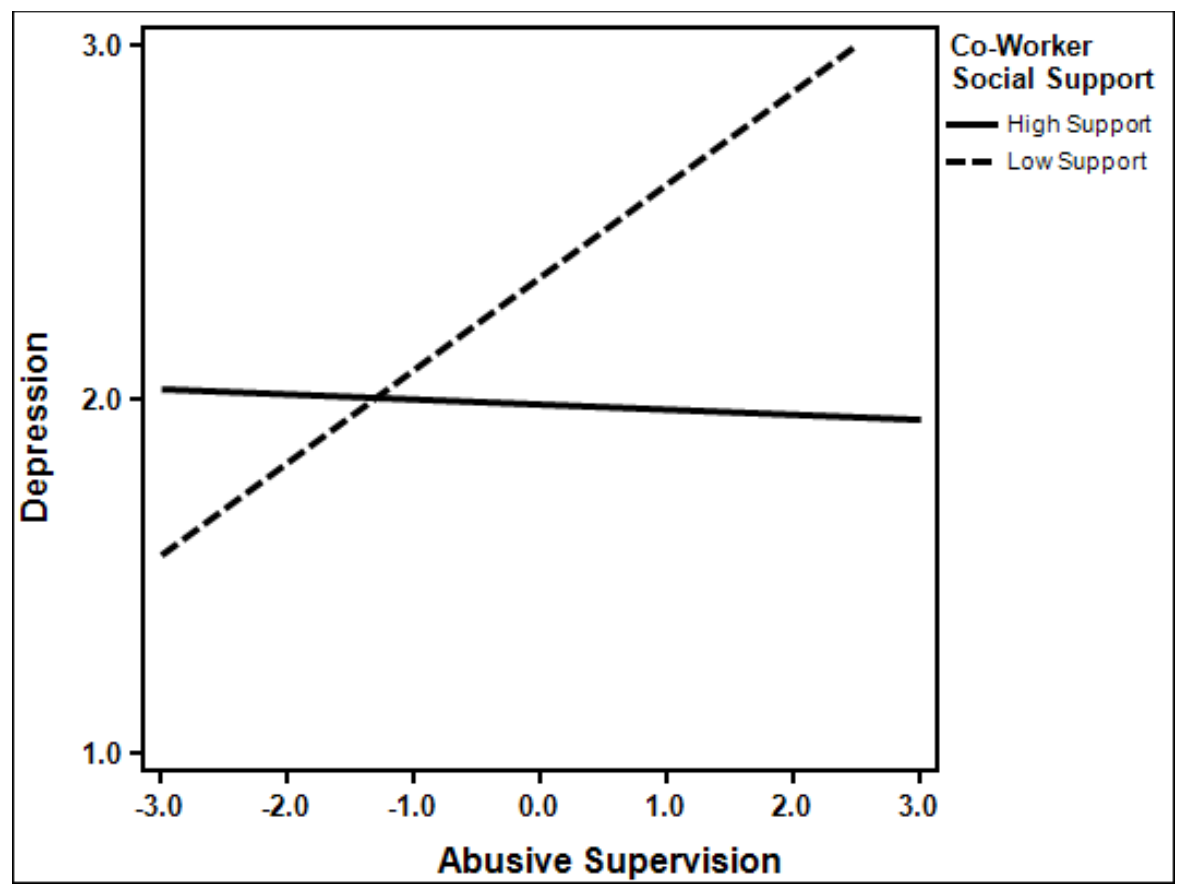

Figure 10. Co-Worker Support as a Moderator between Abusive Supervision and Irritation

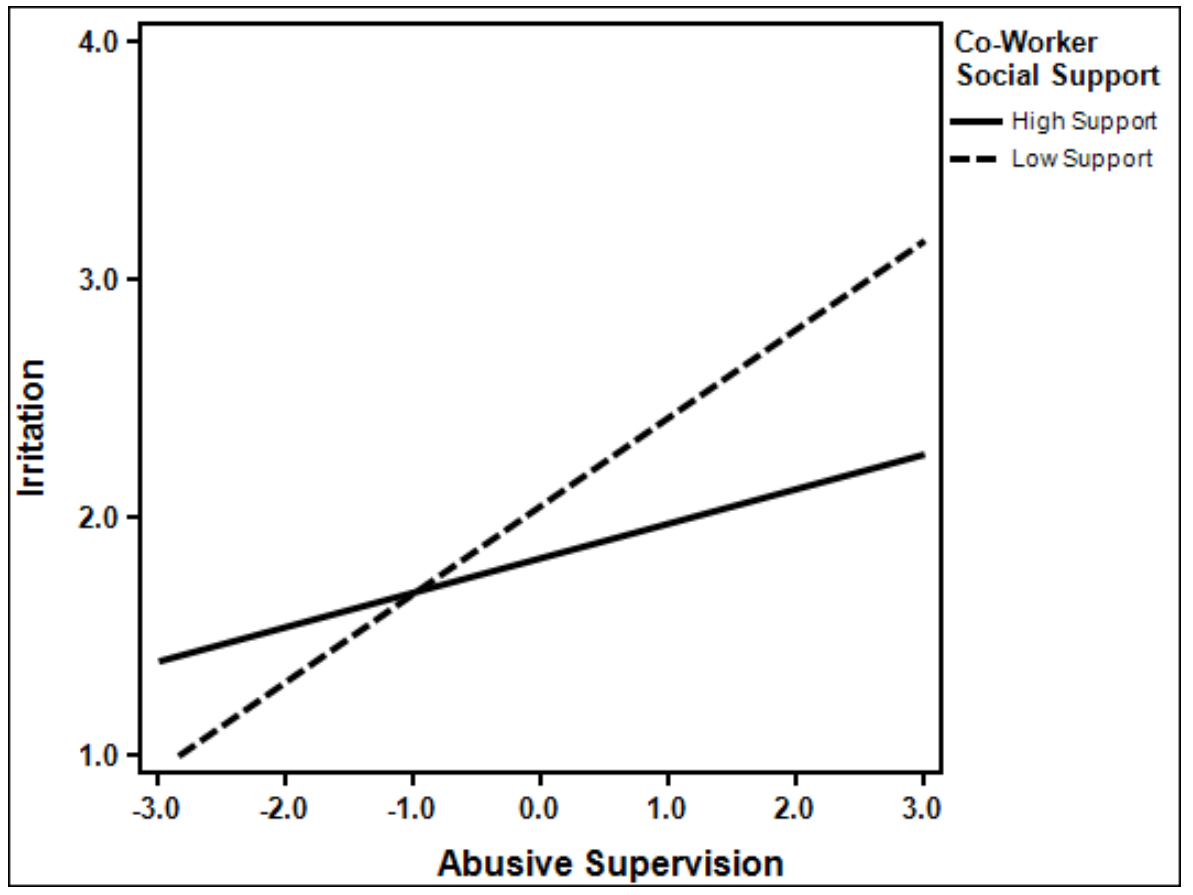


Hypothesis $8 \mathrm{~b}$ posited that supervisor social support would buffer the relationship between conflict with co-workers and outcomes (see Tables 18 through 20). When the interaction term between conflict with co-workers and social support was added to the regression it significantly contributed to the variances predicted in physical symptoms $\left(\Delta R^{2}=.019, F(1,268)=6.47, p<.05\right)$, and irritation $\left(\Delta R^{2}=.014, F(1,270)=4.80, p<\right.$ .05 ), as found in Tables 19 and 20. The interaction term did not result in a significant increase in variance explained for turnover intentions $\left(\Delta R^{2}=.005, F(1,267)=1.55, n s\right)$, job satisfaction $\left(\Delta R^{2}=.000, F(1,268)=.00, n s\right)$, affective commitment $\left(\Delta R^{2}=.009, F\right.$ $(1,267)=3.17, n s)$, perceived stress $\left(\Delta R^{2}=.005, F(1,267)=1.51, n s\right)$, well-being $\left(\Delta R^{2}=\right.$ $.000, F(1,271)=.09, n s)$, and depression $\left(\Delta R^{2}=.009, F(1,270)=2.90, n s\right)$, as found in Tables 18 through 20 . 
Table 18. Supervisor Social Support as a Moderator between Conflict with Co-Workers and Job Satisfaction, Turnover Intentions and Affective Commitment

\begin{tabular}{|c|c|c|c|c|c|c|c|c|c|}
\hline & \multicolumn{3}{|c|}{ Turnover Intentions } & \multicolumn{3}{|c|}{ Job Satisfaction } & \multicolumn{3}{|c|}{ Affective Commitment } \\
\hline & $\begin{array}{c}\text { Step } 1 \\
\beta \\
\end{array}$ & $\begin{array}{c}\text { Step } 2 \\
\beta\end{array}$ & $\begin{array}{c}\text { Step } 3 \\
\beta\end{array}$ & $\begin{array}{c}\text { Step } 1 \\
\beta\end{array}$ & $\begin{array}{c}\text { Step } 2 \\
\beta\end{array}$ & $\begin{array}{c}\text { Step } 3 \\
\beta\end{array}$ & $\begin{array}{c}\text { Step } 1 \\
\beta\end{array}$ & $\begin{array}{c}\text { Step } 2 \\
\beta\end{array}$ & $\begin{array}{c}\text { Step } 3 \\
\beta\end{array}$ \\
\hline Age & $-.23 * *$ & $-.18 *$ & $-.17 *$ & $.20 *$ & .10 & .10 & $.16^{*}$ & .12 & .12 \\
\hline Gender & .01 & .06 & .06 & -.02 & $-.11 *$ & $-.11 *$ & -.04 & -.08 & -.09 \\
\hline Tenure & -.11 & -.11 & -.12 & .00 & .00 & .00 & .07 & .06 & .05 \\
\hline $\begin{array}{l}\text { Conflict With } \\
\text { Co-Workers }\end{array}$ & -- & .05 & .08 & -- & -.08 & -.08 & -- & $.13^{*}$ & $.17 * *$ \\
\hline $\begin{array}{l}\text { Supervisor } \\
\text { Social } \\
\text { Support }\end{array}$ & -- & $-.28 * * *$ & $-.27 * * *$ & -- & $.52 * * *$ & $.52 * * *$ & -- & $.45 * * *$ & $.46 * * *$ \\
\hline $\begin{array}{l}\text { Conflict with } \\
\text { Co-Workers } \\
\text { X Supervisor } \\
\text { Social } \\
\text { Support }\end{array}$ & -- & -- & .08 & -- & -- & .00 & -- & -- & .11 \\
\hline$R^{2}$ & $.097 * * *$ & $.179 * * *$ & $.184 * * *$ & $.040 *$ & $.323 * * *$ & $.323 * * *$ & $.045^{* *}$ & $.230 * * *$ & $.239 * * *$ \\
\hline$\Delta R^{2}$ & -- & $.082 * * *$ & .005 & -- & $.282 * * *$ & .000 & -- & $.185 * * *$ & .009 \\
\hline
\end{tabular}

Note $\mathrm{N}=270 * p<.05 * * p<.01 * * * p<.001$ 
Table 19. Supervisor Social Support as a Moderator between Conflict with Co-Workers and Perceived Stress, Physical Symptoms and Well-Being



Table 20. Supervisor Social Support as a Moderator between Conflict with Co-Workers and Depression and Irritation

Age

Gender

Tenure

Conflict With Co-Workers

Supervisor Social Support

Conflict with Co-Workers X

Supervisor Social Support

\begin{tabular}{cccccc} 
& Depression & \multicolumn{3}{c}{ Irritation } \\
\hline Step 1 & Step 2 & Step 3 & Step 1 & Step 2 & Step 3 \\
$\beta$ & $\beta$ & $B$ & $\beta$ & $\beta$ & $\beta$ \\
\hline$-.16^{*}$ & -.07 & -.07 & -.13 & -.04 & -.05
\end{tabular}

\begin{tabular}{lcccccc}
\hline$R^{2}$ & .021 & $.183^{* * *}$ & $.192^{* * *}$ & .016 & $.178^{* * * *}$ & $.193^{* * *}$ \\
\hline$\Delta R^{2}$ & -- & $.162^{* * *}$ & .009 & -- & $.163^{* * *}$ & $.014^{*}$ \\
\hline
\end{tabular}

Note $\mathrm{N}=273 * p<.05 * * p<.01 * * * p<.001$ 
The moderation effects are illustrated in Figures 10 and 11. In support of hypothesis $8 b$, the relationships between conflict with co-workers and physical symptoms $\left(b=.27, \mathrm{SE}_{b=} .05, p<.001\right)$ and irritation $\left(b=.17, \mathrm{SE}_{b}=.05, p<.001\right)$ were strengthened when supervisor social support was low (-1 SD). Additionally, the relationships between conflict with co-workers and physical symptoms $\left(b=.03, \mathrm{SE}_{b}=.05, n s\right)$ and irritation $(b=$ $\left.-.03, \mathrm{SE}_{b}=.05, n s\right)$ were not significantly different from zero when supervisor social support was high (+1 SD), providing evidence for the buffering hypothesis. Therefore, partial support was found for hypothesis $8 b$.

Figure 11. Supervisor Social Support as a Moderator between Conflict with Co-Workers and Physical Symptoms

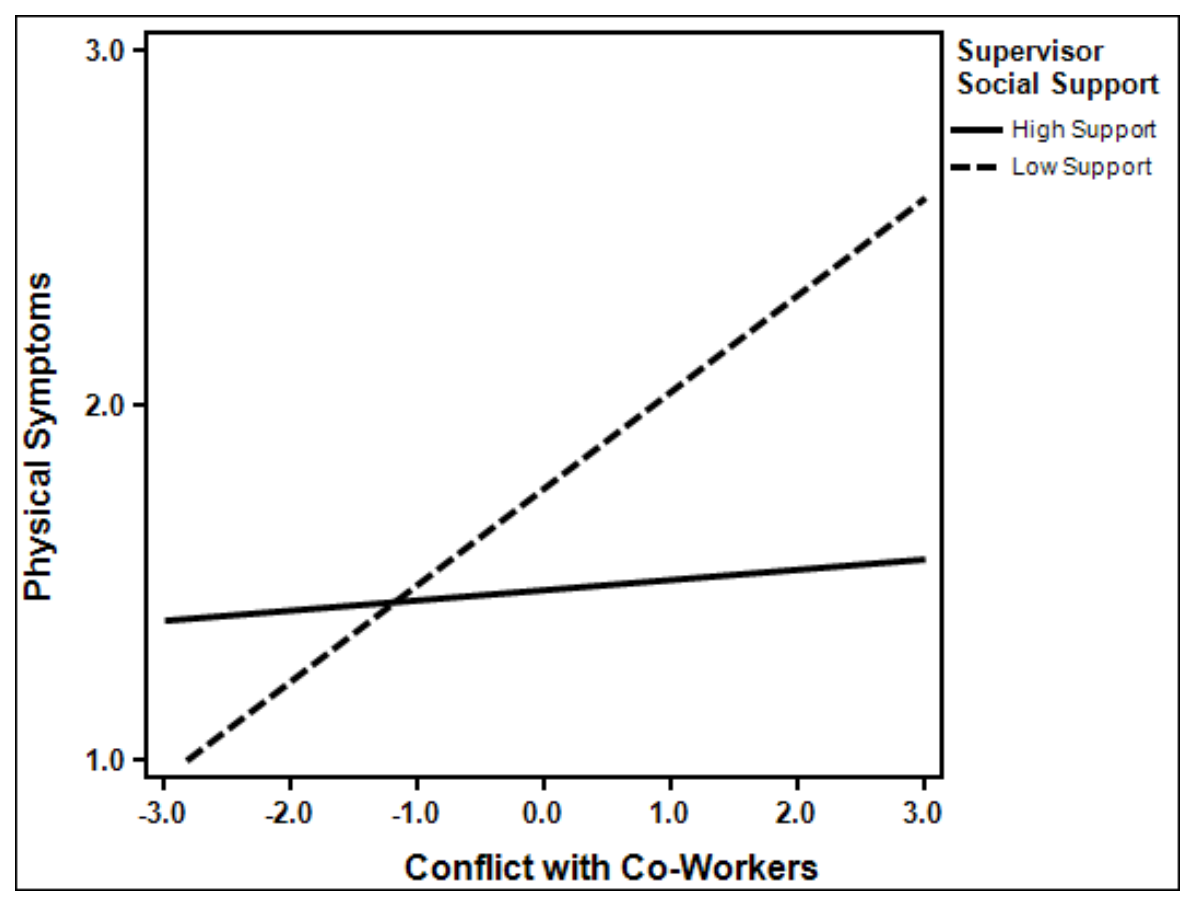


Figure 12. Supervisor Social Support as a Moderator between Conflict with Co-Workers and Irritation

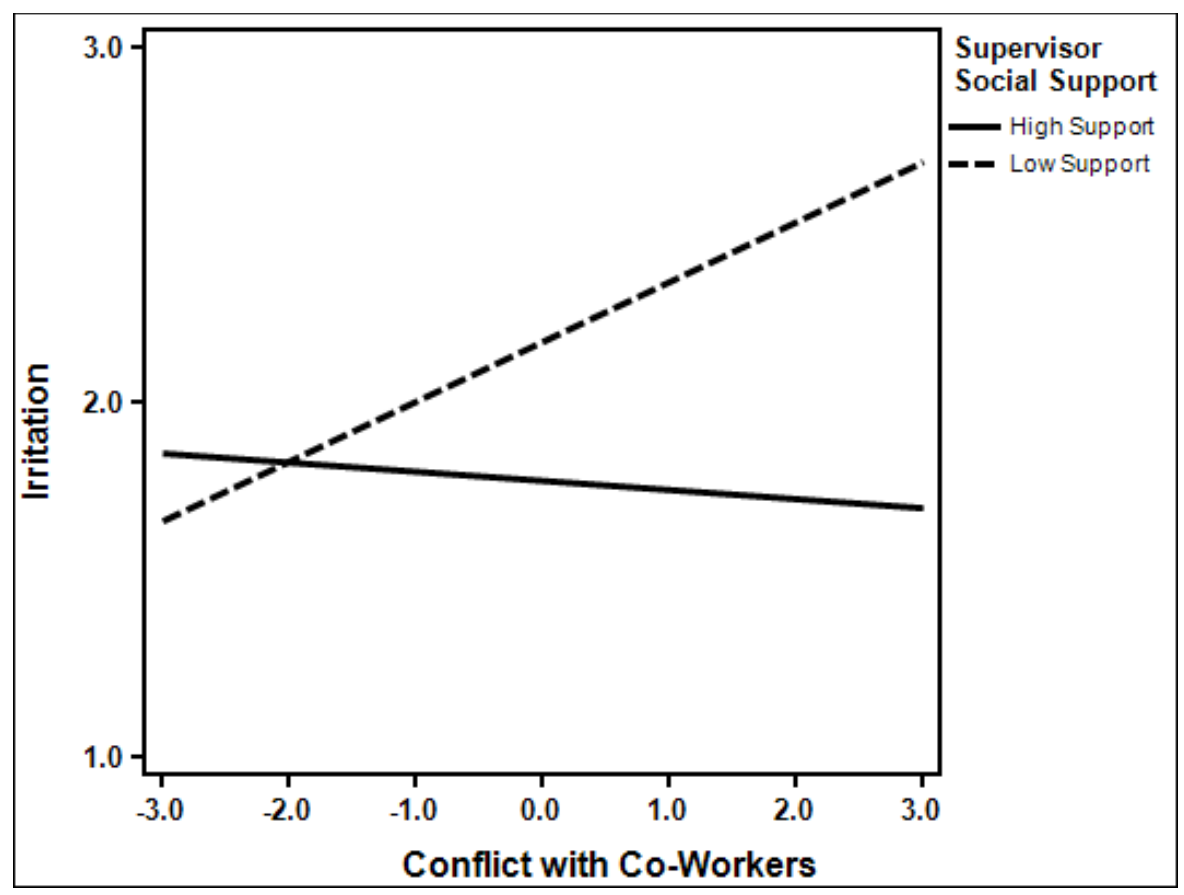

\section{Within-Domain Social Support as a Moderator}

Hypothesis $8 \mathrm{c}$ posited that supervisor social support would exacerbate the relationship between supervisor aggression and outcomes. All information can be found in Tables 21 through 26. The interaction term between conflict with supervisor and supervisor social support accounted for a significant increase of the variance explained while predicting job satisfaction $\left(\Delta R^{2}=.009, F(1,267)=3.75, p<.05\right)$, affective commitment $\left(\Delta R^{2}=.024, F(1,267)=8.48, p<.01\right)$, perceived stress $\left(\Delta R^{2}=.020, F\right.$ $(1,267)=6.57, p<.05)$, and irritation $\left(\Delta R^{2}=.042, F(1,268)=14.74, p<.001\right)$, found in Tables 21 through 23. The interaction term did not result in a significant increase in variance explained in turnover intentions $\left(\Delta R^{2}=.002, F(1,267)=.60, n s\right)$, physical 
symptoms $\left(\Delta R^{2}=.005, F(1,267)=1.71, n s\right)$, well-being $\left(\Delta R^{2}=.002, F(1,269)=.69, n s\right)$, or depression $\left(\Delta R^{2}=.000, F(1,268)=.009, n s\right)$.

The increase in the variances explained in affective commitment $\left(\Delta R^{2}=.022, F\right.$ $(1,267)=7.85, p<.01)$, perceived stress $\left(\Delta R^{2}=.018, F(1,267)=5.90, p<.05\right)$, and irritation $\left(\Delta R^{2}=.020, F(1,267)=7.68, p<.01\right)$, were significant when the interaction term for abusive supervision and supervisor social support were added into the regression. The interaction term did not account for a significant increase in the variance explained for turnover intentions $\left(\Delta R^{2}=.000, F(1,267)=.04, n s\right)$, job satisfaction $\left(\Delta R^{2}=\right.$ $.008, F(1,267)=3.15, n s)$, physical symptoms $\left(\Delta R^{2}=.000, F(1,267)=.00, n s\right)$, and well-being $\left(\Delta R^{2}=.003, F(1,267)=1.27, n s\right)$ and depression $\left(\Delta R^{2}=.001, F(1,267)=.33\right.$, $n s)$, found in Tables 24 through 26. 
Table 21. Supervisor Social Support as a Moderator between Conflict with Supervisors and Job Satisfaction, Turnover Intentions and Affective Commitment

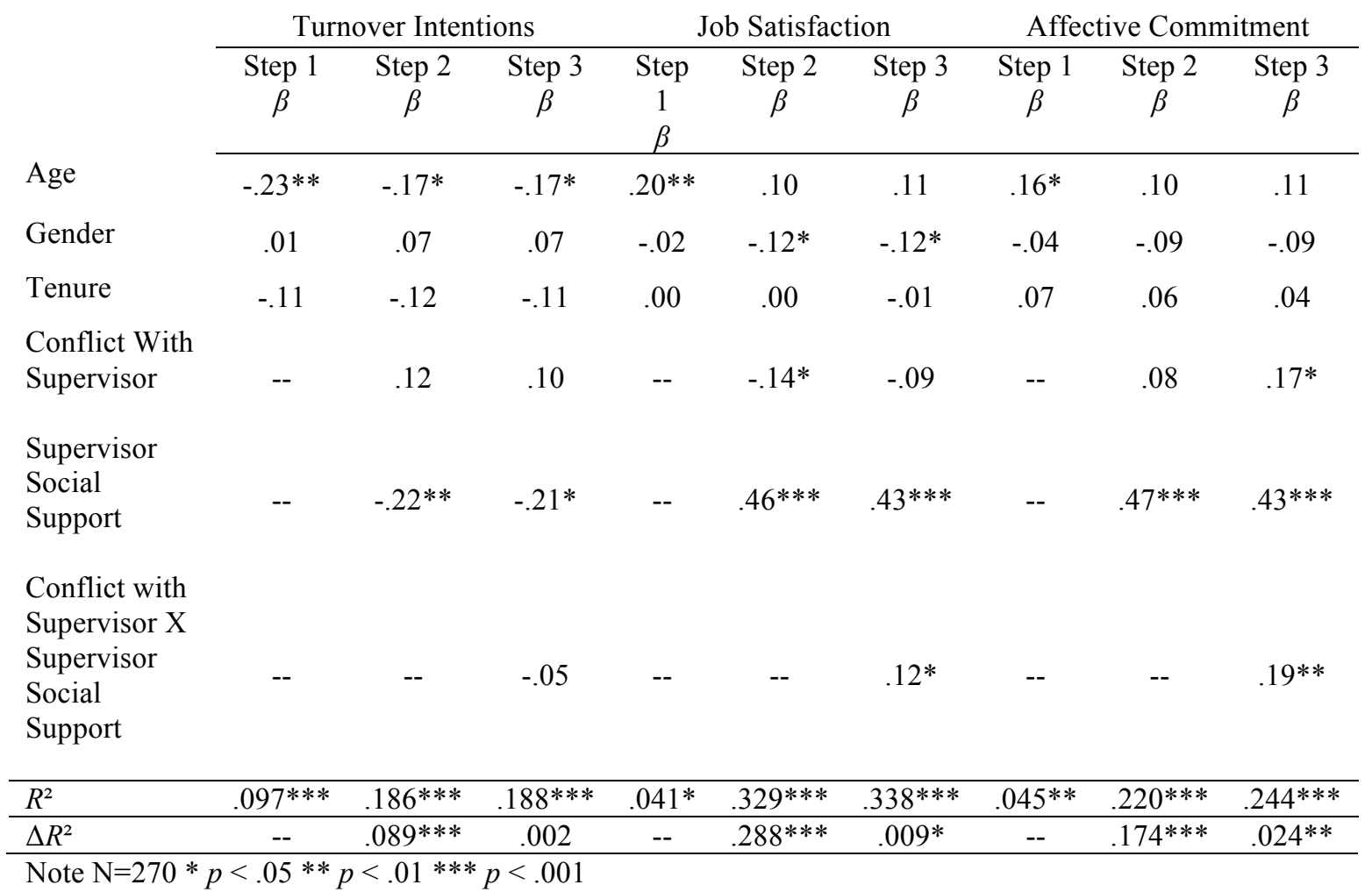


Table 22. Supervisor Social Support as a Moderator between Conflict with Supervisors and Perceived Stress, Physical Symptoms and Well-Being

\begin{tabular}{|c|c|c|c|c|c|c|c|c|c|}
\hline & \multicolumn{3}{|c|}{ Perceived Stress } & \multicolumn{3}{|c|}{ Physical Symptoms } & \multicolumn{3}{|c|}{ Well-Being } \\
\hline & $\begin{array}{c}\text { Step } 1 \\
\beta\end{array}$ & $\begin{array}{c}\text { Step } 2 \\
\beta\end{array}$ & $\begin{array}{c}\text { Step } 3 \\
\beta\end{array}$ & $\begin{array}{c}\text { Step } 1 \\
\beta\end{array}$ & $\begin{array}{c}\text { Step } 2 \\
\beta\end{array}$ & $\begin{array}{c}\text { Step } 3 \\
\beta\end{array}$ & $\begin{array}{c}\text { Step } 1 \\
\beta \\
\end{array}$ & $\begin{array}{c}\text { Step } 2 \\
\beta\end{array}$ & $\begin{array}{c}\text { Step } 3 \\
\beta \\
\end{array}$ \\
\hline Age & $-.28 * * *$ & $-.21 * *$ & $-.20 * *$ & -.13 & -.05 & -.05 & $.23 * *$ & $.13 *$ & $.13 *$ \\
\hline Gender & -.09 & -.02 & -.01 & $.14^{*}$ & $.23 * * *$ & $.23 * * *$ & $.19^{* *}$ & .09 & .09 \\
\hline Tenure & .11 & .10 & .08 & -.03 & -.05 & -.04 & -.10 & -.09 & -.08 \\
\hline $\begin{array}{l}\text { Conflict } \\
\text { With } \\
\text { Supervisors }\end{array}$ & -- & $.17^{*}$ & $.26 * *$ & -- & $.30 * * *$ & $.26^{* *}$ & -- & $-.32 * * *$ & $-.35 * * *$ \\
\hline $\begin{array}{l}\text { Supervisor } \\
\text { Social } \\
\text { Support }\end{array}$ & -- & $-.20 * *$ & $-.23 * *$ & -- & -.12 & -.10 & -- & $.19 * *$ & $.20 * *$ \\
\hline $\begin{array}{l}\text { Conflict } \\
\text { with } \\
\text { Supervisors } \\
\text { X } \\
\text { Supervisor } \\
\text { Social } \\
\text { Support }\end{array}$ & -- & -- & $.18^{*}$ & -- & -- & -.09 & -- & -- & -.05 \\
\hline$R^{2}$ & $.060 * *$ & $.161 * * *$ & $.182 * * *$ & $.046^{* *}$ & $.179 * * *$ & $.185^{* * *}$ & $.073 * * *$ & $.267 * * *$ & $.269 * * *$ \\
\hline$\Delta R^{2}$ & -- & $.101 * *$ & $.020^{*}$ & -- & $.133 * * *$ & .005 & -- & $.194 * * *$ & .002 \\
\hline
\end{tabular}


Table 23. Supervisor Social Support as a Moderator between Conflict with Supervisors and Depression and Irritation

Age

\begin{tabular}{cccccc} 
& Depression & \multicolumn{3}{c}{ Irritation } \\
\hline $\begin{array}{c}\text { Step 1 } \\
\beta\end{array}$ & $\begin{array}{c}\text { Step 2 } \\
\beta\end{array}$ & $\begin{array}{c}\text { Step 3 } \\
B\end{array}$ & $\begin{array}{c}\text { Step 1 } \\
\beta\end{array}$ & $\begin{array}{c}\text { Step 2 } \\
\beta\end{array}$ & $\begin{array}{c}\text { Step 3 } \\
\beta\end{array}$ \\
\hline$-.17 *$ & -.08 & -.08 & -.14 & -.05 & -.06
\end{tabular}

Gender

$-.05$

Tenure

.05

.05

.05

$-.01$

.09

.08

Conflict With Supervisors

Supervisor Social Support

$\begin{array}{llllll}-- & .31 * * * & .32 * * * & -- & .26 * * * & .14 \\ -- & -.18 * * & -.18 * & -- & -.24 * * * & -.19 * *\end{array}$

Conflict with Supervisors X

Supervisor Social Support

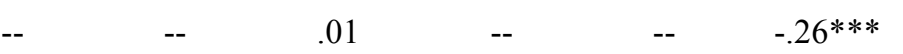

\begin{tabular}{lcccccc}
\hline$R^{2}$ & .024 & $.203 * * *$ & $.203 * * *$ & .018 & $.203 * * *$ & $.245 * * *$ \\
\hline$\Delta R^{2}$ & -- & $.178 * * *$ & .000 & -- & $.185 * * *$ & $.042 * * *$ \\
\hline
\end{tabular}

Note $\mathrm{N}=271 * p<.05 * * p<.01 * * * p<.001$

Table 24. Supervisor Social Support as a Moderator between Abusive Supervision and Job Satisfaction, Turnover Intentions and Affective Commitment

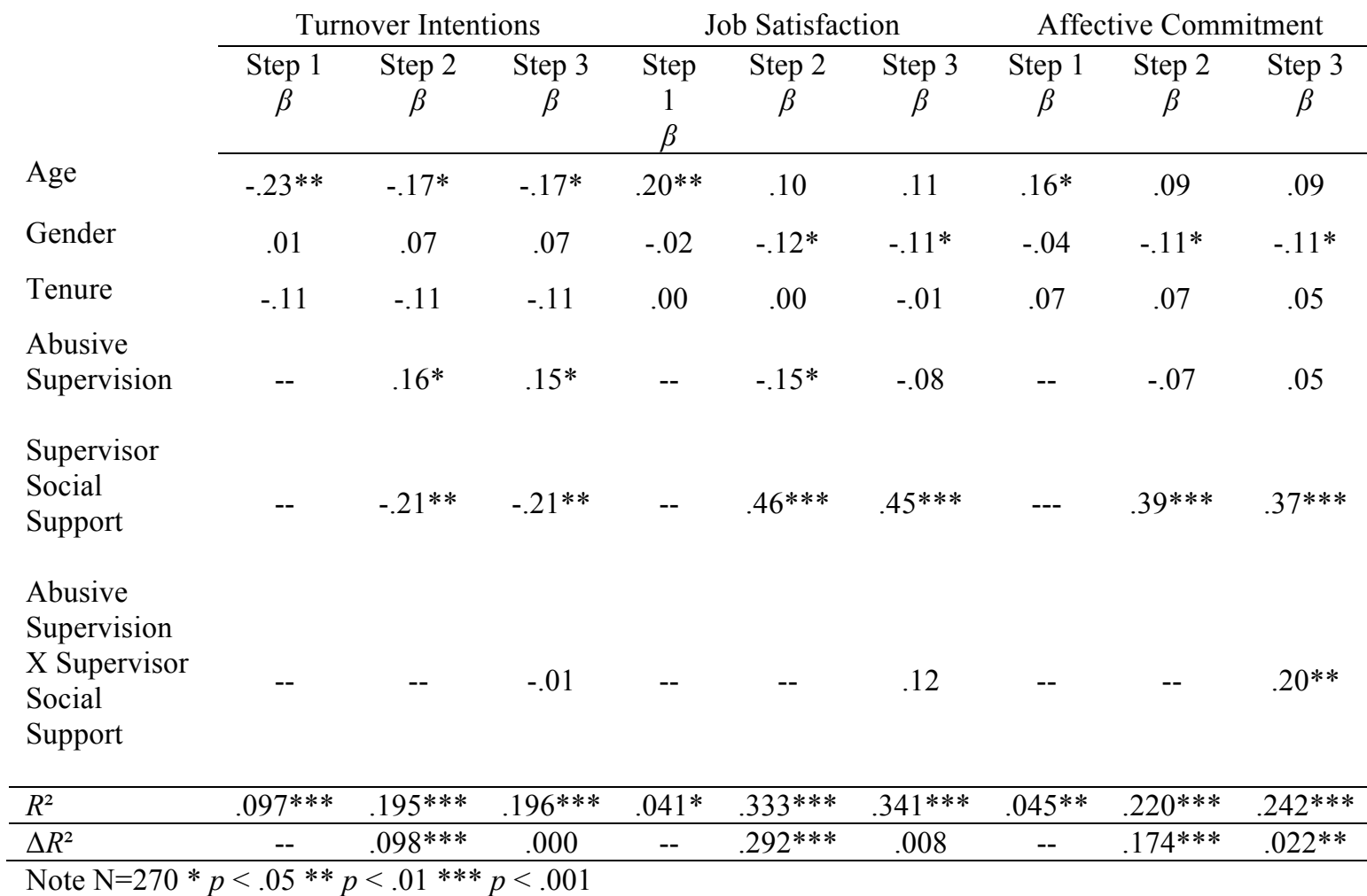


Table 25. Supervisor Social Support as a Moderator between Abusive Supervision and Perceived Stress, Physical Symptoms and Well-Being

\begin{tabular}{|c|c|c|c|c|c|c|c|c|c|}
\hline & \multicolumn{3}{|c|}{ Perceived Stress } & \multicolumn{3}{|c|}{ Physical Symptoms } & \multicolumn{3}{|c|}{ Well-Being } \\
\hline & $\begin{array}{c}\text { Step } 1 \\
\beta \\
\end{array}$ & $\begin{array}{c}\text { Step } 2 \\
\beta \\
\end{array}$ & $\begin{array}{c}\text { Step } 3 \\
\beta \\
\end{array}$ & $\begin{array}{c}\text { Step } 1 \\
\beta \\
\end{array}$ & $\begin{array}{c}\text { Step } 2 \\
\beta \\
\end{array}$ & $\begin{array}{c}\text { Step } 3 \\
\beta \\
\end{array}$ & $\begin{array}{c}\text { Step } 1 \\
\beta\end{array}$ & $\begin{array}{c}\text { Step } 2 \\
\beta \\
\end{array}$ & $\begin{array}{c}\text { Step } 3 \\
\beta \\
\end{array}$ \\
\hline Age & $-.28 * * *$ & $-.22 * *$ & $-.21 * *$ & -.13 & -.06 & -.06 & $.23^{* *}$ & $.14^{*}$ & $.14^{*}$ \\
\hline Gender & -.09 & -.03 & -.02 & $.14^{*}$ & $.23 * * *$ & $.23 * * *$ & $.20^{* *}$ & $.12 *$ & $.11^{*}$ \\
\hline Tenure & .11 & .11 & .09 & -.03 & -.04 & -.04 & -.10 & -.09 & -.08 \\
\hline $\begin{array}{l}\text { Abusive } \\
\text { Supervision }\end{array}$ & -- & $.14^{*}$ & $.25^{* *}$ & -- & $.35 * * *$ & $.35 * * *$ & -- & $-.28 * * *$ & $-.32 * * *$ \\
\hline $\begin{array}{l}\text { Supervisor } \\
\text { Social } \\
\text { Support }\end{array}$ & -- & $-.22 * *$ & $-.24 * * *$ & -- & -.11 & -.11 & -- & $.25 * * *$ & $.26 * * *$ \\
\hline $\begin{array}{l}\text { Abusive } \\
\text { Supervision } \\
\text { X } \\
\text { Supervisor } \\
\text { Social } \\
\text { Support }\end{array}$ & -- & -- & $.18^{*}$ & -- & -- & .00 & -- & -- & -.08 \\
\hline$R^{2}$ & $.060 * *$ & $.158^{* * *}$ & $.176^{* * *}$ & $.046^{* *}$ & $.212 * * *$ & $.212 * * *$ & $.065^{* * *}$ & $.272 * * *$ & $.275 * * *$ \\
\hline$\Delta R^{2}$ & -- & $.098^{* * *}$ & $.018^{*}$ & -- & $.166^{* * *}$ & .000 & -- & $.196^{* * *}$ & .003 \\
\hline
\end{tabular}

Table 26. Supervisor Social Support as a Moderator between Abusive Supervision and Depression and Irritation

Age

Gender

Tenure

Abusive Supervision

Supervisor Social Support

Abusive Supervision X Supervisor Social Support

\begin{tabular}{cccccc} 
& Depression & \multicolumn{3}{c}{ Irritation } \\
\hline Step 1 & Step 2 & Step 3 & Step 1 & Step 2 & Step 3 \\
$\beta$ & $\beta$ & $B$ & $\beta$ & $\beta$ & $\beta$ \\
\hline$-.17^{*}$ & -.09 & -.09 & -.14 & -.05 & -.05
\end{tabular}

\begin{tabular}{lcccccc}
\hline$R^{2}$ & .024 & $.201^{* * *}$ & $.202^{* * *}$ & .018 & $.268^{* * *}$ & $.288^{* * *}$ \\
\hline$\Delta R^{2}$ & -- & $.177^{* * *}$ & .001 & -- & $.250^{* * *}$ & $.020^{* *}$ \\
\hline
\end{tabular}

Note $\mathrm{N}=270 * p<.05 * * p<.01 * * * p<.001$ 
The moderation effects are illustrated in Figures 13 through 18. Contrary to hypothesis $8 \mathrm{c}$, there was not a significant relationship between conflict with supervisors and job satisfaction $\left(b=.01, \mathrm{SE}_{b}=.09, n s\right)$, or irritation $\left(b=-.03, \mathrm{SE}_{b=.05, n s) \text { for }}\right.$ participants indicating high supervisor support (+1 SD), depicted in Figures 13 and 16. This suggests a buffering effect rather than the hypothesized exacerbation effect. Additionally, when supervisor social support was high the relationship between conflict with supervisors and affective commitment was strengthened $\left(b=.37, \mathrm{SE}_{b}=.09, p<\right.$ $.001)$, depicted in Figure 14. Support was found for hypothesis 8c, where the relationship between conflict with supervisors and perceived stress was stronger in participants reporting high supervisor social support $\left(b=.27, \mathrm{SE}_{b}=.06, p<.001\right)$ than low social support $\left(b=.09, \mathrm{SE}_{b}=.06, n s\right)$, depicted in Figure 15.

Additionally, contrary to hypothesis $8 \mathrm{c}$ the relationship between abusive supervision and affective commitment was strengthened when supervisor social support was high $\left(b=.29, \mathrm{SE}_{b=} .06, p<.001\right)$, whereas, there was not a significant relationship when supervisor social support was low $\left(b=.09, \mathrm{SE}_{b}=.06, n s\right)$, depicted in Figure 17. Similarly, as depicted in Figure 18, the relationship between abusive supervision and irritation was not significant when support was high $\left(b=.09, \mathrm{SE}_{b}=.06, n s\right)$, yet when supervisor support was low the relationship between abusive supervision and irritation ( $b$ $\left.=.30, \mathrm{SE}_{b}=.06, p<.001\right)$ was strengthened, suggesting a buffering effect rather than the proposed exacerbation effect. In support of hypothesis $8 \mathrm{c}$, when supervisor support was high the perceived stress $\left(b=.29, \mathrm{SE}_{b}=.06, p<.001\right)$ of an individual was higher than supervisor support was low $\left(b=.09, \mathrm{SE}_{b}=.06, n s\right)$, supporting the exacerbation 
hypothesis. Taken as a whole, hypothesis $8 \mathrm{c}$ which predicted that supervisor support would exacerbate the relationships between supervisor aggression and outcomes was not supported except in the case of perceived stress.

Figure 13. Supervisor Social Support as a Moderator between Conflict with Supervisors and Job Satisfaction

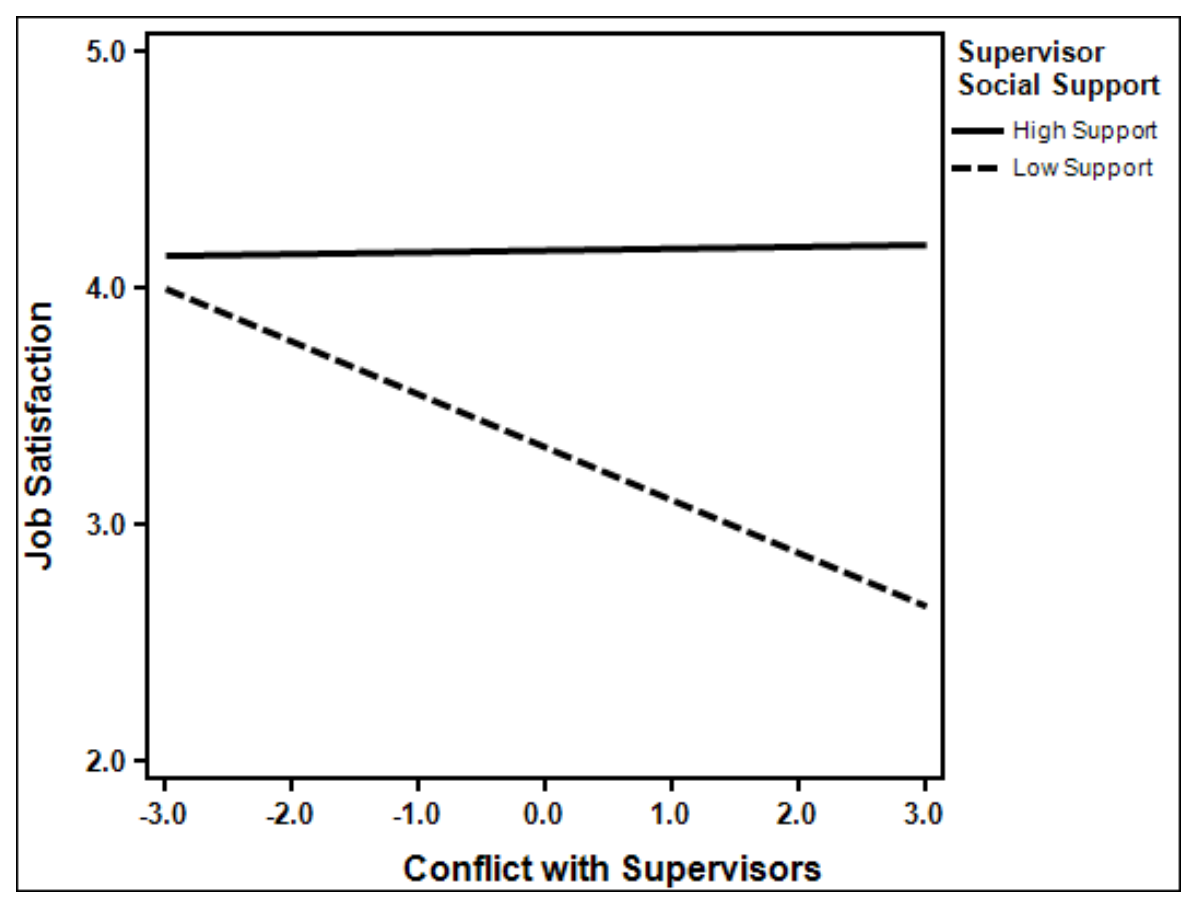


Figure 14. Supervisor Social Support as a Moderator between Conflict with Supervisors and Affective Commitment

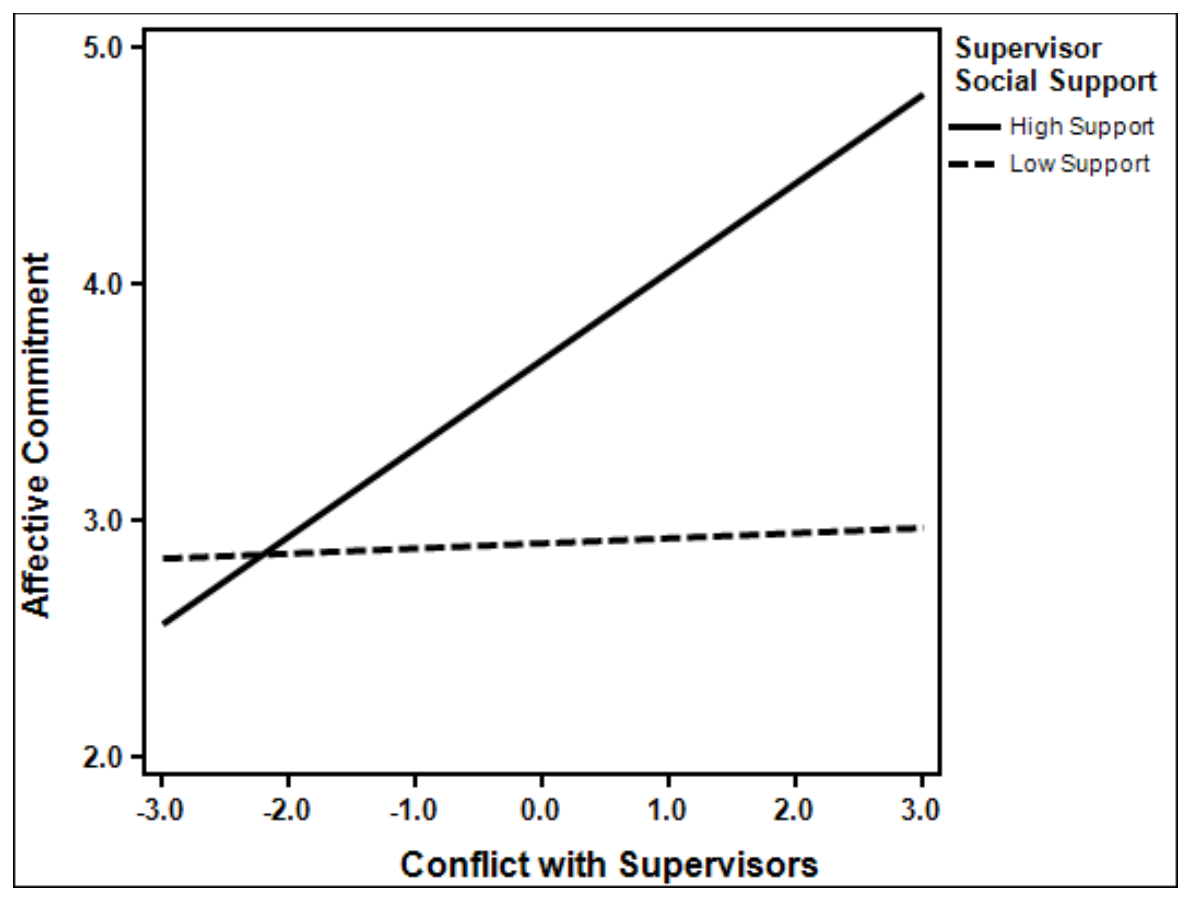

Figure 15. Supervisor Social Support as a Moderator between Conflict with Supervisors and Perceived Stress

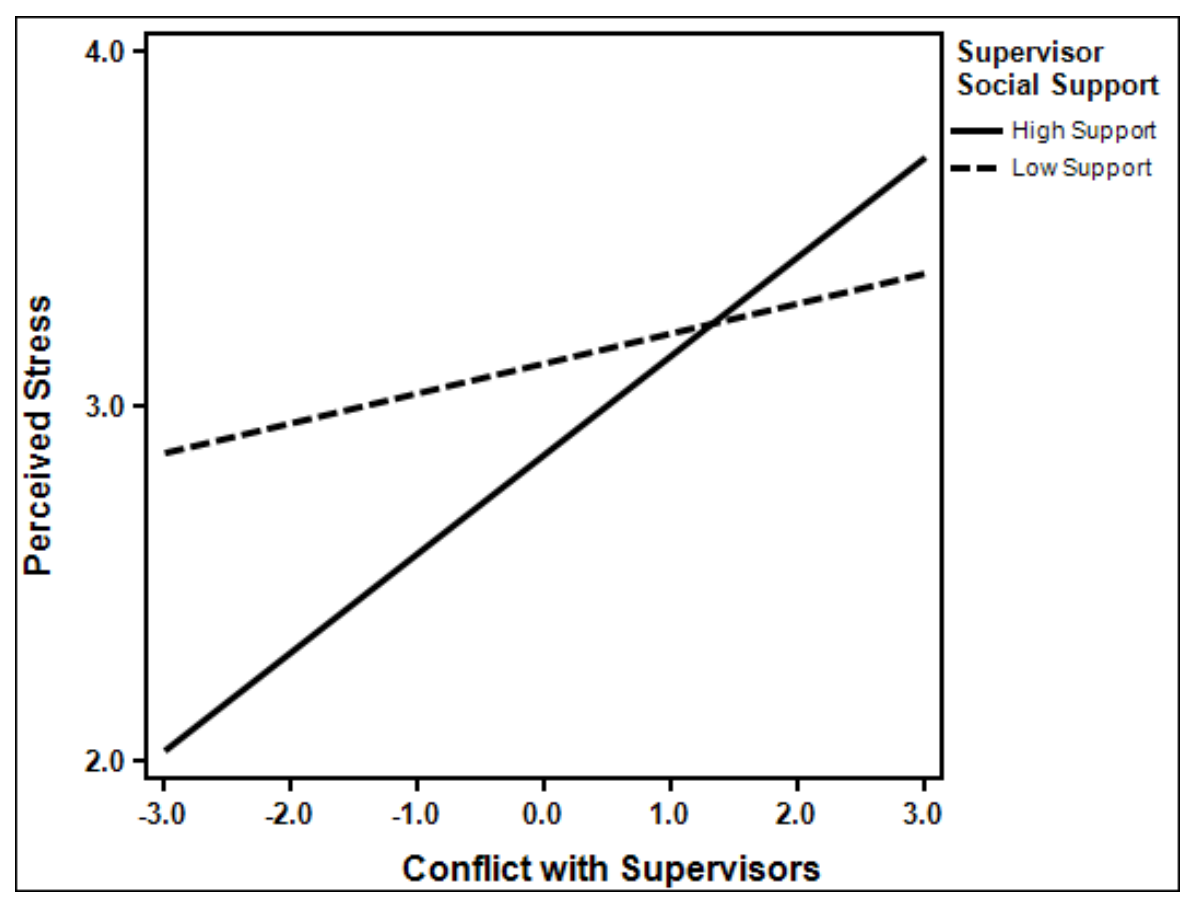


Figure 16. Supervisor Social Support as a Moderator between Conflict with Supervisors and Irritation

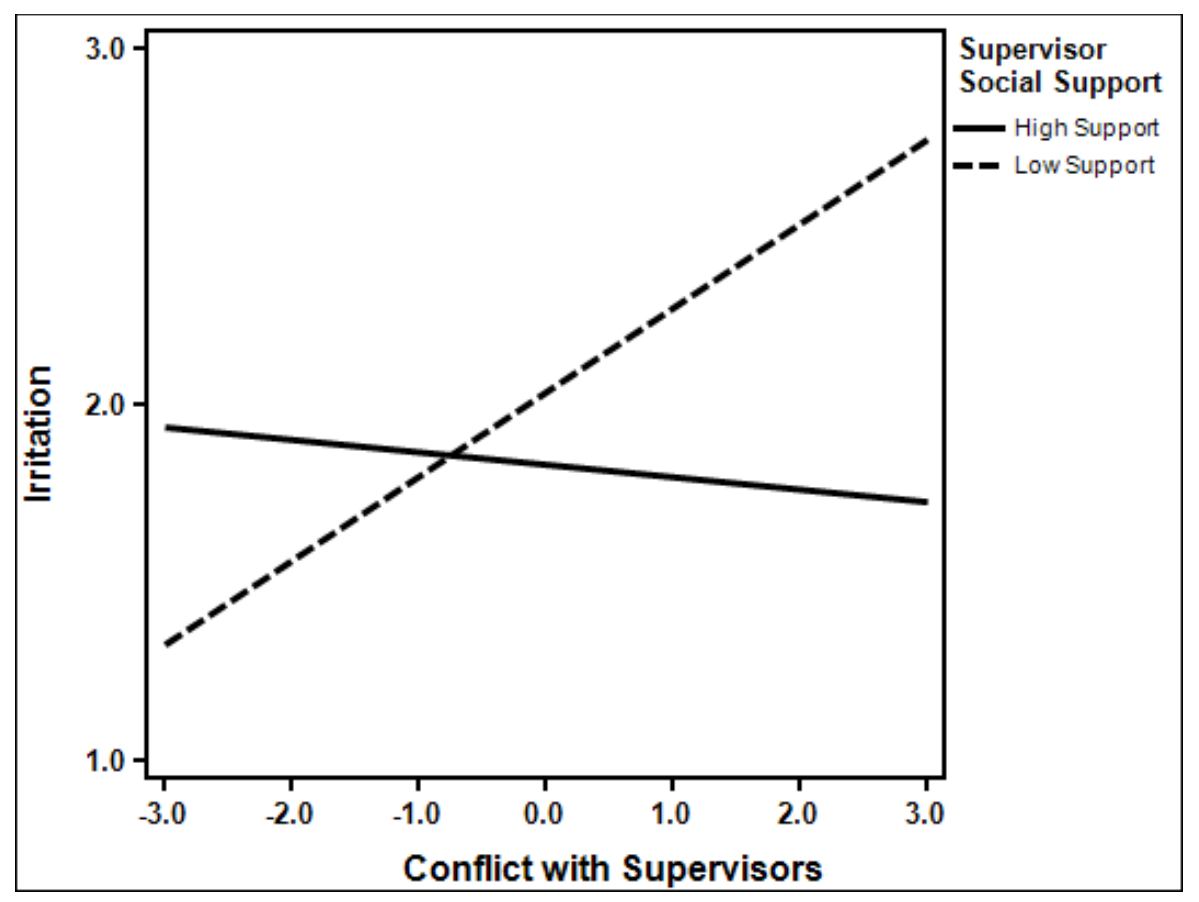

Figure 17. Supervisor Social Support as a Moderator between Abusive Supervision and Affective Commitment

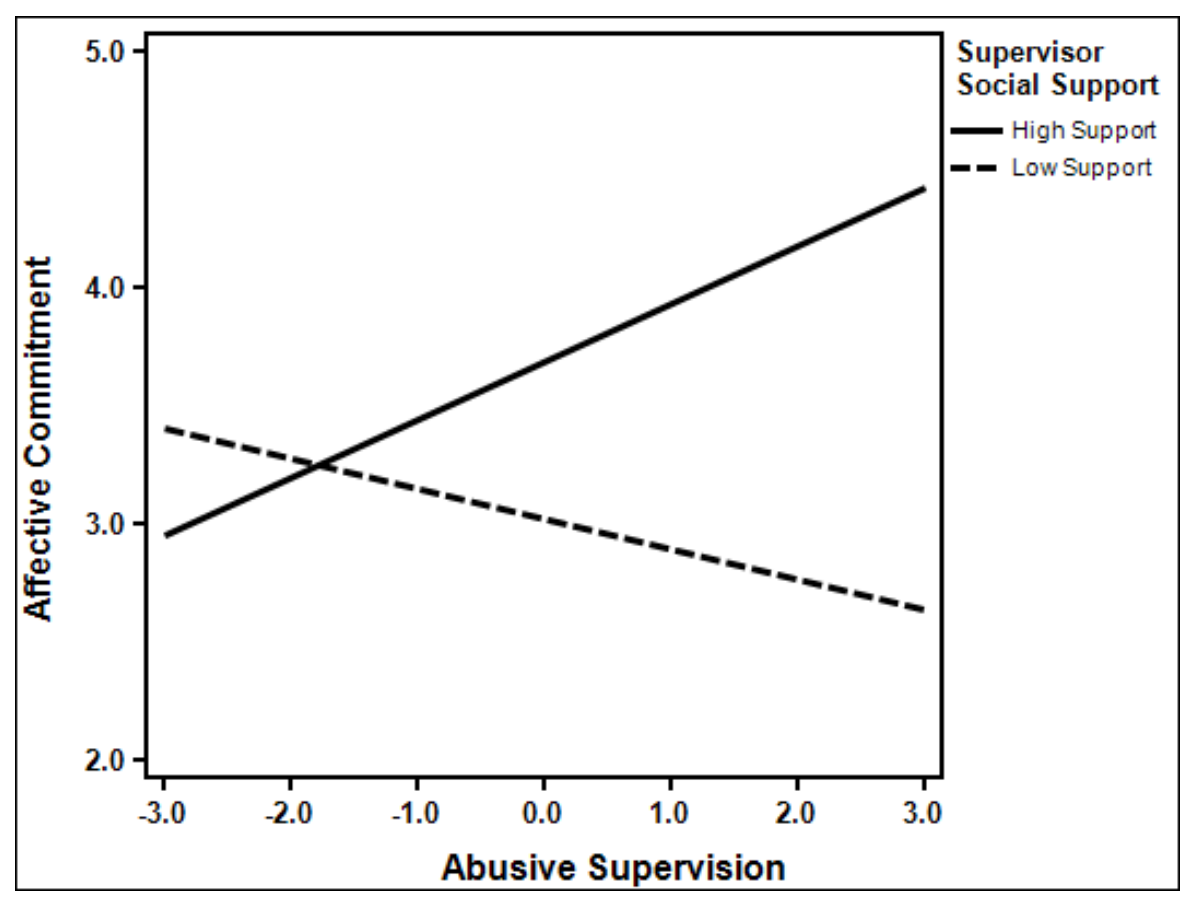


Figure 18. Supervisor Social Support as a Moderator between Abusive Supervision and Perceived Stress



Figure 19. Supervisor Social Support as a Moderator between Abusive Supervision and Irritation

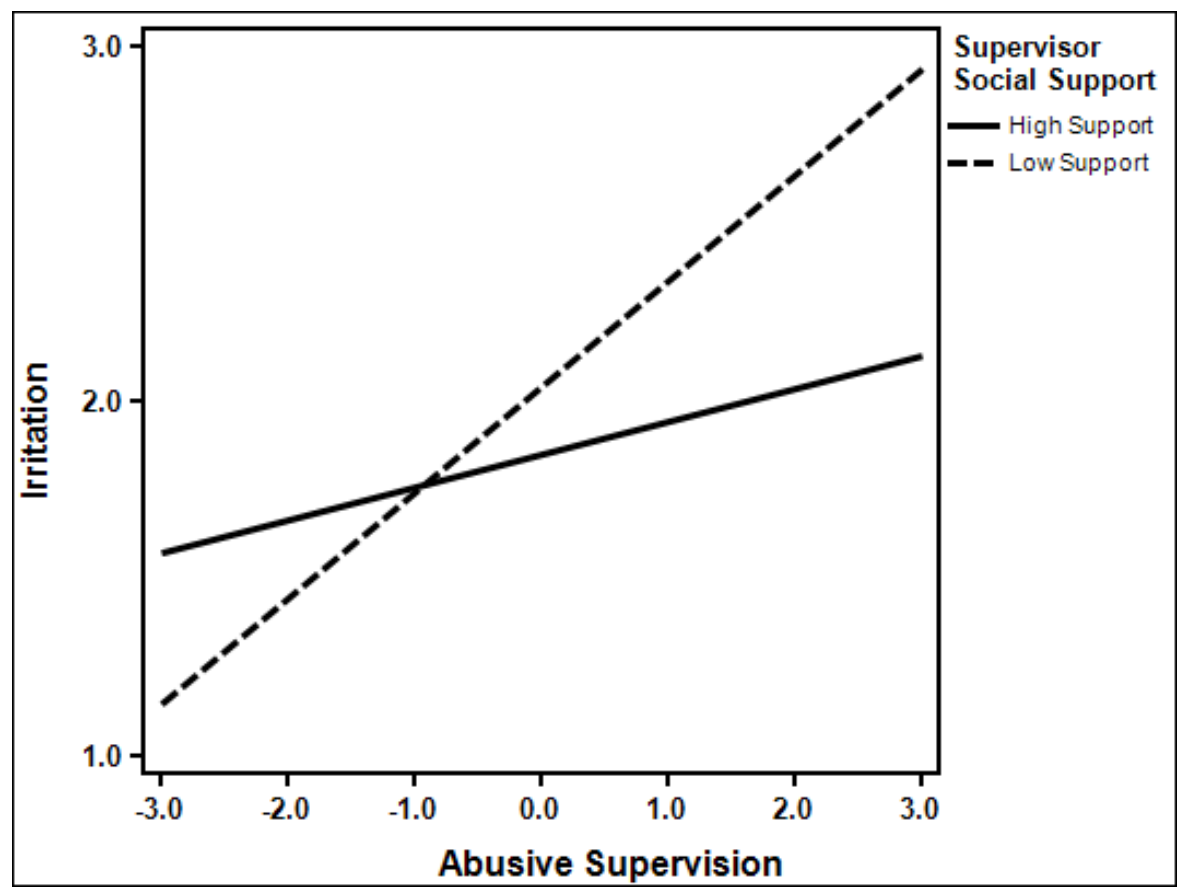


Hypothesis $8 \mathrm{~d}$ posited that co-worker social support would exacerbate the relationship between conflict with co-workers and outcomes (see Tables 27 through 29). The interaction term for co-worker conflict and co-worker social support significantly added to the variance explained in affective commitment $\left(\Delta R^{2}=.012, F(1,267)=3.96, p\right.$ $<.05)$, perceived stress $\left(\Delta R^{2}=.018, F(1,267)=6.40, p<.05\right)$, physical symptoms $\left(\Delta R^{2}=\right.$ $.020, F(1,269)=6.73, p<.05)$, depression $\left(\Delta R^{2}=.024, F(1,268)=9.38, p<.01\right)$, and irritation $\left(\Delta R^{2}=.078, F(1,268)=27.37, p<.001\right)$. The interaction term did not result in a significant prediction of additional variance of turnover intentions $\left(\Delta R^{2}=.003, F(1,267)\right.$ $=1.07, n s)$, job satisfaction $\left(\Delta R^{2}=.008, F(1,269)=.70, n s\right)$, or well-being $\left(\Delta R^{2}=.005, F\right.$ $(1,268)=1.82, n s)$ 
Table 27. Co-Worker Social Support as a Moderator between Conflict with Co-Workers and Job Satisfaction, Turnover Intentions and Affective Commitment

\begin{tabular}{|c|c|c|c|c|c|c|c|c|c|}
\hline & \multicolumn{3}{|c|}{ Turnover Intentions } & \multicolumn{3}{|c|}{ Job Satisfaction } & \multicolumn{3}{|c|}{ Affective Commitment } \\
\hline & $\begin{array}{c}\text { Step } 1 \\
\beta\end{array}$ & $\begin{array}{c}\text { Step } 2 \\
\beta\end{array}$ & $\begin{array}{c}\text { Step } 3 \\
\beta\end{array}$ & $\begin{array}{c}\text { Step } 1 \\
\beta\end{array}$ & $\begin{array}{c}\text { Step } 2 \\
\beta\end{array}$ & $\begin{array}{c}\text { Step } 3 \\
\beta\end{array}$ & $\begin{array}{c}\text { Step } 1 \\
\beta\end{array}$ & $\begin{array}{c}\text { Step } 2 \\
\beta\end{array}$ & $\begin{array}{c}\text { Step } 3 \\
\beta\end{array}$ \\
\hline Age & $-.23 * *$ & $-.19 * *$ & $-.19 *$ & $.20^{* *}$ & .13 & $.13 *$ & $.16^{*}$ & .13 & $.14^{*}$ \\
\hline Gender & .01 & .07 & .07 & -.02 & $-.14^{*}$ & $-.13^{*}$ & -.04 & $-.12 *$ & $-.11 *$ \\
\hline Tenure & -.11 & -.13 & -.13 & .00 & .02 & .02 & .07 & .08 & .07 \\
\hline $\begin{array}{l}\text { Conflict With } \\
\text { Co-Workers }\end{array}$ & -- & .04 & .06 & -- & -.05 & -.04 & -- & $.16^{* *}$ & $.19^{* *}$ \\
\hline $\begin{array}{l}\text { Co-Worker } \\
\text { Social } \\
\text { Support }\end{array}$ & -- & $-.22 * *$ & $-.24 * * *$ & -- & $.46^{* * *}$ & $.45 * * *$ & -- & $.43 * * *$ & $.41 * * *$ \\
\hline $\begin{array}{l}\text { Conflict with } \\
\text { Co-Workers } \\
\text { X Co-Worker } \\
\text { Social } \\
\text { Support }\end{array}$ & -- & -- & .06 & -- & -- & .05 & -- & -- & $.12 *$ \\
\hline$R^{2}$ & $.097 * * *$ & $.149^{* * *}$ & $.153^{* * *}$ & $.040^{*}$ & $.254 * * *$ & $.256^{* * *}$ & $.045^{* *}$ & $.207 * * *$ & $219 * * *$ \\
\hline$\Delta R^{2}$ & -- & $.052 * * *$ & .003 & -- & $214 * * *$ & .002 & -- & $.162 * * *$ & $.012 *$ \\
\hline
\end{tabular}

Note $\mathrm{N}=270-272 * p<.05 * * p<.01 * * * p<.001$ 
Table 28. Co-Worker Social Support as a Moderator between Conflict with Co-Workers and Perceived Stress, Physical Symptoms and Well-Being

\begin{tabular}{|c|c|c|c|c|c|c|c|c|c|}
\hline & \multicolumn{3}{|c|}{ Perceived Stress } & \multicolumn{3}{|c|}{ Physical Symptoms } & \multicolumn{3}{|c|}{ Well-Being } \\
\hline & $\begin{array}{c}\text { Step } 1 \\
\beta\end{array}$ & $\begin{array}{c}\text { Step } 2 \\
\beta\end{array}$ & $\begin{array}{c}\text { Step } 3 \\
\beta\end{array}$ & $\begin{array}{c}\text { Step } 1 \\
\beta\end{array}$ & $\begin{array}{c}\text { Step } 2 \\
\beta\end{array}$ & $\begin{array}{c}\text { Step } 3 \\
\beta\end{array}$ & $\begin{array}{c}\text { Step } 1 \\
\beta \\
\end{array}$ & $\begin{array}{c}\text { Step } 2 \\
\beta \\
\end{array}$ & $\begin{array}{c}\text { Step } 3 \\
\beta \\
\end{array}$ \\
\hline Age & $-.28 * * *$ & $-.20 * *$ & $-.19 * *$ & -.13 & -.06 & -.07 & $.20 * *$ & .12 & .12 \\
\hline Gender & -.09 & .02 & .03 & $.15^{*}$ & $.24 * * *$ & $.24 * * *$ & $.19^{* *}$ & .06 & .07 \\
\hline Tenure & .11 & .08 & .07 & -.03 & -.05 & -.03 & -.08 & -.05 & -.06 \\
\hline $\begin{array}{l}\text { Conflict } \\
\text { With Co- } \\
\text { Workers }\end{array}$ & -- & $.16^{* *}$ & $.20^{* *}$ & -- & $.23 * * *$ & $.18 * *$ & -- & $-.17^{* *}$ & $-.15^{*}$ \\
\hline $\begin{array}{l}\text { Co-Worker } \\
\text { Social } \\
\text { Support }\end{array}$ & -- & $-.33 * * *$ & $-.36 * * *$ & -- & $-.25 * * *$ & $-.21 * *$ & -- & $.43 * * *$ & $.41 * * *$ \\
\hline $\begin{array}{l}\text { Conflict } \\
\text { with Co- } \\
\text { Workers X } \\
\text { Co-Worker } \\
\text { Social } \\
\text { Support }\end{array}$ & -- & -- & $.15^{*}$ & -- & -- & $-.16^{*}$ & -- & -- & .08 \\
\hline$R^{2}$ & $.060 * *$ & $.212^{* * *}$ & $.230^{* * *}$ & $.047 * *$ & $.182 * * *$ & $.202 * * *$ & $.064 * * *$ & $.300^{* * *}$ & $.304 * * *$ \\
\hline$\Delta R^{2}$ & -- & $.152^{* * *}$ & $.018^{*}$ & -- & $.136^{* * *}$ & $.020 *$ & -- & $.236^{* * *}$ & .005 \\
\hline
\end{tabular}

Table 29. Co-Worker Social Support as a Moderator between Conflict with Co-Workers and Depression and Irritation

Age

Gender

Tenure

Conflict With Co-Workers

Co-Worker Social Support

Conflict with Co-Workers X Co-

Worker Social Support

\begin{tabular}{cccccc} 
& Depression & \multicolumn{3}{c}{ Irritation } \\
\hline Step 1 & Step 2 & Step 3 & Step 1 & Step 2 & Step 3 \\
$\beta$ & $\beta$ & $B$ & $\beta$ & $\beta$ & $\beta$ \\
\hline$-.16^{*}$ & -.07 & -.09 & -.13 & -.06 & -.09
\end{tabular}

\begin{tabular}{lcccccc}
\hline$R^{2}$ & .021 & $.290^{* * *}$ & $.314^{* * *}$ & .016 & $.162^{* * *}$ & $.239^{* * *}$ \\
\hline$\Delta R^{2}$ & -- & $.269^{* * *}$ & $.024^{* *}$ & -- & $.145^{* * *}$ & $.078^{* * *}$ \\
\hline
\end{tabular}

Note $\mathrm{N}=271 * p<.05 * * p<.01 * * * p<.001$ 
The moderation effects are illustrated in Figure 19 through 23. Contrary to hypothesis $8 \mathrm{~d}$, when co-worker social support was high there was greater affective commitment $\left(b=.37, \mathrm{SE}_{b}=.08, p<.001\right)$ as conflict with co-workers increased, as depicted in Figure 20. When co-worker social support was low, the relationship between conflict with co-workers and affective commitment was not significant $\left(b=.11, \mathrm{SE}_{b}=\right.$ $.08, n s)$. Additionally, when co-worker social support was high there was not a significant relationship between conflict with co-workers and physical symptoms $\left(b=.04, \mathrm{SE}_{b}=.05\right.$, $n s)$ and depression $\left(b=-.04, \mathrm{SE}_{b}=.04, n s\right)$, whereas when co-worker social support was low there were greater reported physical symptoms $\left(b=.25, \mathrm{SE}_{b=} .05, p<.001\right)$ and more depression $\left(b=.16, \mathrm{SE}_{b}=.04, p<.001\right)$ as conflict with co-workers increased, as illustrated in Figures 22 and 23. When co-worker social support was high, irritation decreased $\left(b=-.17, \mathrm{SE}_{b=} .05, p<.001\right)$ as conflict with co-workers increased, whereas, when co-worker social support was low, irritation increased $\left(b=.22, \mathrm{SE}_{b}=.04, p<.001\right)$, as depicted in Figure 24. Finally, in support of hypothesis 8d, as conflict with co-workers increased there was greater perceived stress with high co-worker support $\left(b=.25, \mathrm{SE}_{b}=\right.$ $.05, p<.001$ ) and the relationship was not significant with low co-worker support ( $b=$ $\left..05, \mathrm{SE}_{b=} .05, n s\right)$, as depicted in Figure 21. Thus, hypothesis 8d, which predicted that coworker social support would exacerbate the relationship between conflict with coworkers and outcomes, was not supported except in the case of perceived stress. 
Figure 20. Co-Worker Social Support as a Moderator between Conflict with Co-Workers and Affective Commitment

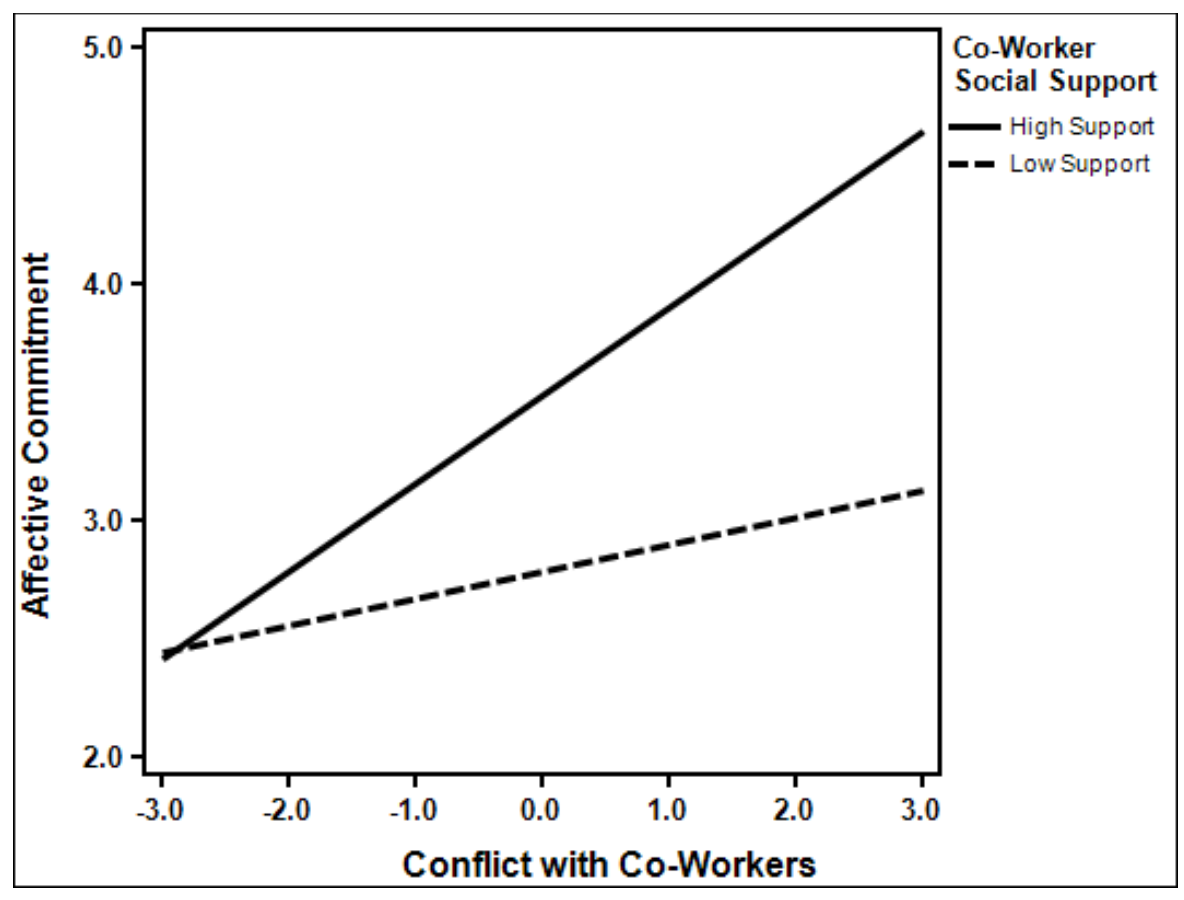

Figure 21. Co-Worker Social Support as a Moderator Conflict with Co-Workers and Perceived Stress

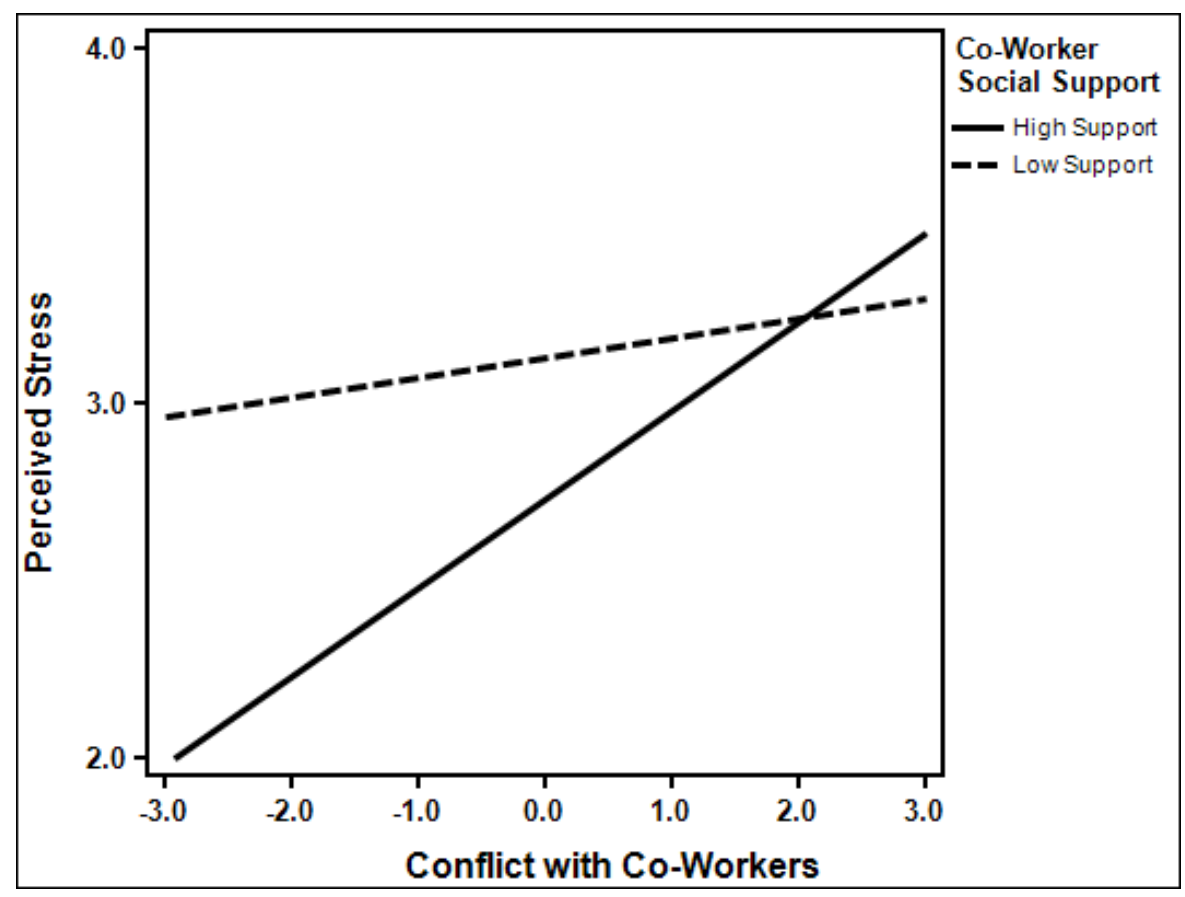


Figure 22. Co-Worker Social Support as a Moderator between Conflict with Co-Workers and Physical Symptoms

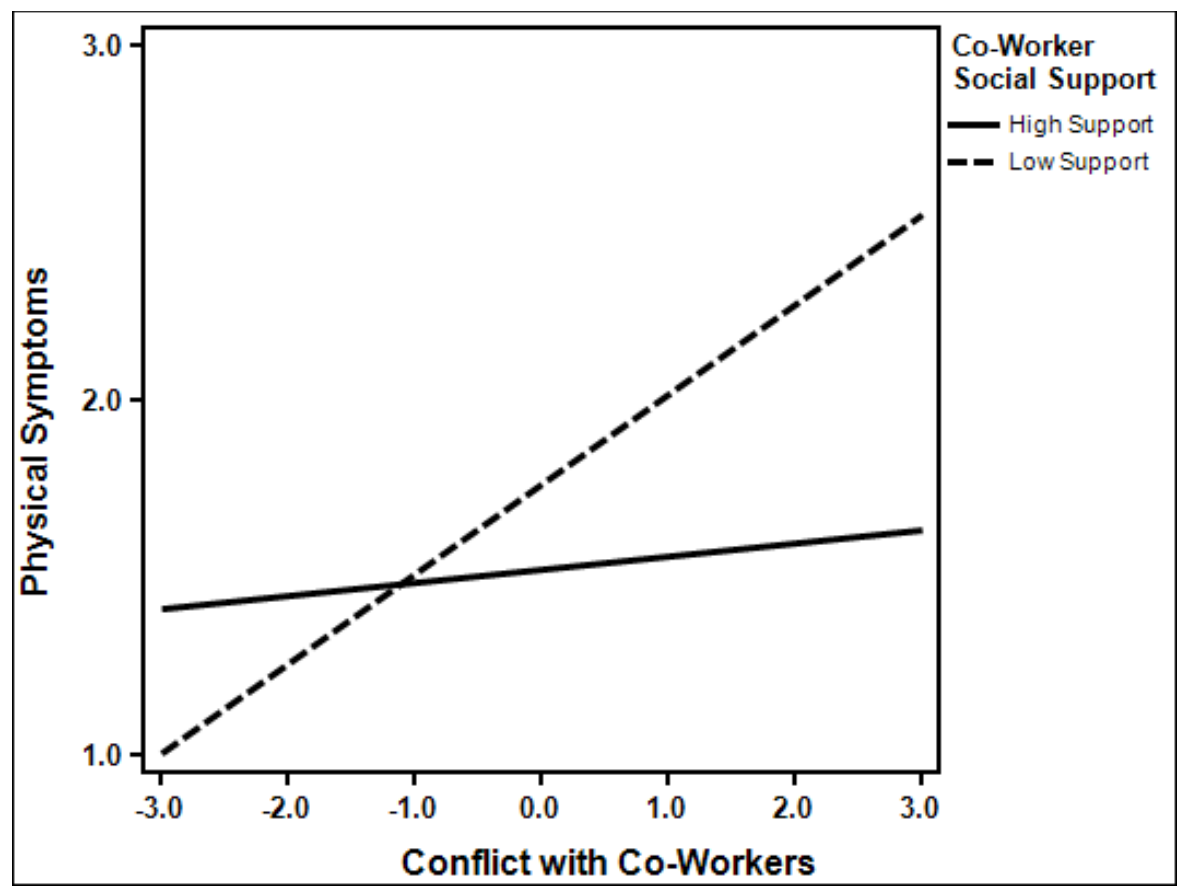

Figure 23. Co-Worker Social Support as a Moderator between Conflict with Co-Workers and Depression

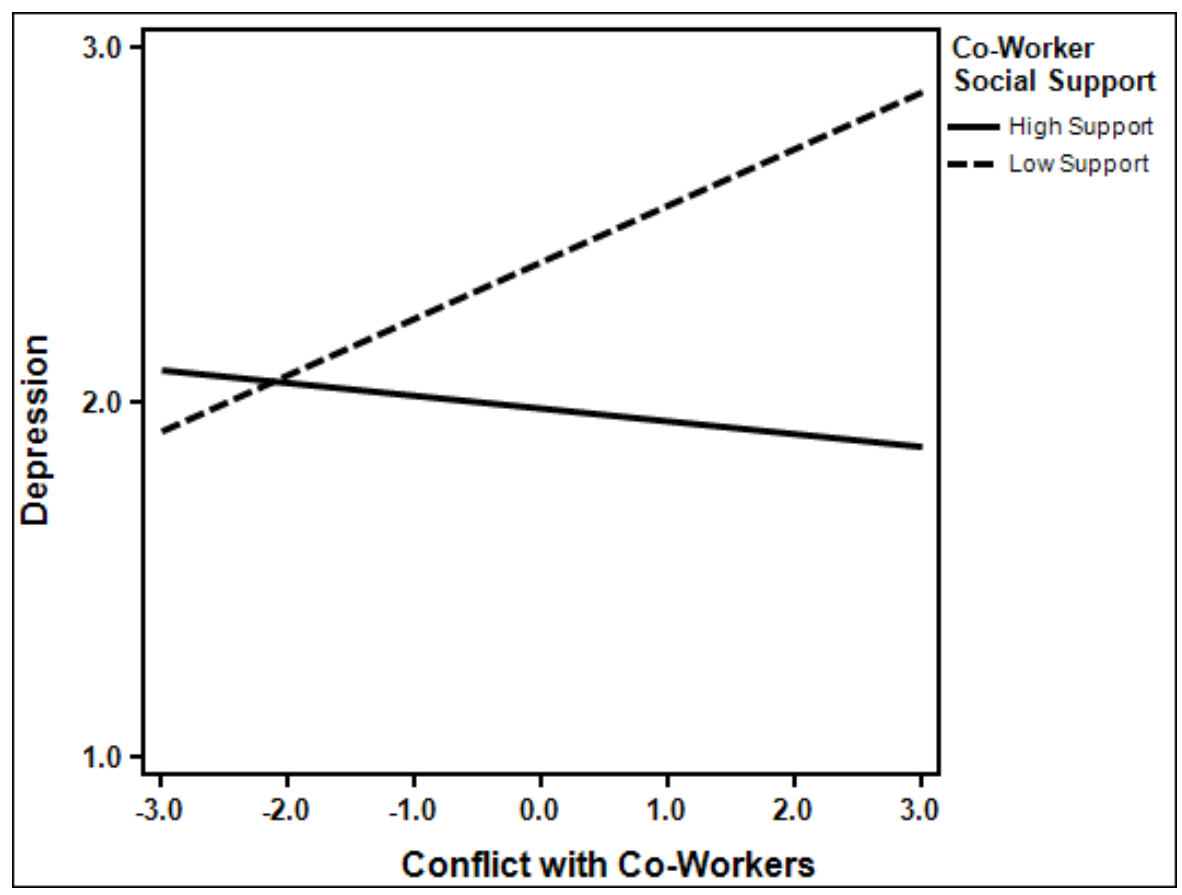


Figure 24. Co-Worker Social Support as a Moderator between Conflict with Co-Workers and Irritation

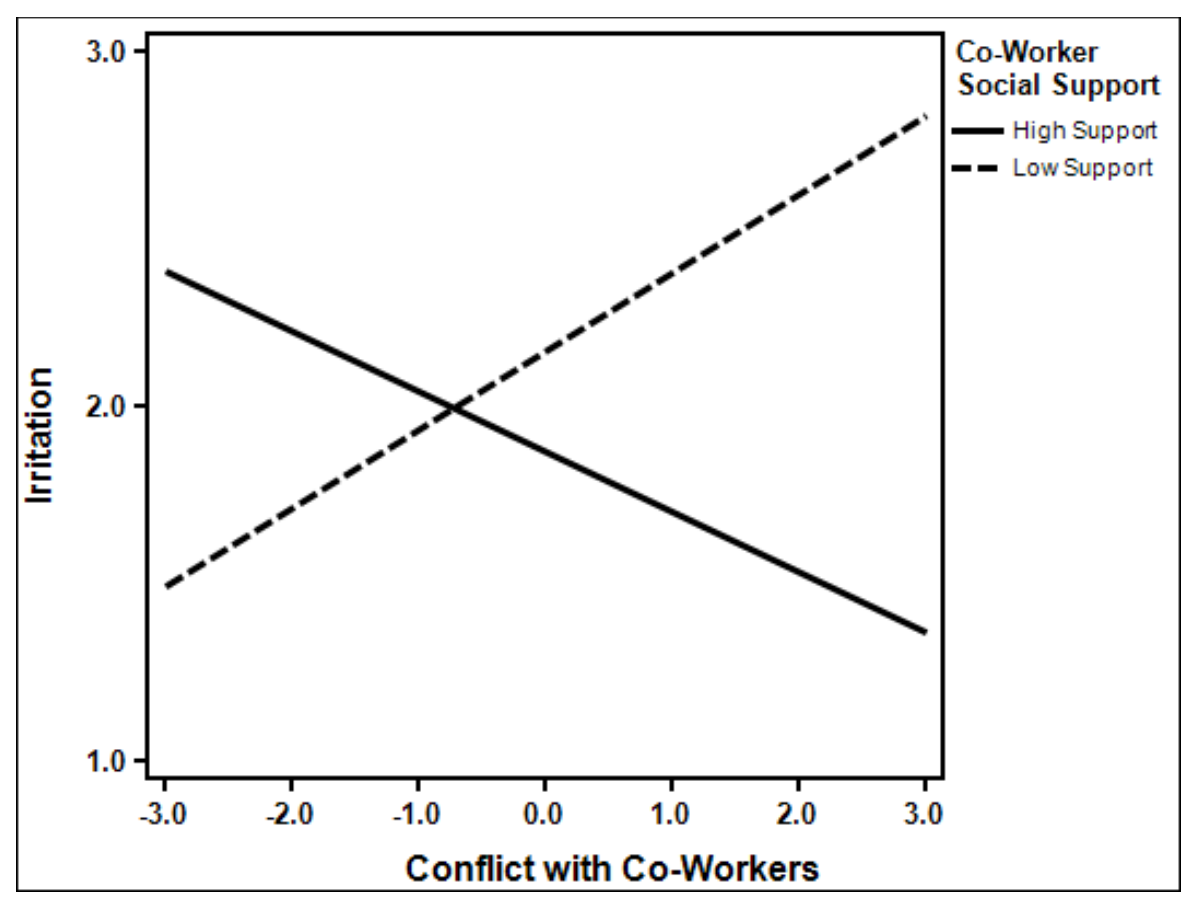

\section{Intensity as a Moderator}

Hypothesis 9 posited that the intensity of workplace aggression would moderate the relationships between workplace aggression and outcomes. All information can be found in Tables 30 through 38. Results are as follows.

The interaction term between conflict with supervisors and intensity explained incremental variance in turnover intentions $\left(\Delta R^{2}=.028, F(1,155)=5.78, p<.05\right)$, job satisfaction $\left(\Delta R^{2}=.055, F(1,155)=12.19, \mathrm{p}>.01\right)$, affective commitment $\left(\Delta R^{2}=.053, F\right.$ $(1,155)=10.98, \mathrm{p}>.01)$, well-being $\left(\Delta R^{2}=.026, F(1,157)=5.47, p<.05\right)$, depression $\left(\Delta R^{2}=.033, F(1,156)=6.49, p<.05\right)$, and irritation $\left(\Delta R^{2}=.031, F(1,156)=6.72, p<\right.$ $.05)$, as found in Tables 30 through 32 . The interaction term was did not result in an 
increase in variance explained in perceived stress $\left(\Delta R^{2}=.006, F(1,155)=1.13, n s\right)$, or physical symptoms $\left(\Delta R^{2}=.003, F(1,155)=.62, n s\right)$.

Table 30. Conflict with Supervisors Intensity as a Moderator between Conflict with Supervisors and Turnover Intentions, Job Satisfaction and Affective Commitment

Age Gender

Tenure

Conflict With

Supervisor

Conflict with Supervisor Intensity

Conflict with Supervisor $\mathrm{X}$ Intensity

Turnover Intentions
Job Satisfaction

Affective Commitment

\begin{tabular}{|c|c|c|c|c|c|c|c|c|}
\hline $\begin{array}{c}\text { Step } 1 \\
\beta\end{array}$ & $\begin{array}{c}\text { Step } 2 \\
\beta\end{array}$ & $\begin{array}{c}\text { Step } \\
\beta\end{array}$ & $\begin{array}{c}\text { Step } \\
1 \\
\beta\end{array}$ & $\begin{array}{c}\text { Step } 2 \\
\beta\end{array}$ & $\begin{array}{c}\text { Step } 3 \\
\beta\end{array}$ & $\begin{array}{c}\text { Step } \\
\beta\end{array}$ & $\begin{array}{c}\text { Step } 2 \\
\beta\end{array}$ & $\begin{array}{c}\text { Step } \\
\beta\end{array}$ \\
\hline-.17 & -.08 & -.08 & $.21 *$ & .07 & .07 & .13 & .04 & .05 \\
\hline .01 & .06 & .07 & -.01 & -.12 & -.13 & -.07 & -.11 & -.12 \\
\hline$-.19 *$ & $-.21 *$ & $-.22 *$ & .02 & .07 & .07 & .16 & $.18^{*}$ & $.19 *$ \\
\hline-- & $.26 * *$ & $.21 *$ & -- & $-.41 * * *$ & $-.33 * * *$ & -- & $-.24 * *$ & -.16 \\
\hline
\end{tabular}

\begin{tabular}{|c|c|c|c|c|c|c|c|c|c|}
\hline$R^{2}$ & $.097 * *$ & $.210 * * *$ & $.238 * * *$ & $.050 *$ & $.243 * * *$ & $.298 * * *$ & $.072 * *$ & $.196^{* * *}$ & $.249 * * *$ \\
\hline$\Delta R^{2}$ & -- & $.113 * * *$ & $.028 *$ & -- & $.193 * * *$ & $.055 * *$ & -- & $.124 * * *$ & $.053 * *$ \\
\hline
\end{tabular}


Table 31. Intensity as a Moderator between Conflict with Supervisors and Perceived Stress, Physical Symptoms and Well-Being

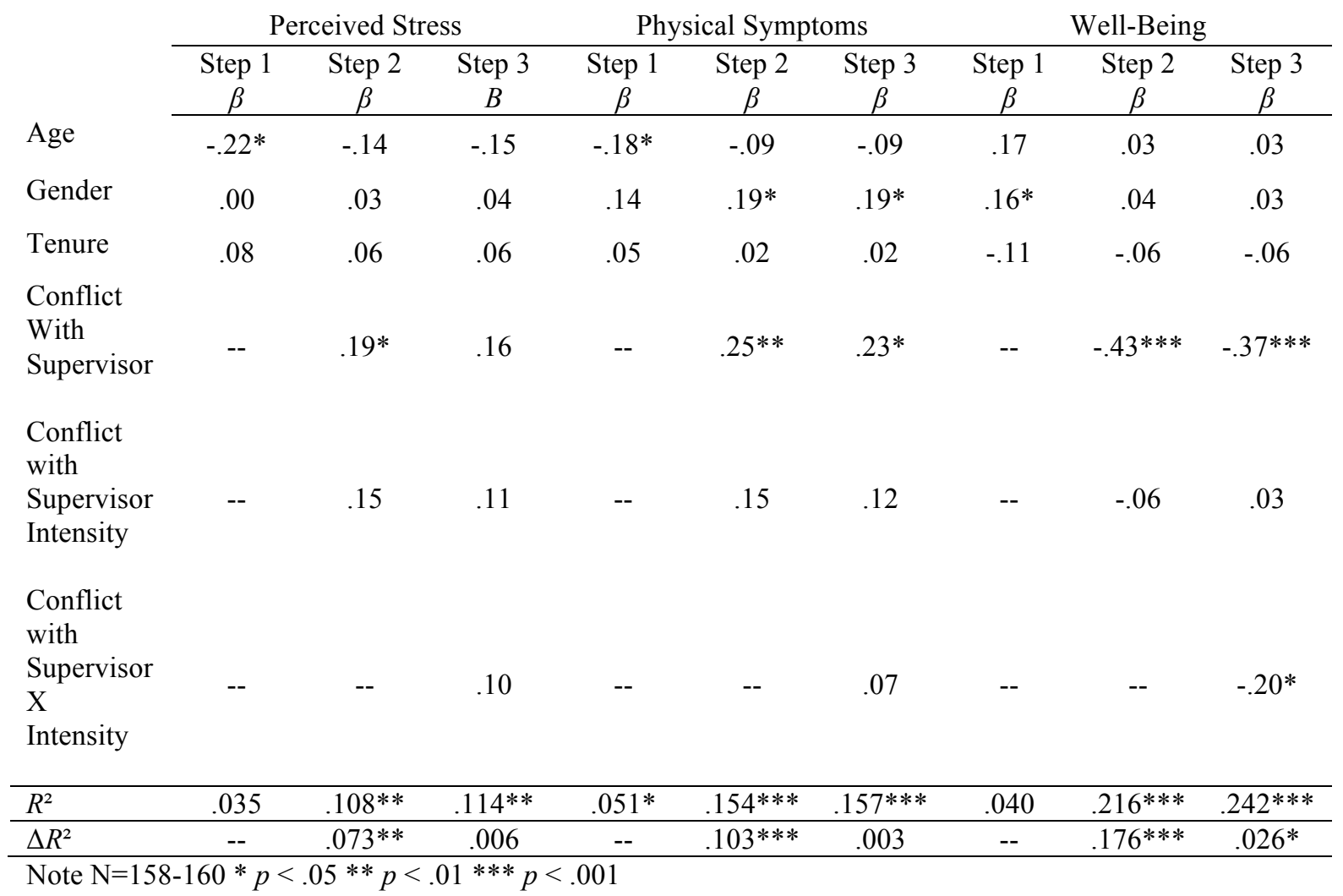

Table 32. Intensity as a Moderator between Conflict with Supervisors and Depression and Irritation

Age

Gender

Tenure

Conflict With Supervisor

Conflict with Supervisor Intensity

Conflict with Supervisor X Conflict with Supervisor Intensity

\begin{tabular}{cccccc} 
& Depression & \multicolumn{3}{c}{ Irritation } \\
\hline Step 1 & Step 2 & Step 3 & Step 1 & Step 2 & Step 3 \\
$\beta$ & $\beta$ & $B$ & $\beta$ & $\beta$ & $\beta$ \\
\hline$-.19^{*}$ & -.06 & -.06 & -.17 & -.05 & -.05
\end{tabular}

\begin{tabular}{|c|c|c|c|c|c|c|}
\hline$R^{2}$ & .029 & $.176^{* * *}$ & $208^{* * *}$ & .029 & $255^{* * *}$ & $285^{* * *}$ \\
\hline$\Delta R^{2}$ & -- & $.147 * * *$ & $.033 *$ & -- & $.225 * * *$ & $.031 *$ \\
\hline
\end{tabular}


The moderation effects are illustrated in Figure 24 through 29. In support of hypothesis 9 , greater intensity $(+1 \mathrm{SD})$ resulted in a stronger relationship between conflict with supervisors and turnover intentions $\left(b=.45, \mathrm{SE}_{b}=.11, p<.001\right)$, job satisfaction $\left(b=-.79, \mathrm{SE}_{b}=.12, p<.001\right)$, affective commitment $\left(b=-.52, \mathrm{SE}_{b=} .11, p<\right.$ $.001)$, well-being $\left(b=-.31, \mathrm{SE}_{b}=.05, p<.001\right)$, depression $\left(b=.38, \mathrm{SE}_{b=} .06, p<.001\right)$ and irritation $\left(b=.35, \mathrm{SE}_{b}=.07, p<.001\right)$, as depicted in figures 25 through 30 . In instances of low intensity (-1 SD) there was not a significant relationship found between conflict with supervisors and turnover intentions $\left(b=.04, \mathrm{SE}_{b}=.10, n s\right)$, job satisfaction $\left(b=-.13, \mathrm{SE}_{b=.11}, n s\right)$, affective commitment $\left(b=.09, \mathrm{SE}_{b=.11}, n s\right)$ and irritation $(b=$ $\left..06, \mathrm{SE}_{b}=.07, n s\right)$. In instances of low intensity, conflict with supervisors and the relationships with well-being $\left(b=-.11, \mathrm{SE}_{b}=.05, p<.05\right)$ and depression $\left(b=.11, \mathrm{SE}_{b=}\right.$ $.06, p<.05)$ were weaker than in high intensity but still statistically significant, as depicted in figures 28 and 29. 
Figure 25. Intensity as a Moderator Conflict with Supervisors and Turnover Intentions

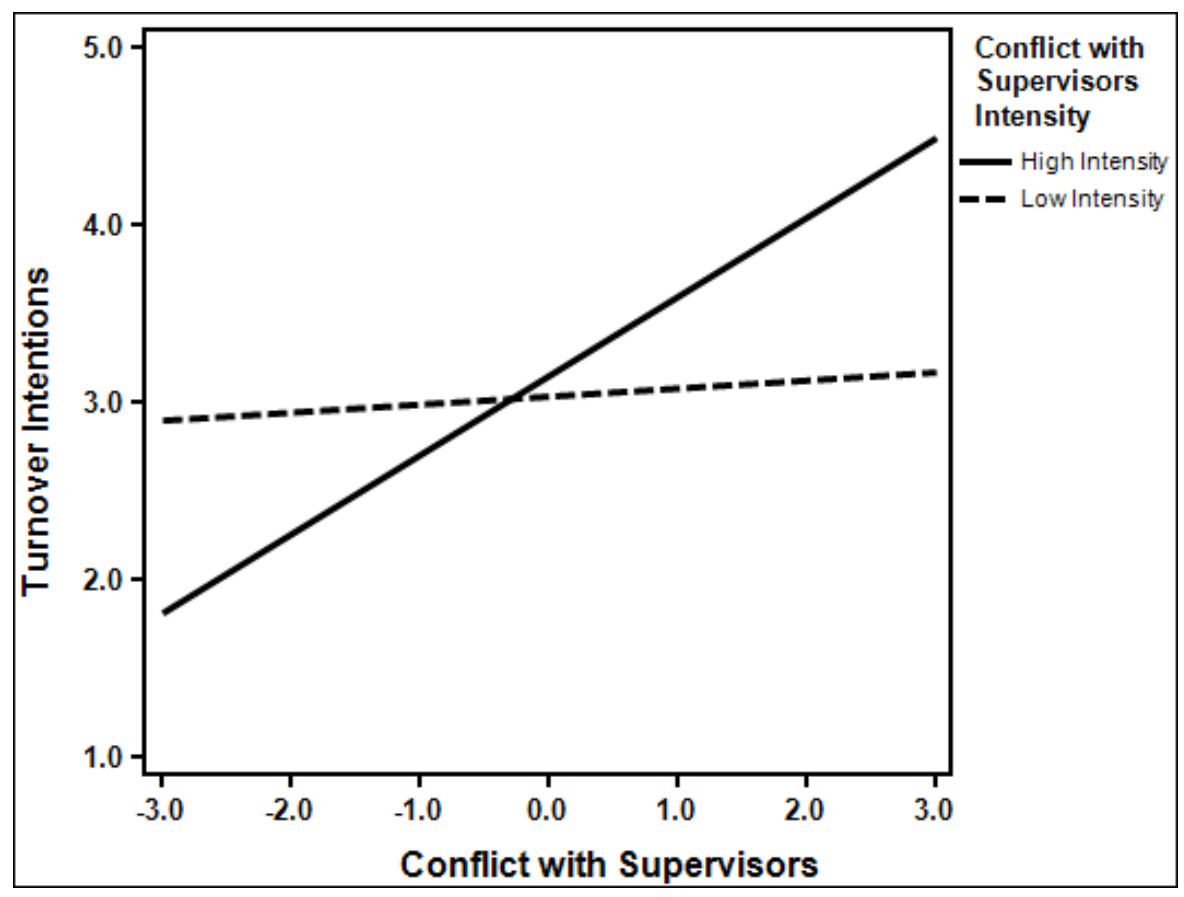

Figure 26. Intensity as a Moderator between Conflict with Supervisors and Job Satisfaction

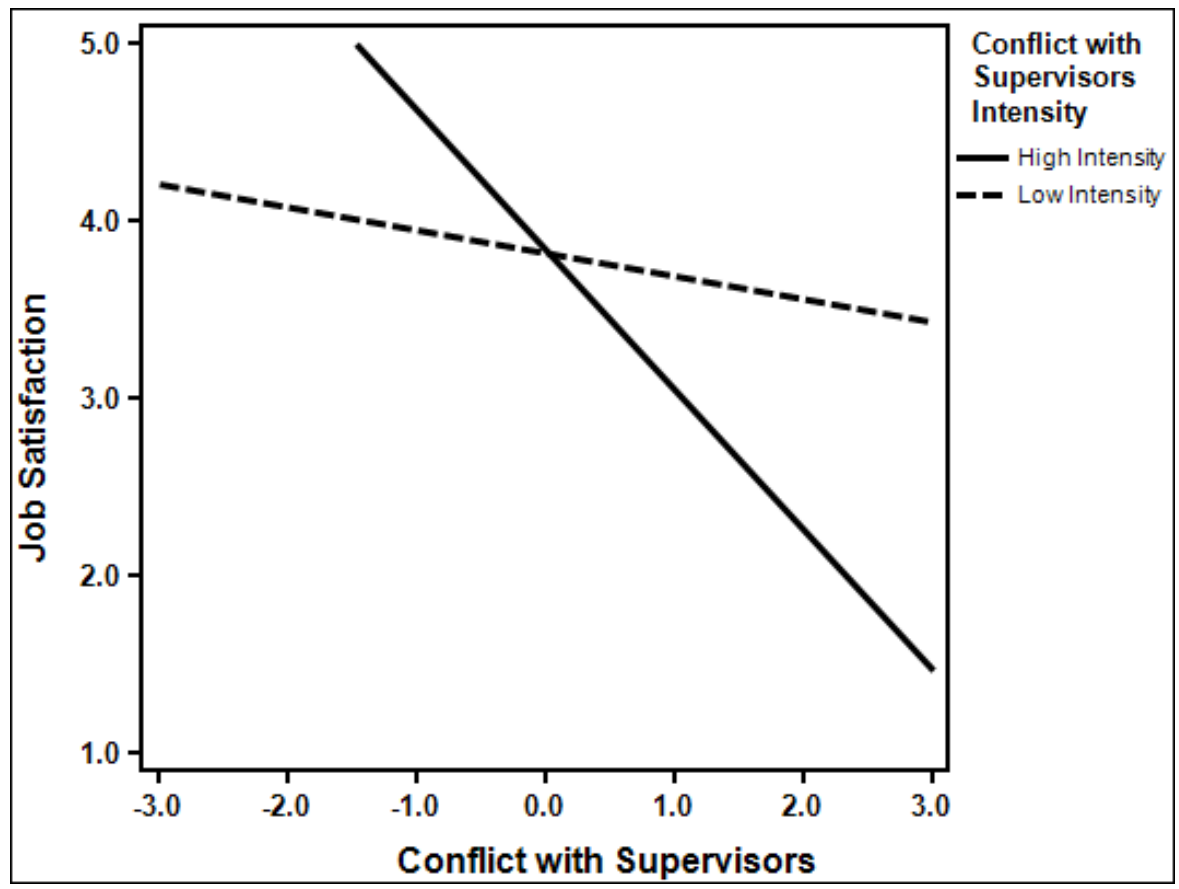


Figure 27. Intensity as a Moderator Conflict with Supervisors and Affective Commitment



Figure 28. Intensity as a Moderator between Conflict with Supervisors and Well-Being

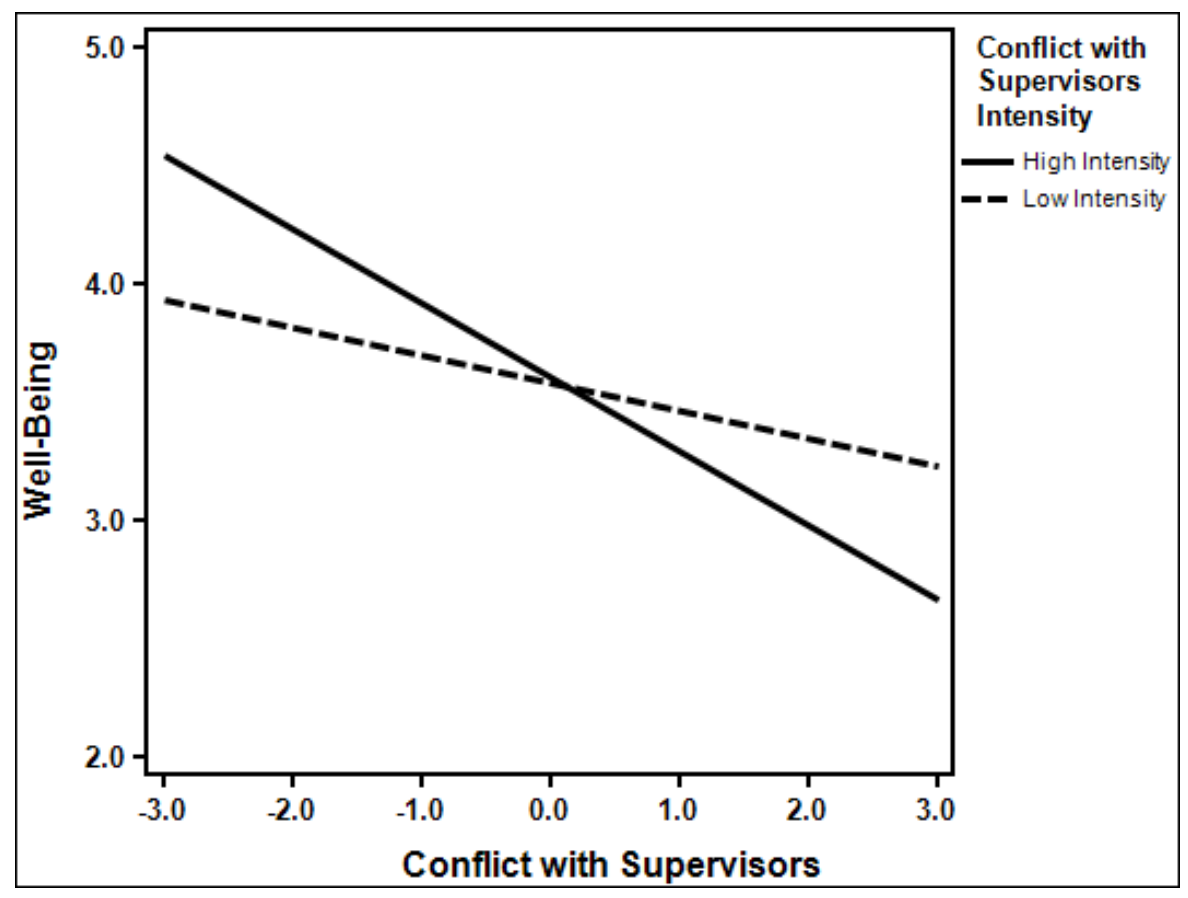


Figure 29. Intensity as a Moderator between Conflict with Supervisors and Depression

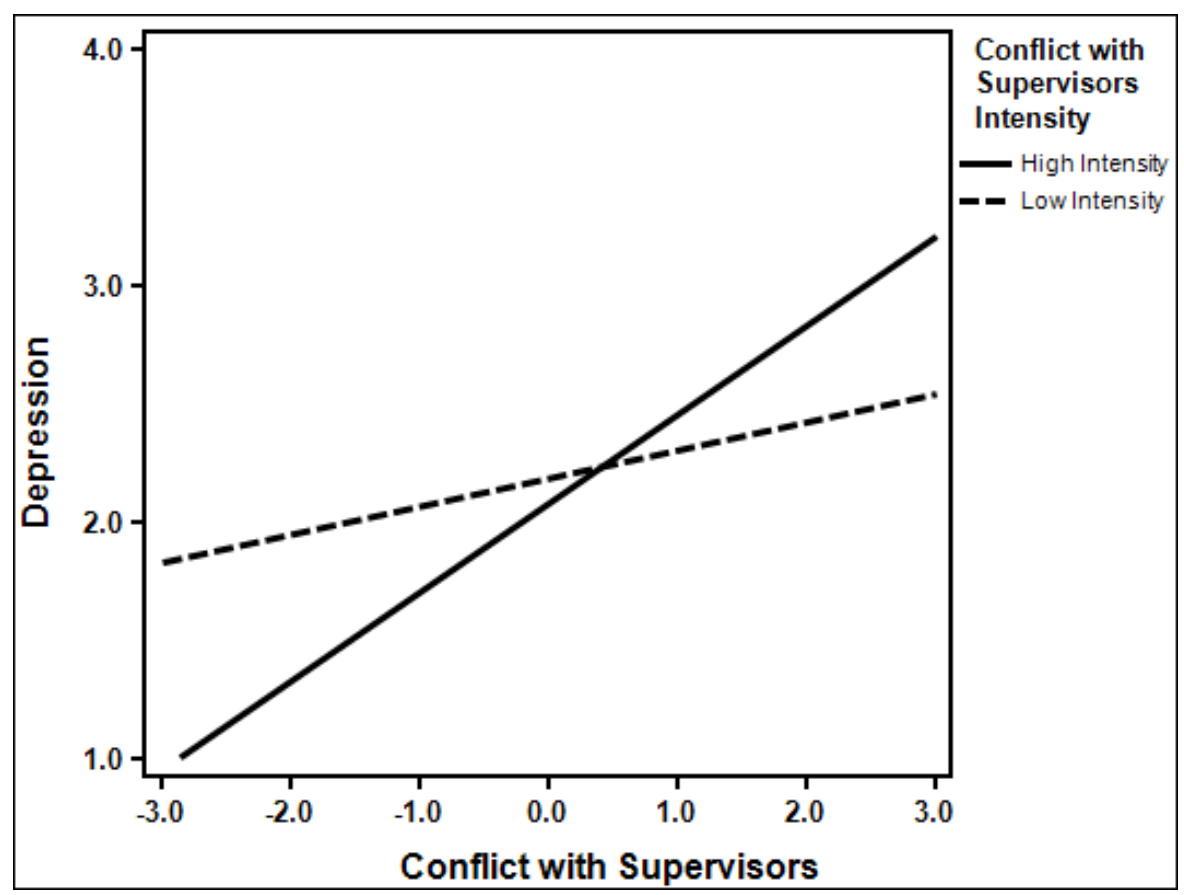

Figure 30. Intensity as a Moderator between Conflict with Supervisors and Irritation

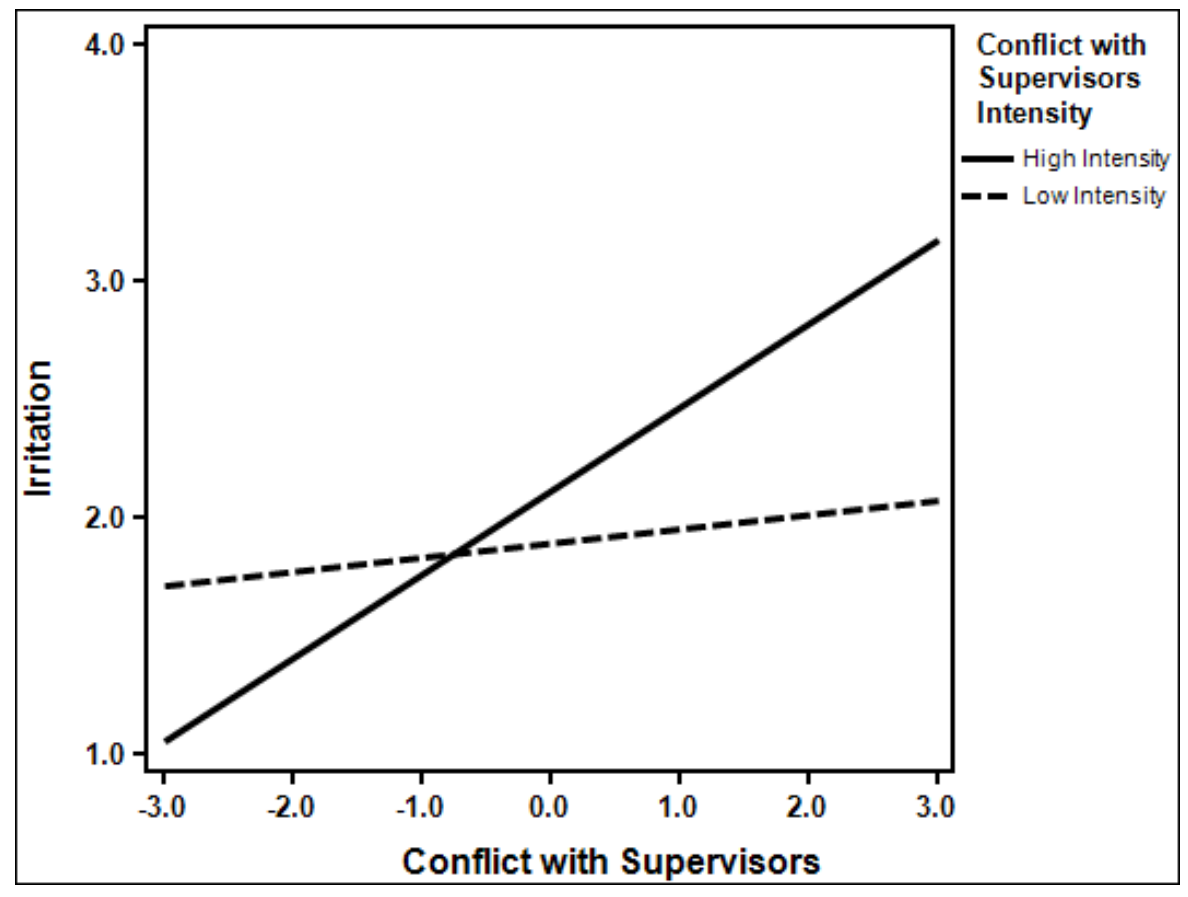


The increase in the variances explained in job satisfaction $\left(\Delta R^{2}=.069, F(1,188)=\right.$ 14.66, $\mathrm{p}>.001)$, affective commitment $\left(\Delta R^{2}=.061, F(1,186)=13.17, \mathrm{p}>.001\right)$, perceived stress $\left(\Delta R^{2}=.045, F(1,155)=9.71, \mathrm{p}>.01\right)$, physical symptoms $\left(\Delta R^{2}=.033, F\right.$ $(1,188)=7.24, \mathrm{p}>.01)$, well-being $\left(\Delta R^{2}=.103, F(1,190)=25.67, \mathrm{p}>.001\right)$, depression $\left(\Delta R^{2}=.103, F(1,189)=24.53, \mathrm{p}>.001\right)$ and irritation $\left(\Delta R^{2}=.053, F(1,189)=12.08, \mathrm{p}>\right.$ .01 ), were significant when the interaction term of conflict with co-workers and intensity were included in the regression. The interaction term did not explain a significant increase in variance in turnover intentions $\left(\Delta R^{2}=.012, F(1,186)=2.53, n s\right)$.

Table 33. Intensity as a Moderator between Conflict with Co-Workers and Turnover Intentions, Job Satisfaction and Affective Commitment

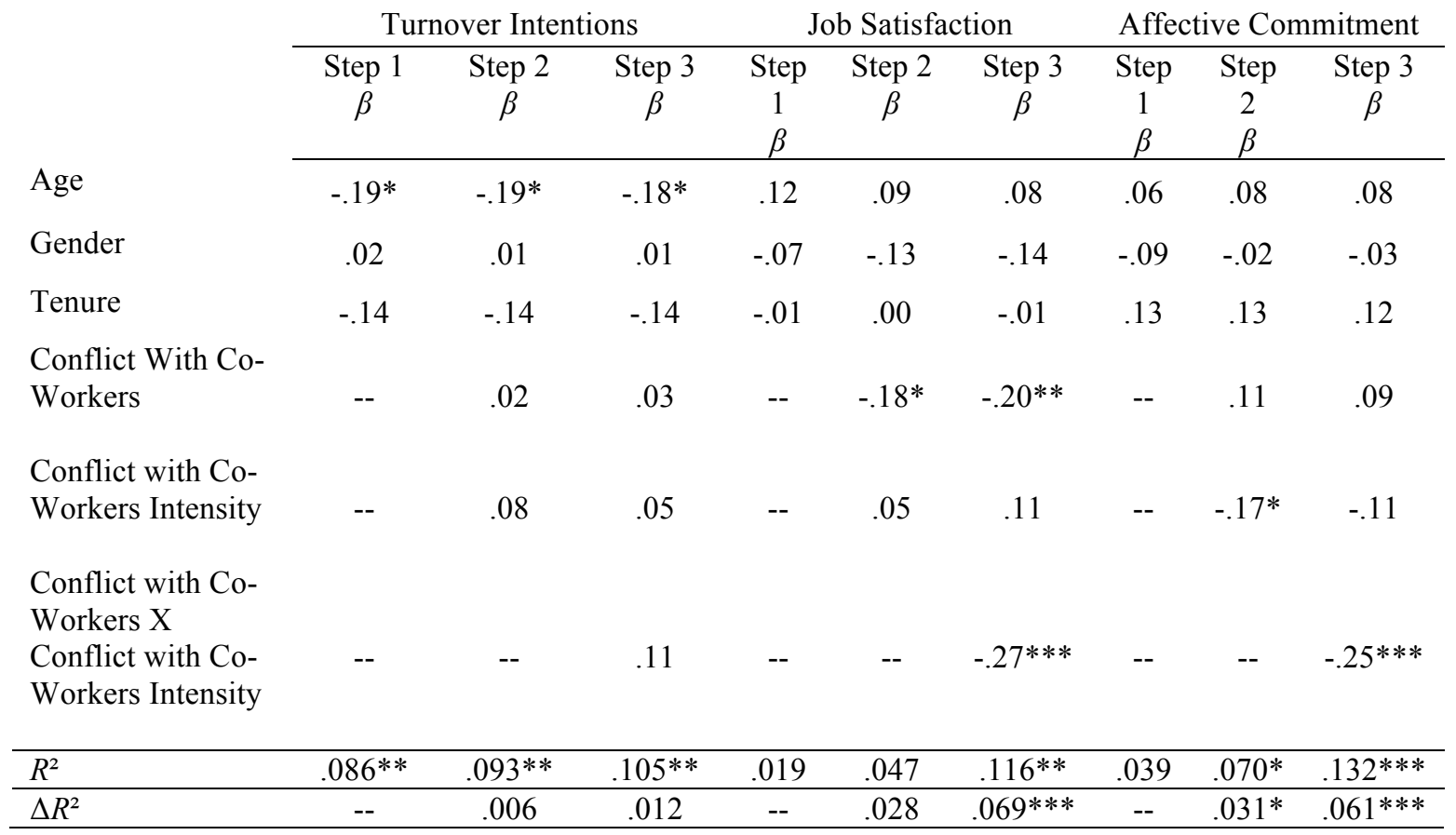

Note $\mathrm{N}=189-191 * p<.05 * * p<.01 * * * p<.001$ 
Table 34. Intensity as a Moderator between Conflict with Co-Workers and Perceived Stress, Physical Symptoms and Well-Being

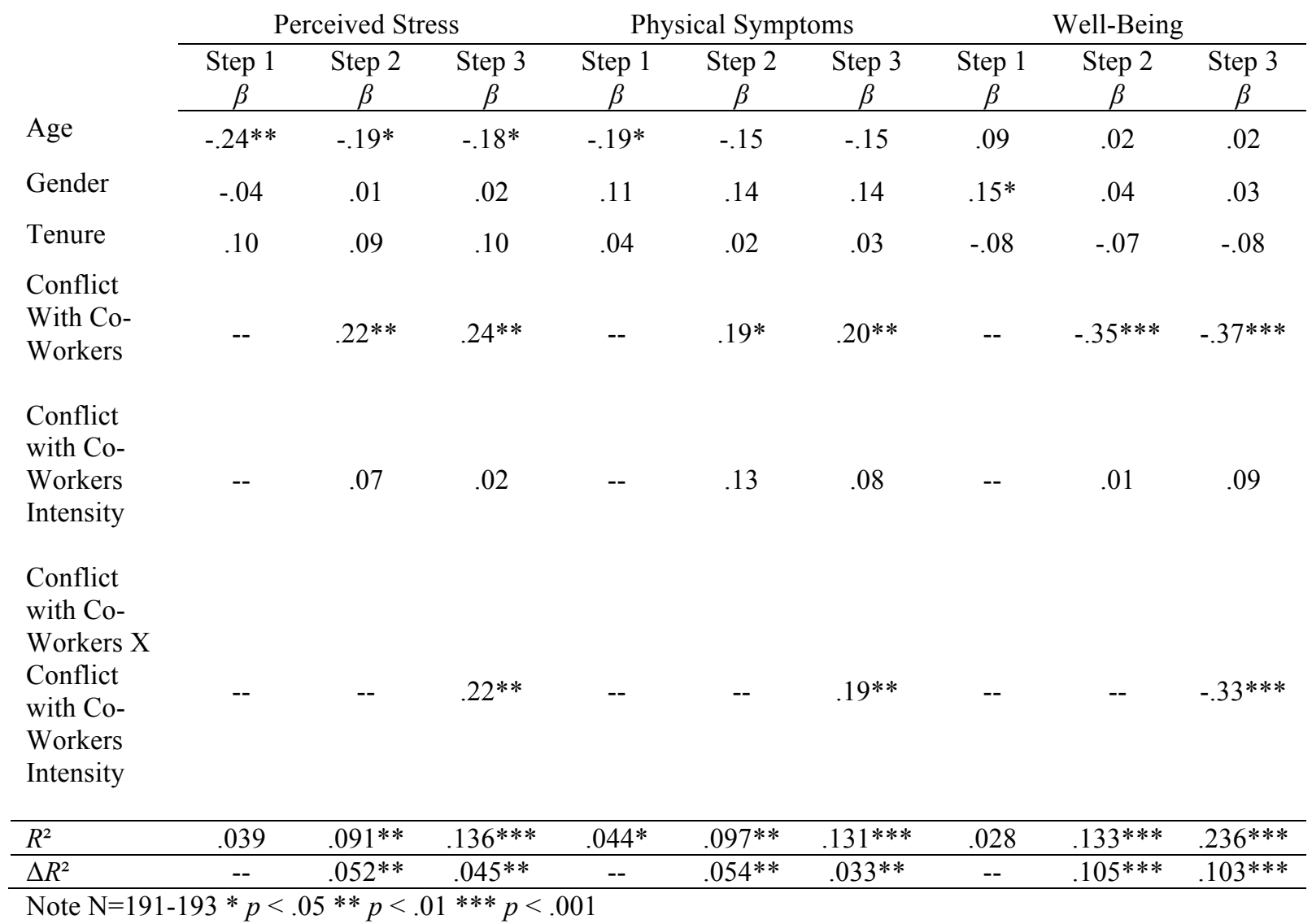


Table 35. Intensity as a Moderator between Conflict with Co-Workers and Depression and Irritation

Age

Gender

Tenure

Conflict With Co-Workers

Conflict with Co-Workers Intensity

Conflict with Co-Workers X Conflict with Co-Workers Intensity

\begin{tabular}{cccccc} 
& Depression & \multicolumn{3}{c}{ Irritation } \\
\hline Step 1 & Step 2 & Step 3 & Step 1 & Step 2 & Step 3 \\
$\beta$ & $\beta$ & $B$ & $\beta$ & $\beta$ & $\beta$ \\
\hline-.16 & -.10 & -.10 & -.11 & -.08 & -.07
\end{tabular}

.02

.08

.10

.02

$-.01$

.00

.05

.03

.05

$-.01$

$-.03$

$-.02$

-- $.29 * * * \quad .31 * * *$

$\begin{array}{ll}-- & .13\end{array}$

$.15^{*}$

$\begin{array}{ll}-- & .07\end{array}$

$-.01$

$--.27 * * *$

$.22 * *$

$--$

$--.33^{* * *}$

$\begin{array}{lll}-- & - & - \\ - & -24 * *\end{array}$

\begin{tabular}{lcccccc}
\hline$R^{2}$ & .020 & $.105^{* *}$ & $.208^{* * *}$ & .013 & $.111^{* * *}$ & $.164^{* * *}$ \\
\hline$\Delta R^{2}$ & -- & $.085^{* * *}$ & $.103^{* * *}$ & -- & $.098^{* * *}$ & $.053^{* *}$ \\
\hline
\end{tabular}

Note $\mathrm{N}=192 * p<.05 * * p<.01 * * * p<.001$

The moderation effects are illustrated in Figures 30 through 36. In support of hypothesis 9 , when intensity was high $(+1 \mathrm{SD})$ there were stronger relationships between conflict with co-workers and job satisfaction $\left(b=-.68, \mathrm{SE}_{b}=.10, p<.001\right)$, affective commitment $\left(b=-.25, \mathrm{SE}_{b}=.10, p<.05\right)$, perceived stress $\left(b=.34, \mathrm{SE}_{b}=.05, p<.001\right)$,

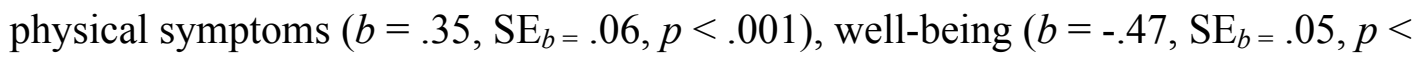
$.001)$, depression $\left(b=.48, \mathrm{SE}_{b}=.05, p<.001\right)$ and irritation $\left(b=.34, \mathrm{SE}_{b}=.06, p<.001\right)$. Whereas when intensity was low there was not a significant relationship found between conflict with co-workers and job satisfaction $\left(b=.11, \mathrm{SE}_{b}=.10, n s\right)$, perceived stress $(b=$ $\left..01, \mathrm{SE}_{b}=.05, n s\right)$, physical symptoms $\left(b=.00, \mathrm{SE}_{b}=.06, n s\right)$, well-being $\left(b=-.02, \mathrm{SE}_{b}=\right.$ $.04, n s)$, depression $\left(b=-.02, \mathrm{SE}_{b}=.05, n s\right)$ and irritation $\left(b=-.08, \mathrm{SE}_{b}=.06, n s\right)$. 
Figure 31. Intensity as a Moderator between Conflict with Co-Workers and Job Satisfaction

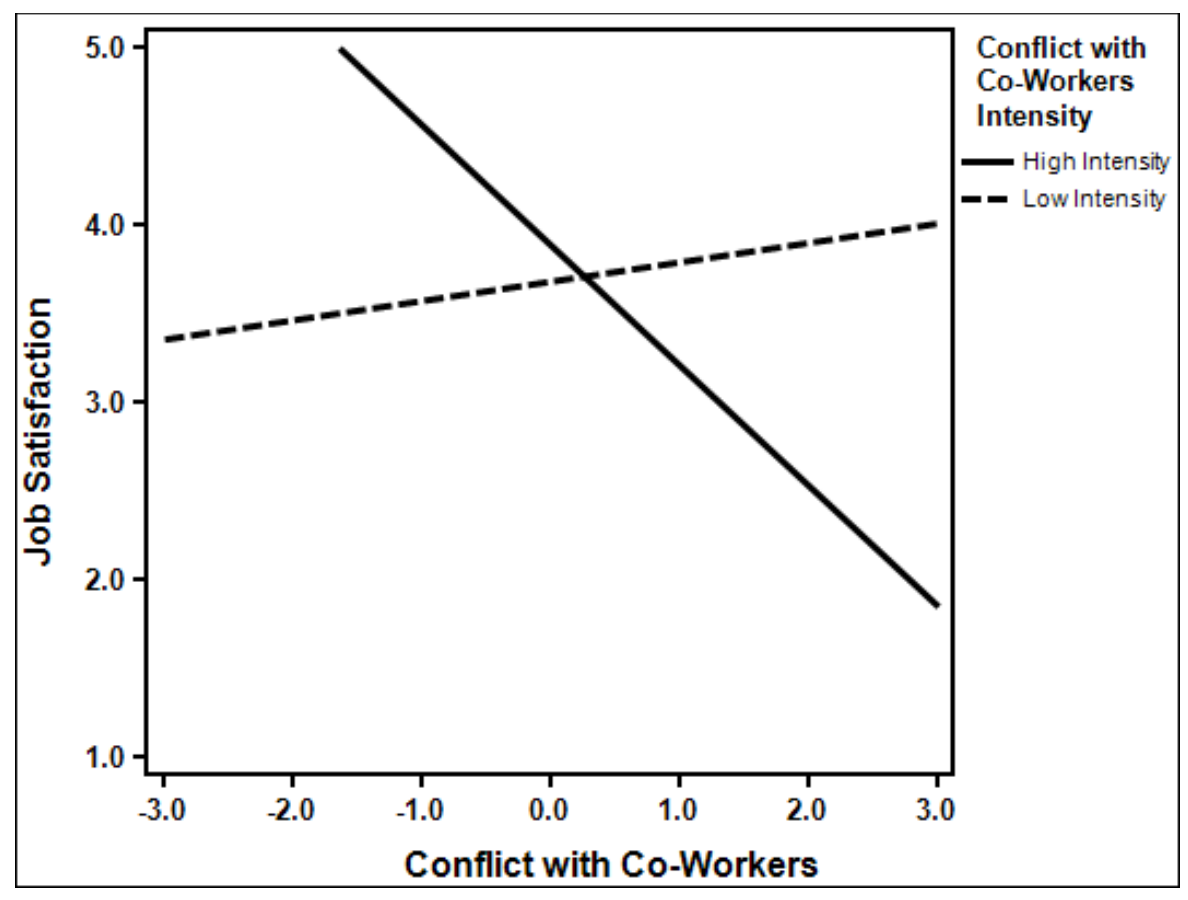

Figure 32. Intensity as a Moderator between Conflict with Co-Workers and Affective Commitment

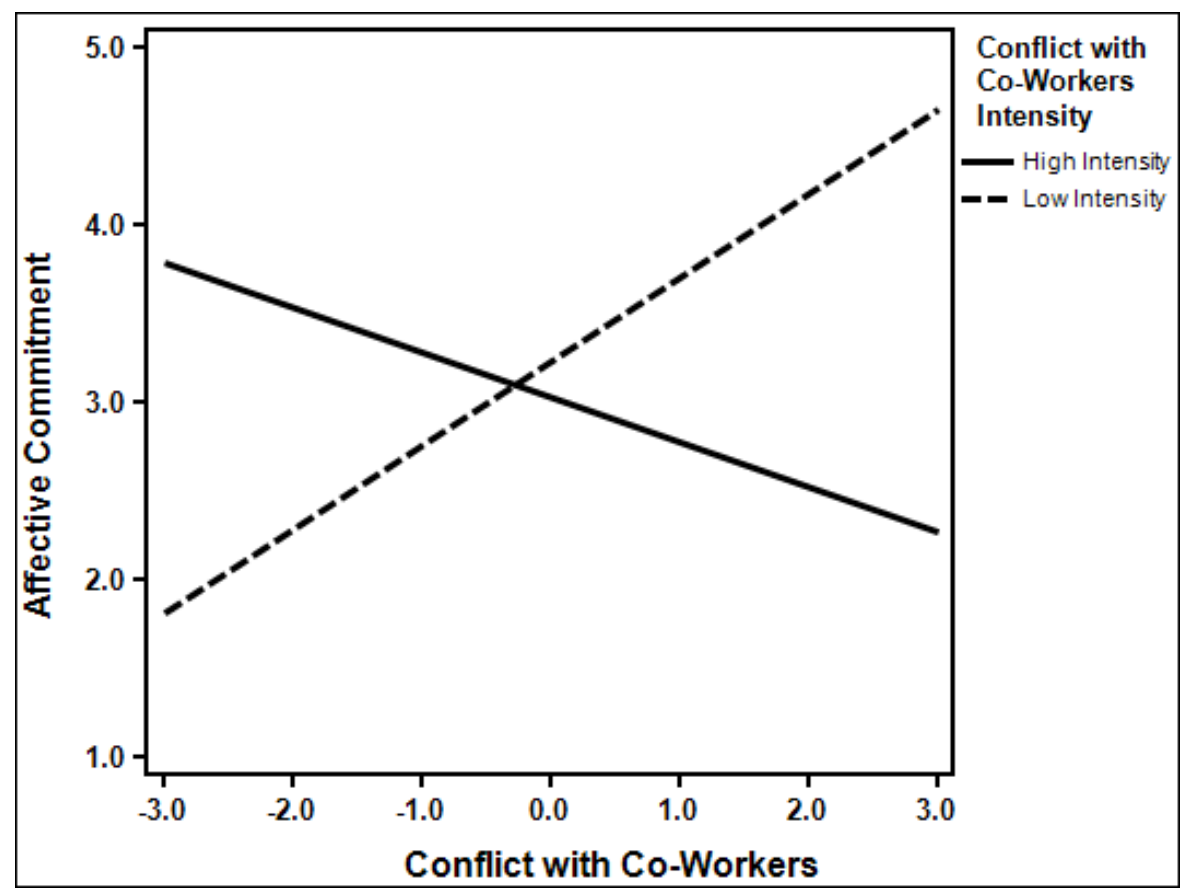


Figure 33. Intensity as a Moderator between Conflict with Co-Workers and Perceived Stress



Figure 34. Intensity as a Moderator between Conflict with Co-Workers and Physical Symptoms

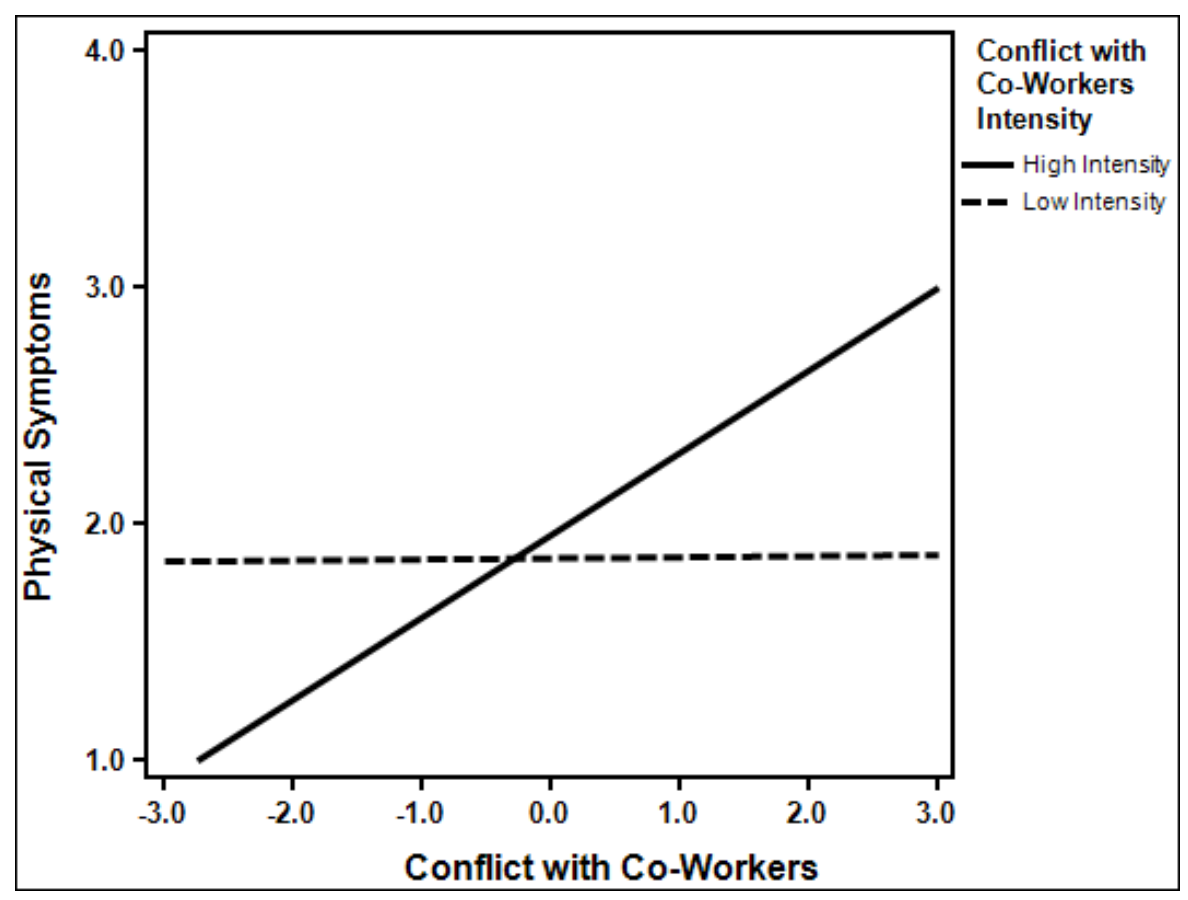


Figure 35. Intensity as a Moderator between Conflict with Co-Workers and Well-Being

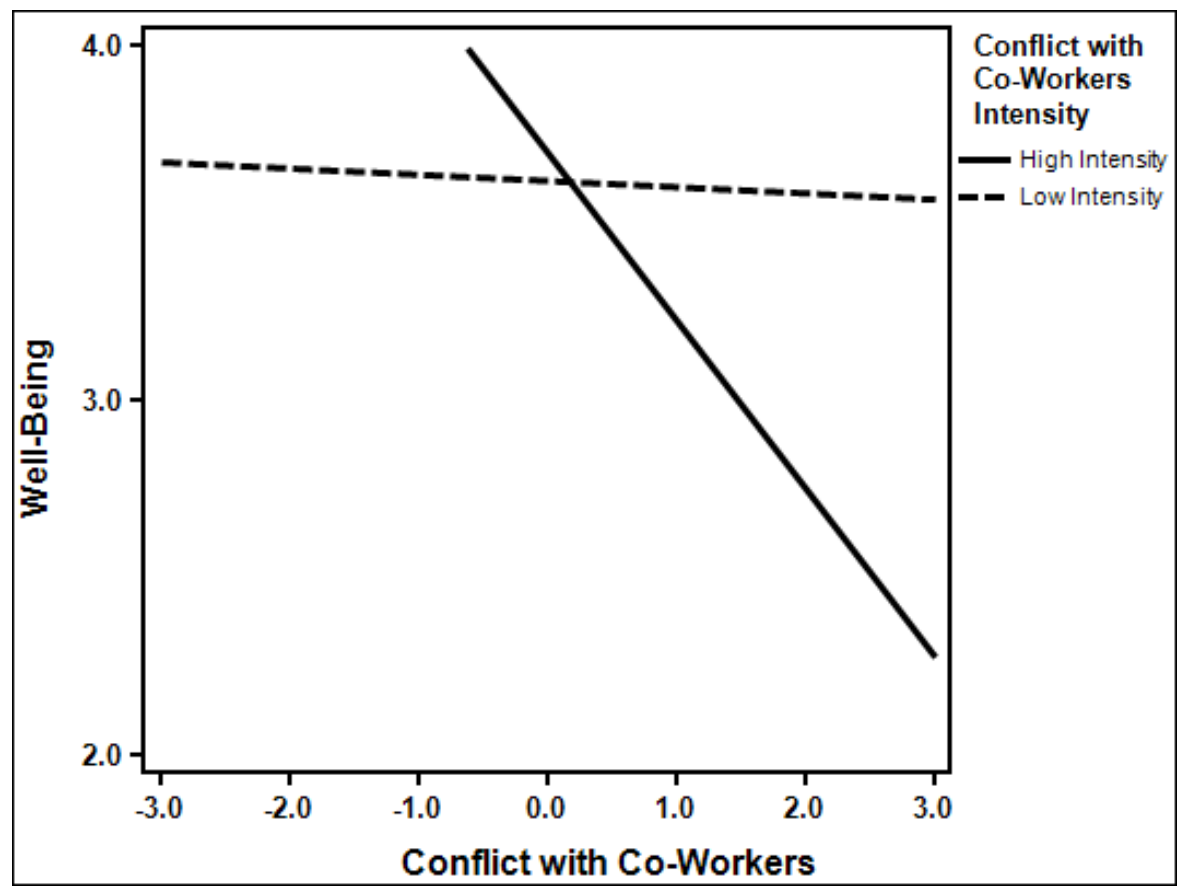

Figure 36. Intensity as a Moderator between Conflict with Co-Workers and Depression

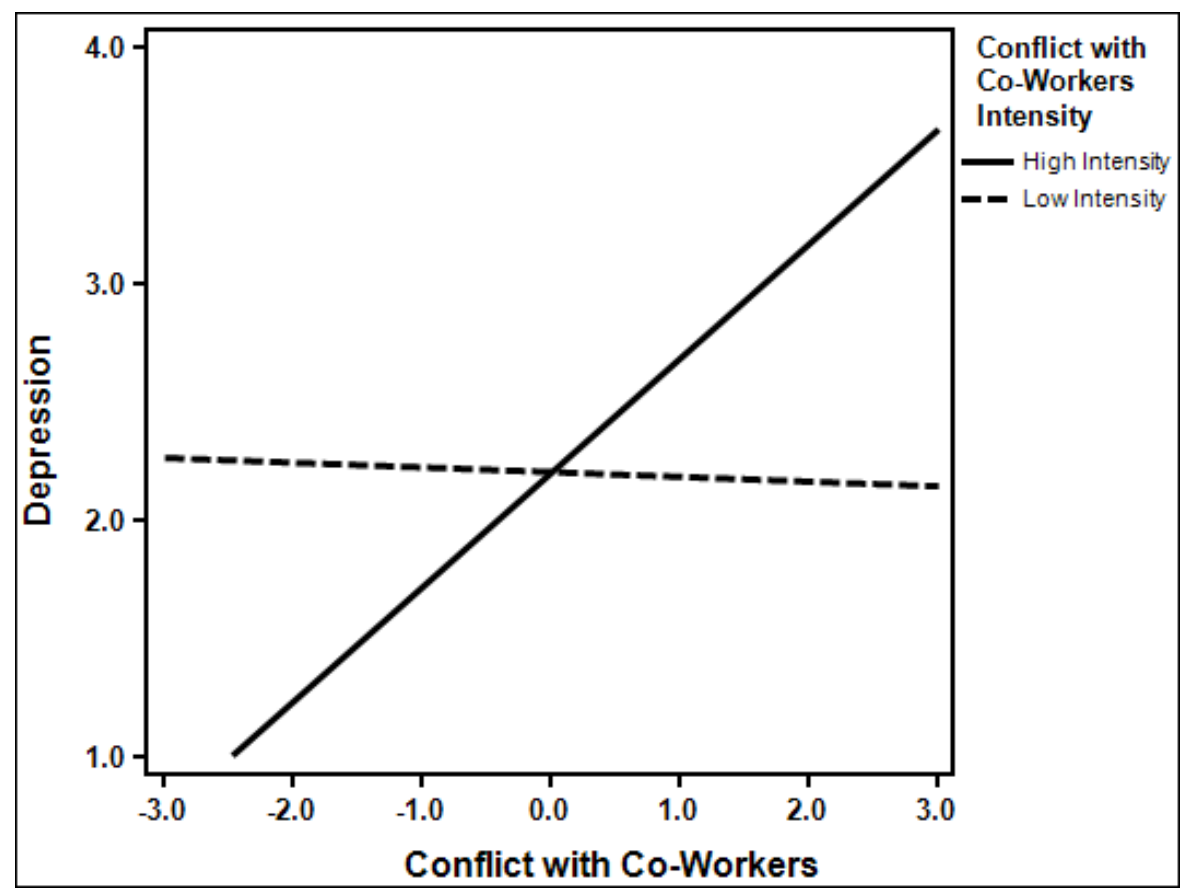


Figure 37. Intensity as a Moderator between Conflict with Co-Workers and Irritation

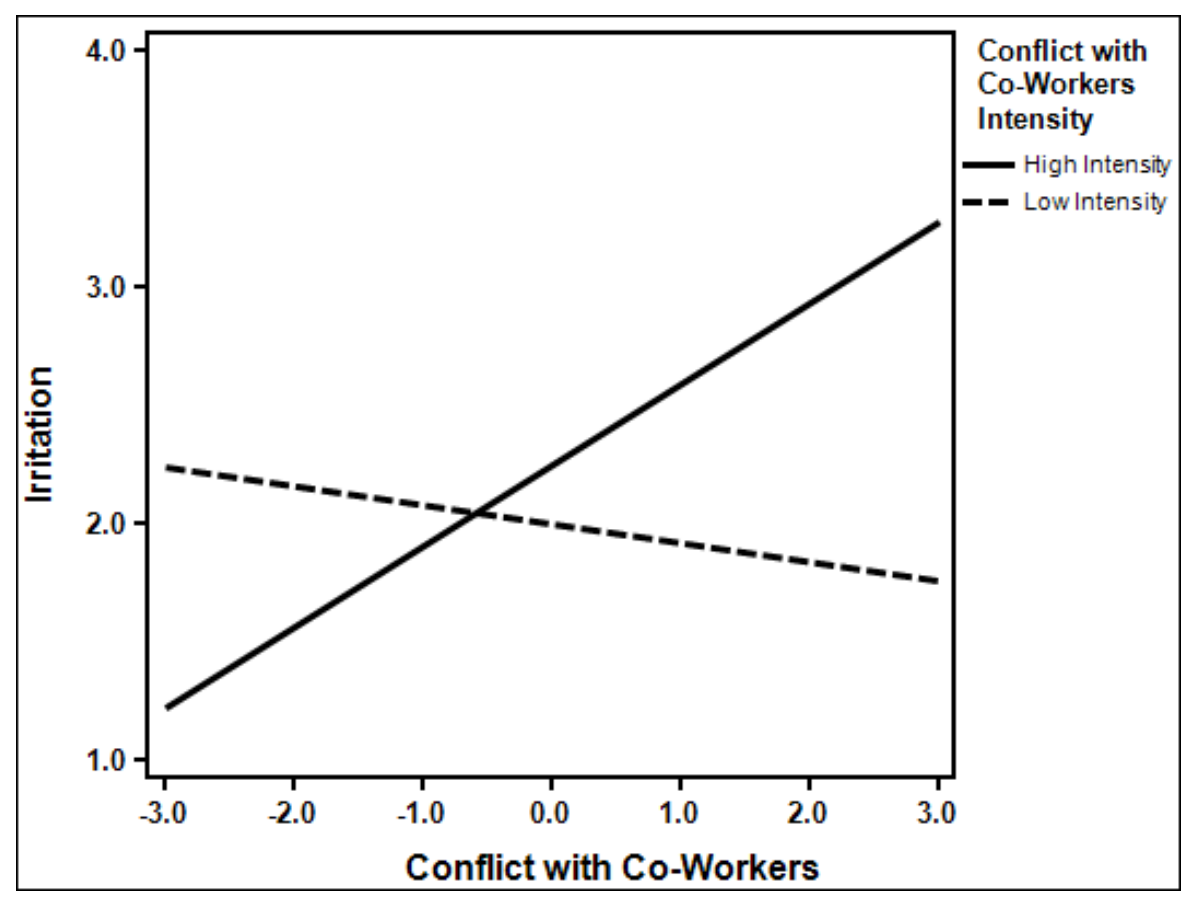

The interaction term for abusive supervision and intensity explained incremental variance in job satisfaction $\left(\Delta R^{2}=.061, F(1,129)=12.93, \mathrm{p}>.001\right)$. The interaction term did not explain incremental variance in turnover intentions $\left(\Delta R^{2}=.012, F(1,130)=2.06\right.$, $n s)$, affective commitment $\left(\Delta R^{2}=.009, F(1,130)=1.99, n s\right)$, perceived stress $\left(\Delta R^{2}=.009\right.$, $F(1,130)=1.45, n s)$, physical symptoms $\left(\Delta R^{2}=.004, F(1,129)=.62, n s\right)$, well-being $\left(\Delta R^{2}=.002, F(1,129)=.39, n s\right)$, depression $\left(\Delta R^{2}=.001, F(1,129)=.15, n s\right)$ or irritation $\left(\Delta R^{2}=.008, F(1,129)=1.73, n s\right)$. 
Table 36. Intensity as a Moderator between Abusive Supervision and Turnover Intentions, Job Satisfaction and Affective Commitment

\begin{tabular}{|c|c|c|c|c|c|c|c|c|c|}
\hline & \multicolumn{3}{|c|}{ Turnover Intentions } & \multicolumn{3}{|c|}{ Job Satisfaction } & \multicolumn{3}{|c|}{ Affective Commitment } \\
\hline & $\begin{array}{c}\text { Step } 1 \\
\beta\end{array}$ & $\begin{array}{c}\text { Step } 2 \\
\beta\end{array}$ & $\begin{array}{c}\text { Step } 3 \\
\beta\end{array}$ & $\begin{array}{c}\text { Step } 1 \\
\beta\end{array}$ & $\begin{array}{c}\text { Step } 2 \\
\beta\end{array}$ & $\begin{array}{c}\text { Step } 3 \\
\beta\end{array}$ & $\begin{array}{c}\text { Step } 1 \\
\beta\end{array}$ & $\begin{array}{c}\text { Step } 2 \\
\beta\end{array}$ & $\begin{array}{c}\text { Step } 3 \\
\beta\end{array}$ \\
\hline Age & $-.26 * *$ & $-.20 *$ & $-.20 *$ & .19 & .09 & .09 & .15 & .05 & .05 \\
\hline Gender & .02 & -.01 & -.03 & .06 & .04 & .07 & -.08 & -.06 & -.04 \\
\hline Tenure & -.08 & -.05 & -.05 & -.01 & -.01 & .00 & .13 & .10 & .10 \\
\hline $\begin{array}{l}\text { Abusive } \\
\text { Supervision }\end{array}$ & -- & $.20^{*}$ & $.16^{*}$ & -- & $-.41 * * *$ & $-.34 * * *$ & -- & $-.33 * * *$ & $-.30 * *$ \\
\hline $\begin{array}{l}\text { Abusive } \\
\text { Supervision } \\
\text { Intensity }\end{array}$ & -- & $.32 * * *$ & $.27 * *$ & -- & $-.29 * * *$ & $-.17^{*}$ & -- & $-.41 * * *$ & $-.37 * * *$ \\
\hline $\begin{array}{l}\text { Abusive } \\
\text { Supervision } \\
\text { X Abusive } \\
\text { Supervision } \\
\text { Intensity }\end{array}$ & -- & -- & .13 & -- & -- & $-.29 * * *$ & -- & -- & -.11 \\
\hline$R^{2}$ & $.097 * *$ & $.253^{* * *}$ & $264 * * *$ & .038 & $.326^{* * *}$ & $.387 * * *$ & $.069^{*}$ & $.386^{* * *}$ & $.395^{* * *}$ \\
\hline$\Delta R^{2}$ & -- & $.155^{* * *}$ & .012 & -- & $.288 * * *$ & $.061 * * *$ & -- & $.318 * * *$ & .009 \\
\hline
\end{tabular}

Note $\mathrm{N}=132-133 * p<.05 * * p<.01 * * * p<.001$ 
Table 37. Intensity as a Moderator between Abusive Supervision and Perceived Stress, Physical Symptoms and Well-Being

\begin{tabular}{|c|c|c|c|c|c|c|c|c|c|}
\hline & \multicolumn{3}{|c|}{ Perceived Stress } & \multicolumn{3}{|c|}{ Physical Symptoms } & \multicolumn{3}{|c|}{ Well-Being } \\
\hline & $\begin{array}{c}\text { Step } 1 \\
\beta\end{array}$ & $\begin{array}{c}\text { Step } 2 \\
\beta\end{array}$ & $\begin{array}{c}\text { Step } 3 \\
\beta\end{array}$ & $\begin{array}{c}\text { Step } 1 \\
\beta\end{array}$ & $\begin{array}{c}\text { Step } 2 \\
\beta\end{array}$ & $\begin{array}{c}\text { Step } 3 \\
\beta\end{array}$ & $\begin{array}{c}\text { Step } 1 \\
\beta\end{array}$ & $\begin{array}{c}\text { Step } 2 \\
\beta\end{array}$ & $\begin{array}{c}\text { Step } 3 \\
\beta\end{array}$ \\
\hline Age & -.14 & -.06 & -.06 & -.15 & -.06 & -.06 & .02 & -.11 & -.11 \\
\hline Gender & -.08 & -.05 & -.07 & .09 & .10 & .09 & $.22 *$ & .10 & .11 \\
\hline Tenure & .06 & .06 & .06 & .01 & .02 & .02 & -.06 & -.01 & -.01 \\
\hline $\begin{array}{l}\text { Abusive } \\
\text { Supervision }\end{array}$ & -- & $.32 * * *$ & $.29 * *$ & -- & $.33 * * *$ & $.32 * * *$ & -- & $-.60 * * *$ & $-.59 * * *$ \\
\hline $\begin{array}{l}\text { Abusive } \\
\text { Supervision } \\
\text { Intensity }\end{array}$ & -- & $.19^{*}$ & .14 & -- & $.26^{* *}$ & $.23^{*}$ & -- & -.08 & -.06 \\
\hline $\begin{array}{l}\text { Abusive } \\
\text { Supervision } \\
\text { X Abusive } \\
\text { Supervision } \\
\text { Intensity }\end{array}$ & -- & -- & .11 & -- & -- & .07 & -- & -- & -.05 \\
\hline$R^{2}$ & .019 & $.173^{* * *}$ & $.182 * * *$ & .032 & $.235^{* * *}$ & $.238^{* * *}$ & .051 & $.409 * * *$ & $.411 * * *$ \\
\hline$\Delta R^{2}$ & -- & $.154 * * *$ & .009 & -- & $.203 * * *$ & .004 & -- & $.359 * * *$ & .002 \\
\hline
\end{tabular}

Table 38. Intensity as a Moderator between Abusive Supervision and Depression and Irritation

Age

Gender

Tenure

Abusive Supervision

Abusive Supervision Intensity

Abusive Supervision X Abusive Supervision Intensity

\begin{tabular}{|c|c|c|c|c|c|}
\hline \multicolumn{3}{|c|}{ Depression } & \multicolumn{3}{|c|}{ Irritation } \\
\hline $\begin{array}{c}\text { Step } 1 \\
\beta \\
\end{array}$ & $\begin{array}{c}\text { Step } 2 \\
\beta\end{array}$ & $\begin{array}{c}\text { Step } 3 \\
B\end{array}$ & $\begin{array}{c}\text { Step } 1 \\
\beta \\
\end{array}$ & $\begin{array}{c}\text { Step } 2 \\
\beta\end{array}$ & $\begin{array}{c}\text { Step } 3 \\
\beta\end{array}$ \\
\hline-.16 & -.05 & -.05 & -.18 & -.05 & -.06 \\
\hline-.11 & -.06 & -.05 & -.07 & -.02 & -.03 \\
\hline .06 & .04 & .04 & -.02 & -.03 & -.03 \\
\hline-- & $.45 * * *$ & $.45 * * *$ & -- & $.51 * * *$ & $.49 * * *$ \\
\hline-- & $.21 * *$ & $.23 *$ & -- & $.28 * * *$ & $.24 * *$ \\
\hline-- & -- & -.03 & -- & -- & .10 \\
\hline .028 & $.298 * * *$ & $.299 * * *$ & .039 & $.418 * * *$ & $.426 * * *$ \\
\hline-- & $.270 * * *$ & .001 & -- & $.379 * *$ & .008 \\
\hline
\end{tabular}

Note $\mathrm{N}=132 * p<.05 * * p<.01 * * * p<.001$ 
The moderation effects are illustrated in Figure 37. In support of hypothesis 9, the relationship between abusive supervision and job satisfaction was stronger when intensity was high $(+1 \mathrm{SD})$ resulting in lower job satisfaction as abusive supervision is greater $(b=$ $\left.-.82, \mathrm{SE}_{b}=.10, p<.001\right)$. When intensity was low $(-1 \mathrm{SD})$ there was not a significant relationship between abusive supervision and job satisfaction $\left(b=-.06, \mathrm{SE}_{b}=.10, n s\right)$. Therefore, partial support is found for hypothesis 9 with intensity moderating many of the relationships between workplace aggression and outcomes.

Figure 38. Intensity as a Moderator between Abusive Supervision and Job Satisfaction

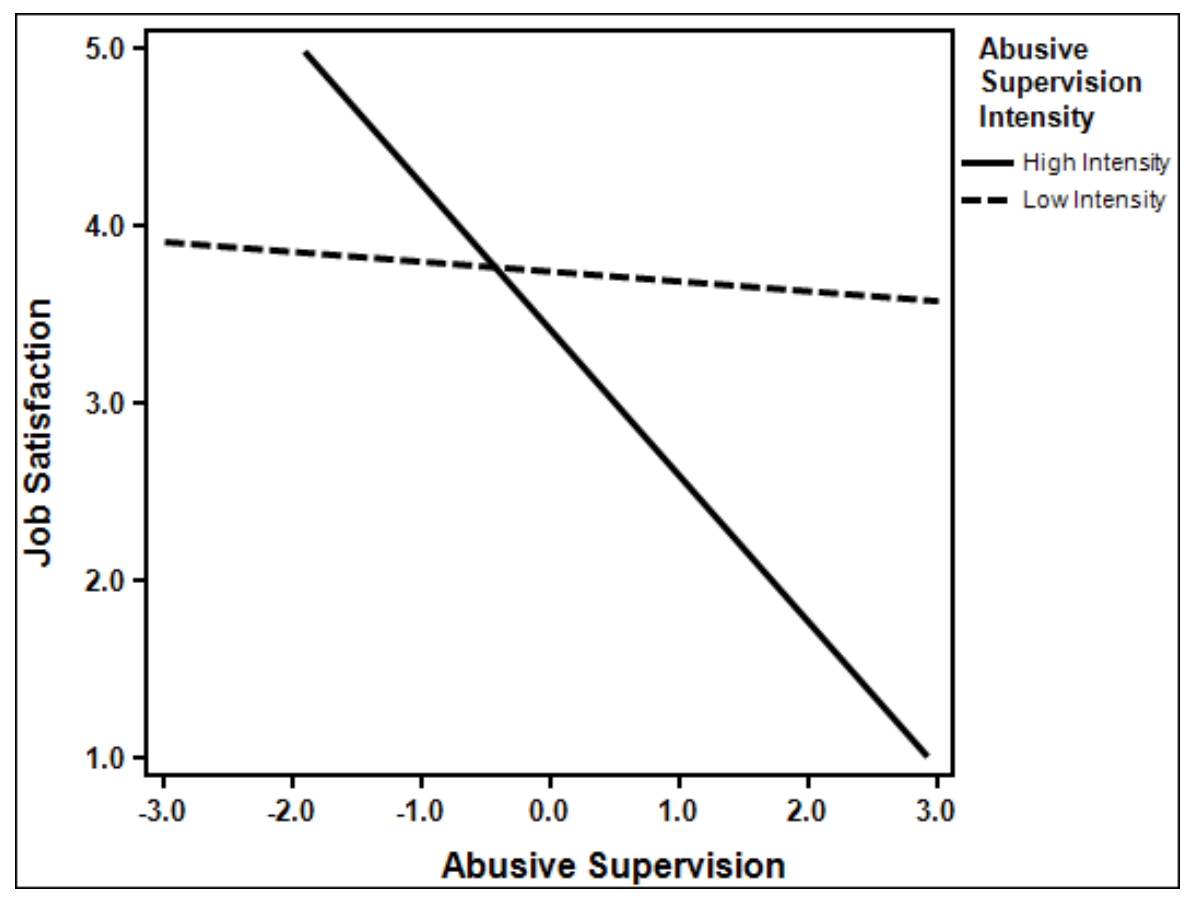




\section{CHAPTER V. DISCUSSION}

The results of this thesis supported many of the posited hypotheses. First, the correlational hypotheses received almost universal support. Extending the work of previous research (e.g., Spector \& Jex, 1998; Tepper, 2000) all three of the workplace aggression variables were significantly related to multiple individual and organizational outcomes. In support of hypothesis one, two sources of interpersonal conflict (conflict with supervisors and conflict with co-workers) were related to lower job satisfaction and higher turnover intentions. Conflict with supervisors was also related to lower affective commitment; however conflict with co-workers was not significantly related to affective commitment. Similarly, and in support of hypothesis two, abusive supervision was related to lower job satisfaction, lower affective commitment, and higher turnover intentions. Taken as a whole, these results support the notion that workplace aggression significantly impacts a number of important organizational outcomes.

Next, addressing a notable gap in the extant research, abusive supervision was significantly related to greater interpersonal conflict, supporting hypothesis three. Similarly, the incivility spiral posited by Andersson and Pearson (1999) suggests that one instance of aggression often leads to another, resulting in an aggressive spiral of overt hostility. Rarely are different types of workplace aggression measured together (Allen et al., 2012) and the results of my study suggests that different types of workplace aggression are highly related. Furthermore, when different types of workplace aggression are measured together, there is an opportunity to test similarities in processes as will be further discussed in the sections below. 
Evidence supporting the relationship between workplace aggression and individual health outcomes is becoming quite robust (e.g., de Wit et al., 2012; Hershcovis, 2011; Nixon et al., 2011; Spector \& Jex, 1998; Tepper, 2000). The results of my study are largely consistent with the existing body of literature, and offer novel findings as well. Workplace aggression was found to be negatively related to well-being and positively related to perceived stress, physical symptoms, depression, and irritation. Answering a call for further research on the relationship between abusive supervision and physical symptoms (e.g., Allen et al., 2012; Nixon, 2011), the current study is the first to explore this relationship, finding a moderate positive relationship between abusive supervision and physical symptoms. The results support hypothesis four and five providing evidence that workplace aggression is significantly related to individual health outcomes, providing strong evidence supporting the link between workplace aggression and employee health.

\section{Differences Based on Source of Aggression}

Building upon previous theoretical and empirical research (e.g., Bruk-Lee \& Spector, 2006; Frone, 2000), hypothesis six posited that there would be a significant difference in the strength of relationships depending on the source of aggression (supervisor vs. co-worker) on the different outcomes (organizational vs. individual). Building on the work of Frone (2000), I hypothesized that aggression from supervisors, as representatives of an organization, would be more strongly related to organizational outcomes. Additionally, as suggested by Frone (2000), conflict with co-workers, representing the social aspects of the workplace, would be more strongly related to 
individual health outcomes. Universal support was found for hypothesis $6 \mathrm{a}$, which suggested that supervisor aggression would be more strongly related to organizational outcomes. In this case, conflict with supervisors and abusive supervision were more strongly related to job satisfaction, turnover intentions, and affective commitment than conflict with co-workers. However, support for hypothesis $6 \mathrm{~b}$ was not found. Significant differences were found between conflict with supervisors and conflict with co-workers in regards to well-being and a significant difference with both types of supervisor aggression (conflict and abusive supervision) and conflict with co-workers in regards to irritation. However, the results suggest that these relationships were stronger for supervisor aggression. No significant differences were found based on the source of aggression for the other health outcomes. Stated plainly, supervisor aggression was more strongly related to both irritation (for abusive supervision and conflict) and well-being (for conflict). These results are consistent with meta-analytic evidence presented by Hershcovis and Barling (2010) suggesting that supervisor initiated aggression was more strongly related to almost every outcome explored than co-worker initiated aggression. The single variable that was more strongly related to co-worker initiated aggression than supervisor initiated aggression was physical symptoms, which was not supported by the results of the current study.

These results strongly suggest that supervisor aggression is much more detrimental to individuals than co-worker aggression. This seems particularly applicable to organizational outcomes, where universal support of this disparity was found. Supervisor initiated aggression is likely more detrimental due to the lack of recourse 
options available to the employees due to the supervisors status (Molm, 1988).

Specifically, when experiencing supervisor-initiated aggression employees experience less control over the situation and have limited response options to the aggression. Accordingly, control is believed to be an important factor of the stressor-strain relationship as highlighted by demand-control theories (Karasek, 1979). Although the difference in relationships between supervisor aggression and co-worker aggression with health outcomes is less clear cut (many of these relationships were non-significant), suggesting that aggression is harmful to employee health regardless of the source. However, the relationships that were found to have significant differences were more strongly related with supervisor aggression. This leads to the conclusion that supervisor initiated aggression is consistently worse for employee outcomes than coworker initiated aggression.

\section{Emotion as a Mediator}

A primary focus of this study was to explore the potential mediating role of jobrelated negative emotions in the relationship between workplace aggression and outcomes. There is some existing support for emotion as a mediator in the conflict literature (e.g., Ilies et al., 2011; Lubbers et al., 2005; Spector \& Bruk-Lee, 2008), but this relationship has not been explored with regards to abusive supervision. As such, a primary concern of this study was to determine whether negative emotion would mediate the relationship of all three of the different types of workplace aggression that were measured. 
The results of the study suggest that job-related negative emotions were a mediator of the relationship between workplace aggression and outcomes, with full or partial mediation found for all relationships. Interestingly, full mediation was more commonly found for organizational outcomes (i.e., turnover intentions, affective commitment, and job satisfaction) than for individual health outcomes. This finding is consistent with the results of previous research studies that have found negative emotions to be an effective predictor of work outcomes (e.g., Grandey et al., 2002; Ilies et al., 2006). These results are slightly counterintuitive considering the relationship that is often found between negative emotions and health (e.g., Warr, 1988; Watson, 1998). However, the finding is consistent with Affective Events Theory (AET) which posits that emotions will influence work attitudes and behaviors (Weiss \& Cropanzano, 1996). This finding is especially noteworthy because it suggests negative emotions are an important variable of consideration for traditional organizational research.

Negative emotions were found to be a full mediator of many of the abusive supervision - outcome relationships. This finding is important because emotion is typically disregarded in abusive supervision research. To date, abusive supervision research has relied almost exclusively on justice theories to explain the relationship between abusive supervision and outcomes (Hershcovis, 2011). However, employee abuse is often the source of negative emotions (Spector \& Bruk-Lee, 2008), an idea that has been largely overlooked. The results of the current study suggest that emotions at work are an important variable that organizational researchers should be considering, 
particularly outside of the domain of occupational health research where it is typically applied.

Altogether, the results of the mediational analysis suggest that negative emotion is an effective mediator of the relationship between workplace aggression and outcomes.

Importantly, this study measured three different types of workplace aggression in tandem and found that similar relationships with negative emotions and outcomes held for all three. It is suggested that job-related negative emotions could be an effective universal mediator between all types of workplace aggression (i.e., bullying, social undermining, incivility, etc.) and outcomes.

\section{The Moderating Effects of Social Support}

This study hypothesized that social support would be a moderator variable between workplace aggression and outcomes. Specifically, it was hypothesized that within-domain social support (i.e., aggression and support from the same source) would exacerbate the relationship between outcomes, whereas, cross-domain social support (i.e., aggression and support from different sources) would buffer the relationship between aggression and outcomes.

The cross-domain hypothesis was supported for many of the relationships between workplace aggression and social support from another source. The results of this study suggest that receiving social support from a source different than the emanating source of aggression can help to weaken the negative effect of workplace aggression on many outcomes. These results were consistent with much of the research on social 
support (e.g., Hobman et al., 2009; Ilies et al., 2011; Peeters et al., 1995). However, there was one outcome, turnover intentions, where this relationship was found in the opposite direction than hypothesized. Specifically, when co-worker social support was high $(+1$ $\mathrm{SD})$, there were higher turnover intentions when supervisor aggression was high, than compared to when co-worker support was low (-1 SD). One possible explanation for this unexpected finding is that when employees are experiencing high supervisor aggression, co-worker support could encourage them to find a new job and escape the abusive relationship. Also in support of the cross-domain hypothesis, supervisor social support was found to act as a buffering variable in the relationships between conflict with coworkers and both physical symptoms and irritation such that when supervisor social support was high, the relationships between conflict with co-workers and both physical symptoms and irritation were weakened. Overall, support was provided that receiving support from a source different than the source of aggression would lessen the harmful impact that the aggression elicits on a variety of outcomes.

Conversely, the within-domain social support exacerbation hypothesis was generally not supported by the findings of this study. Consistent with the findings of the cross-domain social support results, within-domain social support was found to buffer the relationships between workplace aggression and stressors. This result could be due to the fact that employees could have multiple co-workers and supervisors and the withindomain abuse and support could actually be coming from different people. Interestingly, the results suggest that even if an employee has an abusive supervisor they would be better off if the supervisor was supportive as well. Considering the social support 
measure tapped into both emotional and instrumental support, this could be due to a supervisor being both abusive and instrumentally supportive. Specifically, a supervisor may yell or berate employees but also be there to offer support on tasks as well. The social support measure combined instrumental and emotional support, however future research could consider differences in instrumental and emotional support in the withindomain buffering hypothesis. Although abuse and social support often relate negatively (as demonstrated in this study), this does not imply that abuse and support cannot come from the same source. Regardless of the source of the support, social support consistently acts to weaken the relationships between workplace aggression and outcomes. Specifically, social support acts as a buffer in the relationship between workplace aggression and outcomes. The one variable that did support the within-domain exacerbation hypothesis was perceived stress. This result held true for all three of the relationships tested in the within-domain hypothesis (conflict with supervisorsupervisor social support, abusive supervision - supervisor social support, and conflict with co-workers - co-worker social support). One possible explanation is that when the aggression and support are coming from the same source, one does not know what to expect (i.e., the helpful co-worker/supervisor or abusive co-worker/supervisor), leading to more perceived stress.

\section{Intensity as a Moderator}

Finally, the perceived intensity of aggression is a promising line of research that has not yet received much empirical testing (Nixon, 2011). The underlying assumption is that it is not the frequency of aggression that leads to negative outcomes but the intensity 
of the aggression perceived by the victim. This could be particularly true for interpersonal conflict, where scales commonly ask about frequency of arguments or disagreements (e.g., Jehn, 1995; Spector \& Jex, 1998) that could be seemingly innocuous.

The results of this study suggest that perceived intensity is a strong moderator of the relationships between conflict and outcomes, with thirteen of the sixteen relationships tested receiving support. Despite strong relationships between conflict and outcomes found in participants reporting greater intensity conflict (+1 SD), there was generally no relationship found between conflict and outcomes in participants reporting low intensity conflict (-1 SD). In fact, in participants reporting low intensity conflict, affective commitment actually significantly rises as conflict with co-workers becomes greater.

Researchers have long looked for an answer on whether conflict can be beneficial to outcomes or not (Jehn, 1995; Tjosvold, Hui, Ding, \& Hu, 2003; Van de Vliert and De Dreu, 1994). The findings of this study could help to explain the circumstances in which conflict can be detrimental to workplace processes. Considering the lack of relationship between conflicts believed to be low intensity and outcomes and the significant strength of relationships between conflict perceived to be intense and outcomes, intensity could be an extremely important moderating variable. Accordingly, it is not necessarily the conflict that has the significant impact but rather how that conflict is perceived.

The relationship between intensity and abusive supervision results were not as clear cut. The moderating effect of intensity was found on only one of the eight outcomes tested. This finding could be due to the low base rate with regards to intensity of abusive supervision. Although 311 participants responded to the abusive supervision questions in 
the survey, only 148 of them had experienced any amount of abusive supervision, a baseline that is common for most abusive supervision studies (e.g., Aryee et al., 2007, Tepper, 2000; Tepper et al., 2011), and even fewer were included in the regression analysis. This low base rate for abusive supervision intensity likely limited the effectiveness of the regression tests for moderation (Aguinis \& Stone-Romero, 1997). However, another possible explanation could be due to abusive supervision being generally regarded as a higher intensity form of workplace aggression (Hershcovis, 2011). This could lead to the intensity of the abusive supervision being captured in the abusive supervision scale greater than more ambiguous forms of aggression such as interpersonal conflict.

\section{Limitations}

The current study is not without its limitations, primarily the use of personal contacts as a method of recruiting participants, low sample size for some of the moderator variables, and the use of cross-sectional self-report instruments. Participants were recruited primarily through professional contacts of the primary researcher. This sample was not truly random and could share some common characteristics that may not be representative of the general population. However, the diversity achieved across occupations could be beneficial to generalize the results of the current study beyond a specific field or profession.

The low sample size achieved for abusive supervision intensity could have led to the non-significant findings. Detecting moderator effects is difficult due to the statistical 
power required by moderated multiple regression analyses (Aguinis \& Stone-Romero, 1997).

Based on the measures there could have been some confusion on what exactly constitutes a co-worker. For example, is a co-worker someone on the same level who you work directly with, or would this also include people at different levels who are not necessarily your supervisors or subordinates. Also, when measuring co-worker conflict or co-worker support there may be many people the participants could have been referring to. This would be particularly problematic for the within-domain hypothesis.

Another limitation of this study is the use of cross-sectional self-report instruments. The use of a cross-sectional design makes it more difficult to draw conclusions from mediational inferences (Spector, 1994). Additionally, cross-sectional data may lead to inflation in the relationships of variables due to common-methodvariance (CMV; Podsakoff, Mackenzie, Lee \& Podsakoff, 2003). Accordingly, scale characteristics such as common scale formats and common scale anchors could lead to inflation of results. These effects could be compounded by collecting data for all measures at one point in time. Indeed, CMV could lead to inflated results, however, Spector (2006) suggests that the impact of CMV is often exaggerated and suggests CMV it is not as damaging as previously believed.

\section{Directions for Future Research}

The results of this study have highlighted some interesting areas that are ripe for more research. First, the relationships between source of aggression and outcomes received mixed support in the current study. Future research should continue to measure the source of aggression and consider the differential impact on outcomes. Second, social 
support was found to be effective at buffering the relationship between workplace aggression and outcomes regardless of the sources. This finding is contrary to previous social support - aggression research (e.g., Duffy et al., 2002; Hobman et al., 2009). Future research should continue to explore these variables to clarify this relationship.

The results indicating that negative emotion was a mediator in the relationship between workplace aggression and outcomes was a key finding of this study. Future research should continue to explore this potentially important variable. Ideally, research should employ a longitudinal design to provide more compelling support for causality in this relationship. Additionally, the relationship between trait negative affectivity (NA) and state level affect should be considered. This can be accomplished using a longitudinal design and establishing base levels of NA. Using base levels of NA, more accurate state level changes in negative emotions can be determined.

Additionally, intensity of workplace aggression proved to be a very strong moderator of the relationships between interpersonal conflict and outcomes. This moderating relationship should receive further empirical testing to determine the generalizability of findings. However, researchers should keep in mind that due to the low base rates of many workplace aggression variables, a large sample size may be needed to detect the moderation effects of workplace aggression intensity.

Finally, researchers should consider the interaction between workplace aggression, intensity, social support and emotions in tandem. Specifically, researchers should consider the combined interactive effects of all of the variables of interest in this 
study. Although these relationships were tested separately, the possibility of a mediated moderation effect exists. 


\section{List of References}

Adams, A. (1992). Bullying at work: how to confront and overcome it. London: Virago.

Aiken, L., \& West, S. (1991). Multiple regression: Testing and interpreting interactions. Newbury Park, CA: Sage.

Aguinis, H. \& Stone-Romero E. F. (1997). Methodological artifacts in moderated multiple regression and their effects on statistical power. Journal of Applied Psychology, 82, 192-206.

Allen, J., Wittgenstein J., Harari, M., \& Bruk-Lee, V. (2012, November). A qualitative review of workplace aggression: Current trends and future directions. In P. Spector (Chair), Employee responses to workplace abuse. Symposium conducted at the Southern Management Association Meeting, Ft. Lauderdale, FL.

Andersson, L. M., \& Pearson, C. M. (1999). Tit for tat? The spiraling effect of incivility in the workplace. The Academy of Management Review, 24, 452-471.

Aquino, K., \& Bradfield, M. (2000). Perceived victimization in the workplace: The role of situational factors and victim characteristics. Organization Science, 11, 525537.

Aquino, K., Douglas, S., \& Martinko, M. J. (2004). Overt anger in response to victimization: Attributional style and organizational norms as moderators. Journal of Occupational Health Psychology, 9, 152-164.

Aquino, K., Grover, S. L., Bradfield, M., \& Allen, D. G. (1999). The effects of negative affectivity, hierarchical status, and self-determination on workplace victimization. Academy of Management Journal, 42, 260-272.

Aquino, K., Tripp, T. M., \& Bies, R. J. (2001). How employees respond to personal offense: The effects of blame attribution, victim status, and offender status on revenge and reconciliation in the workplace. Journal of Applied Psychology, 86, $52-59$.

Aryee, S., Chen, Z. X., Sun, L. Y., \& Debrah, Y. A. (2007). Antecedents and outcomes of abusive supervision: Test of a trickle-down model. Journal of Applied Psychology, 92,191-201.

Averill, J. (1982). Anger and aggression: An essay on emotion. Springer: New York.

Bamberger, P. A., \& Bacharach, S. B. (2006) Abusive supervision and subordinate problem drinking: Taking resistance, stress, and subordinate personality into account. Human Relations, 59, 1-30.

Barki, H., \& Hartwick, J. (2001). Interpersonal conflict and its management in information system development. MIS Quarterly, 25, 195-228. 
Barling, J. (1996). The prediction, experience, and consequences of workplace violence. In G. R.VandenBos \& E. Q. Bulatao (Eds.), Violence on the job: identifying risks and developing solutions (pp. 29-49). Washington, DC: American Psychological Association.

Baron, R., \& Neuman, J. (1996). Workplace violence and workplace aggression: Evidence on their relative frequency and potential causes. Aggressive Behavior, $22,161-173$.

Baumeister, R. F., \& Tice, D. M. (1990). Anxiety and social exclusion. Journal of Social and Clinical Psychology, 9, 165-195.

Bayazit, M., \& Mannix, E.A. (2003). Should I stay or should I go?: Predicting team members' intent to remain in the team. Small Group Research, 34, 290-321.

Beehr, T. A. (1994). Psychological stress in the workplace. New York: Routledge.

Beehr, T.A., Farmer, S.J., Glazer, S., Gudanowski, D.M., \& Nair, V.N. (2003). The enigma of social support and occupational stress: Source congruence and gender role effects. Journal of Occupational Health Psychology, 8, 220-231.

Benyamini, Y., \& Idler, E. L. (1999) Community studies reporting association between self-rated health and mortality: additional studies, 1995 to 1998. Res Aging, $21,392-401$.

Bies, R. (1999). Interactional (in)justice: The sacred and the profane. In J. R. Greenberg and R. Cropanzano (Eds.), Advances in organizational justice (pp. 89-118). Stanford, CA: Stanford University Press.

Blau, G. (1981). An empirical investigation of job stress, social support, service length and job strain. Organizational Behavior and Human Performance, 27, 279-302.

Bolger, N., DeLongis, A., Kessler, R.C., \& Schilling, E.A. (1989). Effects of daily stress on negative mood. Journal of Personality and Social Psychology, 57, 808-818.

Bowling, N. A, \& Beehr, T. A. (2006). Workplace harassment from the victim's perspective: A theoretical model and meta-analysis. Journal of Applied Psychology, 91, 998-1012.

Brief, A.P., Burke, M.J., George, J.M., Robinson, B.S., \& Webster, J. (1988). Should negative affectivity remain an unmeasured variable in the study of job stress? Journal of Applied Psychology, 73, 529-535.

Brief, A. P., \& Weiss, H. M. (2002). Organizational behavior: Affect in the workplace. Annual Review of Psychology, 53, 279-307.

Brondolo, E., Masheb, R., Stores, J., Stockhammer, T., Tunick, W., Melhado, E., Karlin, W., Schwartz, J., Harburg, E., \& Contrada, R.J. (1998). Anger-Related traits and 
response to interpersonal conflict among New York City traffic agents. Journal of Applied Social Psychology, 28, 2089-2118.

Bruk-Lee, V. (2006). Measuring social stressors in organizations: The development of the Interpersonal Conflict in Organizations Scale (ICOS). Unpublished Doctoral Dissertation, University of South Florida, Florida.

Bruk-Lee, V. \& Nixon, A.E. (2011). Non-task organizational conflict: An understudied source of social stress at work. Poster presented at the APA conference on Work, Stress, and Health, Orlando, Florida.

Bruk-Lee, V., \& Spector, P.E. (2006). The social stressors-counterproductive work behaviors link: Are conflicts with supervisors and coworkers the same? Journal of Occupational Psychology, 11, 145-156.

Buunk, B. P., \& Verhoeven, K. (1991). Companionship and support at work: A microanalysis of the stress-reducing features of social interaction. Basic and Applied Social Psychology, 12, 243-258.

Burton, J.P., Hoobler, J.M., \& Scheur, M.L. (2011). Blaming the boss for abuse: How locus of control influences workplace aggression. Presentation at the Society for Industrial and Organizational Psychologists (SIOP) Chicago, IL.

Cammann, C., Fichman, M., Jenkins, D., \& Klesh, J. (1979). The Michigan Organizational Assessment Questionnaire. Unpublished manuscript, University of Michigan, Ann Arbor.

Cantisano, G. T., Dominguez, J. F. \& Galan, J. A. G. (2006). Mobbing: Its relationships with organizational culture and personal outcomes. Psicothema, 18, 766-771.

Caplan, R. D., Cobb, S., French, J. R. P., Jr., Harrison, R. V., \& Pinneau, S. R. (1980). Job demands and worker health: Main effects and occupational differences. Ann Arbor, MI: Institute for Social Research.

Carsten, J.M., \& Spector, P.E. (1987). Unemployment, job satisfaction, and employee turnover: A meta-analytic test of the Muchinsky model. Journal of Applied Psychology, 72, 374-381.

Cartwright, S., \& Cooper, C. L. (1997). Managing workplace stress. Thousand Oaks, CA: Sage Publications.

Chen, G.C., Sharma, P.N., Edinger, S.K., Shapiro, D.L., \& Farh, J.L. (2011). Motivating and demotivating forces in teams: Cross-level influences of empowering leadership and relationship conflict. Journal of Applied Psychology, 96, 1-18.

Chen, P.Y., \& Spector, P.E. (1992). Relationships of work stressors with aggression, withdrawal, theft and substance use: An exploratory study. Journal of Occupational and Organizational Psychology, 65, 177-184. 
Cortina, L. M., Magley, V. J., Williams, J. H., \& Langhout, R. D. (2001). Incivility in the workplace: Incident and impact. Journal of Occupational Health Psychology, 6, 64-80.

De Dreu, C.K.W., \& Beersma, B. (2005). Conflict in organizations: Beyond effectiveness and performance. European Journal of Work and Organizational Psychology, 14, 105-117.

De Dreu, C.K.W., \& Weingart, L.R. (2003). Task versus relationship conflict, team performance, and team member satisfaction: A meta-analysis. Journal of Applied Psychology, 88, 741- 749.

de Jonge, J., Reuvers, M. M., Houtman, I. L., \& Kompier, M. A. (2000). Linear and nonlinear relations between psychosocial job characteristics, subjective outcomes, and sickness absence: Baseline results from SMASH. Journal of Occupational Health Psychology, 5, 256-268.

de Wit, F.R.C., Greer, L.L., \& Jehn, K.A. (2012). The paradox of intragroup conflict: A meta-analysis. Journal of Applied Psychology, 97, 360-390.

Dormann, C., \& Zapf, D. (1999). Social support, social stressors at work, and depressive symptoms: Testing for main and moderating effects with structural equations in a three-wave longitudinal study. Journal of Applied Psychology, 84, 874-884.

Duffy, M.K., \& Ferrier, W.J. (2003). Birds of a feather...? : How supervisor-subordinate dissimilarity moderates the influence of supervisor. Group and Organization Management, 28, 217-248.

Duffy, M. K., Ganster, D., \& Pagon, M. (2002). Social undermining in the workplace. Academy of Management Journal, 45, 331-351.

Duffy, M.K., Shaw, J.D. \& Stark, E.M. (2000). Performance and Satisfaction in Conflicted Interdependent Groups: When and How Does Self-Esteem Make a Difference? The Academy of Management Journal, 43, 772-782.

Dupre, K.E., Inness, M., Connelly, C.E., Barling, J., \& Hoption, C. (2006). Workplace aggression in teenage part-time employees. Journal of Applied Psychology, 91, 987-997.

Etzion, D. (1984). Moderating effect of social support on the stress-burnout relationship. Journal of Applied Psychology, 69, 615-622.

Evans, O., \& Steptoe, A. (2001). Social support at work, heart rate, and cortisol: A selfmonitoring study. Journal of Occupational Health Psychology, 6, 361-370.

Fredrickson, B. L., \& Levenson, R.W. (1998). Positive emotions speed recovery from the cardiovascular sequelae of negative emotions. Cognition and Emotion, 12, 191220. 
Fisher, C. D. (2000). Moods and emotions while working: Missing pieces of job satisfaction? Journal of Organizational Behavior, 21, 185-202.

Frone, M.L. (1998). Predictors of work injuries among employed adolescents. Journal of Applied Psychology, 83, 565-576.

Frone, M.R. (2000). Interpersonal conflict at work and psychological outcomes: Testing a model among young workers. Journal of Occupational Health Psychology, 5, 246-255.

Gerberich, S.G., Church, T.R., McGovern, P.M., Hansen, H.E., Nachreiner, N.M., Geisser, A.D., Ryan, A.D., \& Mongin, S.J. (2004). An epidemiological study of the magnitude and consequences of work related violence: The Minnesota nurses' study. Occupational Environmental Medicine, 61, 495-503.

Goldberg, D.(1978). Manual of the General Health Questionnaire. Windsor, UK: National Foundation for Educational Research.

Grandey, A. A., Kern, J., \& Frone, M. (2007). Verbal abuse from outsiders versus insiders: Comparing frequency, impact on emotional exhaustion, and the role of emotional labor. Journal of Occupational Health Psychology, 12, 63-79.

Grandey, A. A., Tam, A. P., \& Brauburger, A. L. (2002). Affective states and traits in the workplace: Diary and survey data from young workers. Motivation and Emotion, $26,31-55$.

Greenglass, E. R. (1996). Anger suppression, cynical distrust, and hostility: Implications for coronary heart disease. (pp. 205-225). In C. D. Spielberger, I. G. Sarason, J. M. T. Brebner, E. Greenglass, P. Laungani, \& A. M. O'Roark (Eds.). Stress and Emotion: Anxiety, Anger, and Curiosity, Vol. 16. Washington, D.C.: Taylor \& Francis.

Guerra, J.M., Martinez, I., Munduate, L., \& Medina, F.J. (2005). A contingency perspective on the study of the consequences of conflict types: The role of organizational culture. European Journal of Work and Organizational Psychology, 14, 157-176.

Halbesleben, J. R. B. (2006). Sources of social support and burnout: A meta-analytic test of the conservation of resources model. Journal of Applied Psychology, 91, 11341145 .

Hahn, S.E. (2000). The effects of locus of control on daily exposure, coping and reactivity to work interpersonal stressors: A diary study. Personality and Individual Differences, 29, 729-748.

Hamm-Kerwin, S. \& Doherty, A.J. (2010). Intragroup conflict in nonprofit sport boards. Journal of Sport Management, 24, 245-271. 
Harris, K.J., Harvey, P., \& Kacmar, K.M. (2011). Abusive supervisory reactions to coworker relationship conflict. The Leadership Quarterly, 22, 1010-1023.

Hershcovis, M.S. (2011). "Incivility, social undermining, bullying. . .oh my!'”: A call to reconcile constructs within workplace aggression research. Journal of Organizational Behavior, 42, 499-519.

Hershcovis, M. S., \& Barling, J. (2010). Towards a multi-foci approach to workplace aggression: A meta-analytic review of outcomes from different perpetrators. Journal of Organizational Behavior, 31, 24-44.

Hobman, E.V., Restubog, S.L.V., Bordia, P., \& Tang, R.L. (2009). Abusive Supervision in Advising Relationships: Investigating the Role of Social Support. Applied Psychology: An International Review, 58, 233-256.

Hoobler, J.M., \& Brass, D.J. (2006). Abusive supervision and family undermining as displaced aggression. Journal of Applied Psychology, 91, 1125-1133.

Ilies, R., Johnson, M.D., Judge, T.A., \& Keeney, J. (2011). A within-individual study of interpersonal conflict as a work stressor: Dispositional and situational moderators. Journal of Organizational Behavior, 32, 44-64.

Ilies, R., \& Judge, T. A. (2002). Understanding the dynamic relationship between personality, mood, and job satisfaction: A field experience sampling study. Organizational Behavior and Human Decision Processes, 89, 1119-1139.

Ilies, R., Scott, B. A., \& Judge, T. A. (2006). The interactive effects of personal traits and experienced states on intraindividual patterns of citizenship behavior. Academy of Management Journal, 49, 561-575.

Inness, M., Barling, J., \& Turner, N. (2005). Understanding supervisor-targeted aggression: A within- person, between-jobs design. Journal of Applied Psychology, 90, 731-739.

Janssen, O. (2004). The barrier effect of conflict with superiors in the relationship between employee empowerment and organizational commitment. Work and Stress, 18, 56-65.

Jehn, K. (1995). A multimethod examination of the benefits and detriments of intragroup conflict. Administrative Science Quarterly, 40, 256-282.

Jehn, K.A., Northcraft, G.B., \& Neale, M.A. (1999). Why differences make a difference: A field study of diversity, conflict, and performance in workgroups. Administrative Science Quarterly, 44, 741-763.

Jex, S.M., \& Beehr, T.A. (1991). Emerging theoretical and methodological issues in the study of work-related stress. Personnel and Human Resources Management, 9 , 311-365. 
Julkunen, J. (1996). Suppressing your anger: Good manners, bad health? (pp. 227-240). In C. D. Spielberger, I. G. Sarason, J. M. T. Brebner, E. Greenglass, P. Laungani, \& A. M. O'Roark (Eds.). Stress and Emotion: Anxiety, Anger, and Curiosity, Vol. 16. Washington, D.C.: Taylor \& Francis.

Karasek, R. A. (1979). Job demands, job decision latitude, and mental strain: Implications for job redesign. Administrative Science Quarterly, 24, 285-308.

Keenan, A., \& Newton, T.J. (1985). Stressful events, stressors and psychological strains in young professional engineers. Journal of Occupational Behavior, 6, 151-156.

Kivimaki, M., Ferrie, J., Brunner, E., Head, J., Shipley, M., Vahtera, J., et al. (2005). Justice at work and reduced risk of coronary heart disease among employees. Archives of Internal Medicine, 165, 2245-2251.

Klainin, P. (2009). Stress and health outcomes: The mediating role of negative affectivity in female healthcare workers. International Journal of Stress Management, 16, 45-64.

Lavoie,K.L., Miller, S.B., Conway, M. \& Fleet, R.P. (2001). Anger, negative emotions, and cardiovascular reactivity during interpersonal conflict in women. Journal of Psychosomatic Research, 51, 503-512.

Lazarus, R. S., \& Folkman, S. (1984). Stress, appraisal, and coping. New York: Springer.

Leavy, R. L. (1983). Social support and psychological disorder: A review. Journal of Community Psychology, 11, 3-21.

LeBlanc, M., \& Kelloway, E. (2002). Predictors and outcomes of workplace violence and aggression. Journal of Applied Psychology, 87, 444-453.

Lee, R. T., \& Ashforth, B. E. (1996). A meta-analytic examination of the correlates of the three dimensions of job burnout. Journal of Applied Psychology, 81, 123-133.

Leventhal, H., \& Patrick-Miller, L. (2000). Emotions and physical illness: Causes and indicators of vulnerability. In M. Lewis \& J. M. Haviland-Jones (Eds.), Handbook of emotions ( $2^{\text {nd }}$ ed., pp. 523-537). New York: Guilford.

Lian, H., Ferris, D. L., \& Brown, D. J. (2012). Does Power Distance Exacerbate or Mitigate the Effects of Abusive Supervision? It Depends on the Outcome. Journal of Applied Psychology, 97, 107-123.

Li, Y., Ahlstrom, D., \& Ashkanasy, N.M. (2010). A multilevel model of affect and organizational commitment. Asia Pacific Journal of Management, 27, 193-213.

Liu, J., Kwan, H.O., Wu, L.Z., \& Wu, W. (2010). Abusive supervision and subordinate supervisor-directed deviance: The moderating role of traditional values and the 
mediating role of revenge cognitions. Journal of Occupational and Organizational Psychology, 83, 835-856.

Liu, C., Spector, P.E., \& Shi, L. (2005). Use of both qualitative and quantitative approaches to study job stress in different gender and occupational groups. Journal of Occupational Health Psychology, 13, 357-370.

Loeber, R., \& Hay, D. (1997). Key issues in the development of aggression and violence from childhood to early adulthood. Annual Review of Psychology, 48, 371-410.

Lubbers, R., Loughlin, C., \& Zweig, D. (2005). Young workers' job self-efficacy and affect: Pathways to health and performance. Journal of Vocational Behavior, 67, 199-214.

Marrs, M. E. M. (1999). Antecedents and outcomes of verbal aggression in the workplace. Unpublished doctoral dissertation, University of Missouri, Columbia.

Medina, F.J., Munduate, L., Dorado, M.A., Martinez, I., \& Guerra, J.M. (2005). Types of intragroup conflict and affective reactions. Journal of Managerial Psychology, 20, 219- 230.

Mendelson, M.B., Catano, V.M., \& Kelloway, K. (2000). The role of stress and social support in Sick Building Syndrome. Work \& Stress, 14, 137-155.

Meyer, J. P., \& Allen, N. J. (1991). A three-component conceptualization of organizational commitment. Human Resource Management Review, 1, 61-98.

Meyer, J. P., Allen, N. J., \& Smith, C. A. (1993). Commitment to organizations and occupations: Extension and test of a three-component conceptualization. Journal of Applied Psychology, 78, 538-551.

Mitchell, M. S., \& Ambrose, M. L. (2007). Abusive supervision and workplace deviance and the moderating effects of negative reciprocity beliefs. Journal of Applied Psychology, 92, 1159-1168.

Molm, L. D. (1988). The structure and use of power: A comparison of reward and punishment power. Social Psychology Quarterly, 51, 109-122.

Nakata, A., Haratani, T., Takahashi, M., Kawakami, N., Arito, H., Kobayashi, F., \& Araki, S. (2004). Job Stress, social support, and prevalence of insomnia in a population of Japanese daytime workers. Social Science \& Medicine, 59, 17191730.

Narayanan, L., Menon, S., \& Spector, P.E. (1999). A cross-cultural comparison of job stressors and reaction among employees holding comparable jobs in two countries. International Journal of Stress Management, 6, 197-212. 
Nelson, M.L., \& Friedlander, M.L. (2001). A close look at conflictual supervisory relationships: The trainee's perspective. Journal of Counseling Psychology, 48, 384-395.

Nixon, A.E. (2011). Charting a Semantic Jungle: A Novel Method for Examining the Moderators of Workplace Aggression. Unpublished Doctoral Dissertation, University of South Florida, Florida.

Nixon, A.E., Mazzola, J.J., Bauer, J., Krueger, J.R., \& Spector, P.E. (2011). Can work make you sick? A meta-analysis of the relationships between job stressors and physical symptoms. Work and Stress, 25, 1-22.

O’Leary, A. (1990). Stress, emotion, and human immune function. Psychological Bulletin, 108, 363-382.

Olweus D. (1978). Aggression in schools: Bullies and whipping boys. Washington, DC: Hemisphere.

Peeters, M.C.W., Buunk, B.P., \& Schaufeli, W.B. (1995). Social interactions and feelings of inferiority among correctional officers: A daily event-recording approach. Journal of Applied Social Psychology, 25, 1025-1089.

Penney, L.M., \& Spector. P.E. (2005). Job stress, incivility, and counterproductive work behavior (CWB): the moderating role of negative affectivity. Journal of Organizational Behavior, 26, 777-796.

Piferi, R.L., \& Lawler, K.A. (2000). Hostility and cardiovascular reactivity of women during interpersonal confrontation. Women and Health, 30, 111-129.

Podsakoff, P. M., MacKenzie, S. B., Lee, J. Y., \& Podsakoff, N. P. (2003). Common method biases in behavioral research: A critical review of the literature and recommended remedies. Journal of Applied Psychology, 88, 879-903.

Pondy, L. R. (1969). Varieties of organizational conflict. Administrative Science Quarterly, 14, 499-506.

Potter, P. T., Smith, B. W., Strobel, K. R., \& Zautra, A. J. (2002). Interpersonal workplace stressors and well-being: A multiwave study of employees with and without arthritis. Journal of Applied Psychology, 87, 789-796.

Rafferty, A.E., Restubog, S.L.D., \& Jimmieson, N.L. (2010). Losing sleep: Examining the cascading effects of supervisors' experience of injustice on subordinates' psychological health. Work \& Stress, 24, 36-55.

Raver, J.L., \& Barling, J. (2008). Workplace aggression and conflict: Constructs, commonalities, and challenges for future inquiry. In The psychology of conflict and conflict management in organizations, edited by De Dreu, Carsten K. W., 
Gelfand, Michele J., 211-244. New York, NY: Taylor \& Francis Group/Lawrence Erlbaum Associates, 2008.

Rook, K. S. (2001). Emotional health and positive versus negative social exchanges: A daily diary analysis. Applied Developmental Science, 5, 86-97.

Schat, A. C. H., \& Kelloway, E. (2003). Reducing the adverse consequences of workplace aggression and violence: The buffering effects of organizational support. Journal of Occupational Health Psychology, 8, 110-122.

Schat, A. C. H., Frone, M., \& Kelloway, E. K. (2006). The prevalence of workplace aggression in the U.S. workforce: Findings from a national study.In E. K. Kelloway, J. Barling, \& J. J. Hurrell Jr. (Eds.), Handbook of workplace violence (pp. 579-606). Thousand Oaks,CA: Sage.

Schwartz, J.E., \& Stone, A.A. (1993). Coping with daily work problems: Contributions of problem content, appraisals, and person factors. Work and Stress, 7, 47- 62.

Smith, C., \& Ellsworth, P. (1985). Patterns of cognitive appraisal in emotion. Journal of Personality and Social Psychology, 48, 813-838.

Smith, C.S., \& Sulsky, L. (1995). An investigation of job-related coping strategies across multiple stressors and samples. In L.R. Murphy, J.J. Hurrell, S.L. Sauter, \& G.P. Keita (Eds.), Job stress interventions (pp. 109-123). Washington, DC: American Psychological Association.

Spector, P.E. (1978). Organizational frustration: A model and review of the literature. Personnel Psychology, 31, 815-829.

Spector, P. (1987). Interactive effects of perceived control and job stressors on affective reactions and health outcomes for clerical workers. Work and Stress, 1, 155-162.

Spector, P.E. (2006). Method variance in organizational research: Truth or urban legend? Organizational Research Methods, 9, 221-232.

Spector, P.E., \& Bruk-Lee, V. (2008). Conflict, Health, and Well-Being. In The psychology of conflict and conflict management in organizations, edited by De Dreu, Carsten K. W., Gelfand, Michele J., 267-288. New York, NY:Taylor \& Francis Group/Lawrence Erlbaum Associates, 2008.

Spector, P. E., Chen, P. Y., \& O'Connell, B. J. (2000). A longitudinal study of relations between job stressors and job strains while controlling for prior negative affectivity and strains. Journal of Applied Psychology, 85, 211-218.

Spector, P.E., Dwyer, D.J., \& Jex, S.M. (1988). Relation of job stressors to affective, health, and performance outcomes: A comparison of multiple data sources. Journal of Applied Psychology, 73, 11-19. 
Spector, P. E., \& Jex, S. M. (1998). Development of four self-report measures of job stressors and strain: Interpersonal conflict at work scale, organizational constraints scale, quantitative workload inventory, and physical symptoms inventory. Journal of Occupational Health Psychology, 3, 356-367.

Spector, P.E., Zapf, D., Chen, P.Y., \& Frese, M. (2000). Why negative affectivity should not be controlled in job stress research: Don't throw out the baby with the bath water. Journal of Organizational Behavior, 21, 79-95.

Spence Laschinger, H.K., Leiter, M., Day, A., \& Gilin, D. (2009). Workplace empowerment, incivility, and burnout: impact on staff nurse recruitment and retention outcomes. Journal of Nursing Management, 17, 302-311.

Spooner-Lane, R. (2004). The influence of work stress and work support on burnout in public hospitals nurses. Unpublished masters thesis, Queensland University of Technology, Australia.

Steptoe, A. (2000). Stress, social support and cardiovascular activity over the working day. International Journal of Psychophysiology, 37, 299-308.

Stone, A. A. (1987). Event content in a daily survey is differentially associated with concurrent mood. Journal of Personality and Social Psychology, 52, 56-58.

Taylor, S. E. (1991). The asymmetrical impact of positive and negative events: The mobilization-minimization hypothesis. Psychological Bulletin, 110, 67-85.

Tepper, B. J. (2000). Consequences of abusive supervision. Academy of Management Journal, 43, 178-190.

Tepper, B. J. (2007). Abusive supervision in work organizations: Review, synthesis, and research agenda. Journal of Management, 33, 261-289.

Tepper, B. J., Duffy, M. K., Hoobler, J. M., \& Ensley, M. D. (2004) Moderators of the relationship between coworkers' organizational citizenship behavior and fellow employees' attitudes. Journal of Applied Psychology, 89, 455-465.

Tepper, B. J., Duffy, M. K., Henle, C. A., \& Lambert, L. S. (2006). Procedural injustice, victim precipitation, and abusive supervision. Personnel Psychology, 59, 101123.

Tepper, B.J., \& Henle, C.A. (2011). A case for recognizing distinctions among constructs that capture interpersonal mistreatment in work organizations. Journal of Organizational Behavior, 32, 487-498.

Tepper, B.J., \& Henle, C.A., Lambert, L.S., Giacalone, R.A., \& Duffy, M.K. (2008). Abusive supervision and subordinates' organizational deviance. Journal of Applied Psychology, 93, 721-732. 
Tepper, B. J., Moss, S., \& Duffy, M. K. (2011). Antecedents of abusive supervision: Supervisor perceptions of deep-level dissimilarity, relationship conflict, and subordinate performance. Academy of Management Journal, 54, 279-294.

Thomas, J. L., Bliese, P. D., \& Jex, S., M. (2005). Interpersonal conflict and organizational commitment: Examining two levels of supervisory support as multilevel moderators. Journal of Applied Social Psychology, 35, 2375-2398.

Tjosvold, D., Hui, C., Ding, D.Z., \& Hu, J. (2003) Conflict values and team relationships: Conflict's contributions to team effectiveness and citizenship in China. Journal of Organizational Behavior, 24, 69-88.

Tucker, J.S., Sinclair, R.R., \& Thomas, J.L. (2005). The multilevel effects of occupational stressors on soldiers' well-being, organizational attachment, and readiness. Journal of Occupational Health Psychology, 3, 276-299.

Twenge, J. M., Baumeister, R. F., Tice, D. M., \& Stuck, T. S. (2001). If you can't join them, beat them: Effects of social exclusion on aggressive behavior. Journal of Personality and Social Psychology, 81, 1058-1069.

U.S. Postal Service Commission on a Safe and Secure Workplace. (2000). Report of the United States Postal Service Commission on a Safe and Secure Workplace. New York: Columbia University, National Center on Addiction and Substance Abuse.

Van de Vliert, E., \& de Dreu, C. (1994). Optimizing performance by conflict stimulation. International Journal of Conflict Management, 5, 211-222.

VandenBos, G. R. \& Bulatao E. Q. (1996). Violence on the job: Identifying risks and developing solutions. Washington, DC: American Psychological Association.

Van Katwyk, P. T., Fox, S., Spector, P. E., \& Kelloway, E. K. (2000). Using the JobRelated Affective Wellbeing Scale (JAWS) to investigate affective responses to work stressors. Journal of Occupational Health Psychology, 5, 219-230.

Viswesvaran, C., Sanchez, J.I., \& Fisher, J. (1999). The role of social support in the process of work stress: A meta-analysis. Journal of Vocational Behavior, 54, $314-334$.

Vittengl, J. R., \& Holt, C. S. (1998). A time-series diary study of mood and social interaction. Motivation and Emotion, 22, 255-275.

Vodosek, M. (2007). Intragroup conflict as a mediator between cultural diversity and work group outcomes. International Journal of Conflict Management, 18, 345375 .

Warr, P. (1998). Age, work, and mental health. In K. W. Schaie \& C. Schooler (Eds.), Impact of work on older adults (pp. 252-296). New York: Springer. 
Watson, D. (1988). Intraindividual and interindividual analyses of positive and negative affect: Their relation to health complaints, perceived stress, and daily activities. Journal of Personality and Social Psychology, 54, 1020-1030.

Watson, D., \& Clark, L.A. (1984). Negative affectivity: The disposition to experience aversive emotional states. Psychological Bulletin, 96, 465-490.

Weiss, H. M., \& Cropanzano, R. (1996). Affective events theory: A theoretical discussion of the structure, causes and consequences of affective experiences at work. Research in Organizational Behavior, 18, 1-74.

Williams, E. J. (1959). The comparison of regression variables. Journal of the Royal Statistical Society (Series B), 21, 396-399.

Yagil, D. (2006). The relationship of abusive and supportive workplace supervision to employee Burnout and upward influence tactics. Journal of Emotional Abuse, 6, 49-65.

Zohar, D. (1999). When things go wrong: The effect of daily work hassles on effort, exertion and negative mood. Journal of Occupational and Organizational Psychology, 72, 265-283. 
Appendix A: IRB Approval

\begin{tabular}{l|l}
5 \\
$5 \square$
\end{tabular} \mid $\begin{aligned} & \text { LLORIDA } \\
& \text { INTERNATIONAL } \\
& \text { UNIVERSITY }\end{aligned}$

\section{MEMORANDUM}

To: Josh Allen

CC: $\quad$ Dr. Valentina Bruk-Lee

From:

Date: December 7, 2012

Proposal Title: $\quad$ "Testing And Expanding An Emotion-Centered Model Of Workplace Aggression: The Moderating Effects Of Perceived Intensity And Social Support In The Workplace"

IRB Exemption \# 112012-00

The Social and Behavioral Institutional Review Board of Florida International University has reviewed your study for the use of human subjects via the Exempt Review process. Your study was deemed Exempt by the Institutional Review Board on November 20, 2012.

As a requirement of IRB approval you are required to:

1) Submit a completion report (Form B-2) upon completion of your project in order for the file to be closed.

2) Submit a proposal and receive approval for any additions or changes in the procedures involving human subjects.

3) Provide immediate written notification to the IRB of every serious or unusual or unanticipated adverse event as well as problems with the rights or welfare of the human subjects. You must confirm the receipt of serious AE reports with the IRB office.

4) Close out your project with the IRB office when the study is finished or discontinued.

Special Conditions: N/A

Please note that your IRB exemption number is indicated above. For further information, you may visit the FIU IRB website at http://research.fiu.edu/compliance/compliance.html. 
Appendix B: Demographic Information

Gender? M or F

Age in years?

On average, how many hours of week do you work?

How many years have you been at your current company?

What is your race?

1. White/Caucasian

2. African American

3. Hispanic

4. Asian

5. Native American

6. Pacific Islander

7. Other

What type of industry do you work in?

1. Trades/Skilled Labor

2. Education/Academia

3. Management, professional and related

4. Technical

5. Service

6. Health/Medical Care

7. Government

8. Other, please indicate

What type of job do you perform?

1. Sales

2. Customer Service

3. Technical

4. Clerical

5. Managerial

6. Training

7. Professional

8. Other, please indicate 
Appendix C: Conflict with Supervisors and Coworkers and Intensity Scale (Frone, 2000;

Nixon, 2011)

Please answer this question and the follow up question considering the past month

If previous question has been experienced please answer

Conflict five point likert $1=$ never $5=$ all the time

Follow up questions are answered on a 5 point likert $1=$ not at all $5=$ greatly

Supervisors

1a. How often do you get into arguments with your supervisor?

1b. In general, how much did these arguments upset you?

2a. How often does your supervisor yell at you at work?

b. In general, how much does this yelling upset you?

3a. How often is your supervisor rude to you at work?

3 b. In general, how much does this rudeness upset you?

4a. How does you supervisor do nasty things to you at work?

4b. In general, how much do these nasty things upset you?

\section{Coworkers}

1a. How often do you get into arguments with your coworkers?

1b. In general, how much did these arguments upset you?

2a. How often do coworkers yell at you at work?

2b. In general, how much does this yelling upset you?

3a. How often are coworkers rude to you at work?

$3 \mathrm{~b}$. In general, how much does this rudeness upset you?

4a. How often do coworkers do nasty things to you at work?

4b. In general, how much do these nasty things upset you? 
Appendix D: Abusive Supervision Scale and Intensity Scale (Ambrose \& Mitchell, 2007; Nixon, 2011)

During the past year have you been in a situation where any of your superiors:

If previous question has been experienced please answer

5 point likert scale with $1=$ cannot remember him/her using this behavior with me and 5

$=$ he/she often uses this behavior with me

Follow up questions are answered on a 5 point likert $1=$ not at all $5=$ greatly

During the past 5 years have you been in a situation where any of your superiors:

1a. Ridiculed me?

1b. In general, how much did this behavior upset you?

2a. Tells me my thoughts and feelings are stupid?

2b. In general, how much did this behavior upset you?

3a. Puts me down in front of others?

3b. In general, how much did this behavior upset you?

4a. Makes negative comments about me to others?

4b. In general, how much did this behavior upset you?

5a. Tells me I'm incompetent?

$5 b$. In general, how much did this behavior upset you? 
Appendix E: Job-related Affective Well-being Scale (JAWS; Van Katwyk; Fox, Spector \& Kelloway, 1999)

Below are a number of statements that describe different emotions that a job can make a person feel. Please indicate the amount to which any part of your job (e.g., the work, coworkers, supervisor, clients, pay) has made you feel that emotion in the past 30 days.

\begin{tabular}{|c|c|c|c|c|c|}
\hline $\begin{array}{l}\text { Please check one response for each item that best indicates how } \\
\text { often you've experienced each emotion at work over the past } 30 \\
\text { days. }\end{array}$ & $\begin{array}{l}\bar{D} \\
\stackrel{\bar{\nu}}{Z}\end{array}$ & $\frac{\lambda}{0}$ & 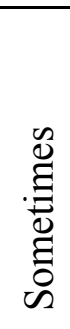 &  &  \\
\hline 1. My job made me feel angry. & & & & & \\
\hline 2. My job made me feel anxious. & & & & & \\
\hline 3. My job made me feel bored. & & & & & \\
\hline 4. My job made me feel depressed. & & & & & \\
\hline 5. My job made me feel discouraged. & & & & & \\
\hline 6. My job made me feel disgusted. & & & & & \\
\hline 7. My job made me feel fatigued. & & & & & \\
\hline 8. My job made me feel frightened. & & & & & \\
\hline 9. My job made me feel furious. & & & & & \\
\hline 10. My job made me feel gloomy. & & & & & \\
\hline
\end{tabular}


Appendix F: Workplace Social Support (adapted from Hobman et al., 2009; SpoonerLane, 2004)

Please indicate how much you agree with following statements

5 point likert $1=$ strongly disagree $5=$ strongly agree

\section{Coworker}

1. My coworkers help me figure out how to solve problems.

2. My coworkers always seem to make time for me if I need to discuss my work.

3. My coworkers cooperate with me to get things done at work.

4. I feel comfortable asking my coworkers for help if I have a problem.

5. When I'm frustrated by some aspect of my work, my coworkers try to understand.

6. My coworkers are understanding and sympathetic.

Supervisor

7. My supervisor helps me figure out how to solve problems.

8. My supervisor always seems to make time for me if I need to discuss my work.

9. My supervisor cooperates with me to get things done at work.

10. I feel comfortable asking my supervisor for help if I have a problem.

11. When I'm frustrated by some aspect of my work, my supervisor tries to understand.

12. My supervisor is understanding and sympathetic. 
Appendix G: Turnover Intentions (Cammann, Fichman, Jenkins, \& Klesh, 1979)

Please indicate how much you agree with the following statements

5 point Likert scale with $1=$ strongly disagree and $5=$ strongly agree

1. I am currently able and willing to take a better job with a different employer in my current field if one becomes available

2. I am currently able and willing to relocate to take a better job with a different employer in my current field if one becomes available.

3. In the past year, I have thought about looking for a job with a different employer.

4. In the past year, I have applied for a job with a different employer in my current field.

5. I plan to seek employment with a different employer in my current field during the next year.

6. I do not plan to continue working for my current employer during the next five years. 
Appendix H: Job Satisfaction (Cammann, Fichman, Jenkins, \& Klesh, 1979)

Please indicate how much you agree with the following statements 5 point likert scale with $1=$ strongly disagree and $5=$ strongly agree

1. All in all I am satisfied with my current job.

2. In general, I don't like my current job.

3. In general, I like working in my current job. 
Appendix I: Affective commitment (Meyer, Allen \& Smith, 1993)

Please indicate how much you agree with the following statements

5 point likert $1=$ strongly disagree $5=$ strongly agree

1. I would be very happy to spend the rest of my career with this organization.

2. I really feel as if this organization's problems are my own.

3. I do not feel a strong sense of "belonging" to my organization. (R)

4. I do not feel "emotionally attached" to this organization. (R)

5. I do not feel like "part of the family" at my organization. (R)

6. This organization has a great deal of personal meaning for me. 
Appendix J: Perceived Stress Scale (PSS; Cohen, Kamarck, \& Mermelstein, 1983)

The questions on this page ask you about your feelings and thoughts during the last month. In each case, you will be asked to indicate by selecting how often you felt or thought a certain way

5 point likert scale with $1=$ never and $5=$ very often

1. In the last month, how often have you been upset because of something that happened unexpectedly?

2. In the last month, how often have you felt that you were unable to control the important things in your life?

3. In the last month, how often have you felt nervous of "stressed"?

4. In the last month, how often have you felt confident about your ability to handle your personal problems?

5. In the last month, how often have you felt that things were going your way?

6. In the last month, how often have you found that you could not cope with all the things you had to do?

7. In the last month, how often have you been able to control irritations in your life

8. In the last month, how often have you felt that you were on top of things

9. In the last month, how often have you been angered because of things that happened that were outside of your control?

10. In the last month, how often have you felt difficulties were piling up so high that you could not overcome them? 
Appendix K: General Well-Being (GHQ-12; Goldberg, 1978)

Please indicate the extent to which you have experienced these things in the past month

4 point likert $1=$ not at all $4=$ very often

1. Able to concentrate

2. Loss of sleep over worry

3. Playing a useful part

4. Capable of making decisions

5. Felt constantly under strain

6. Couldn't overcome difficulties

7. Able to enjoy day-to-day activities

8. Able to face problems

9. Feeling unhappy or depressed

10. Losing confidence

11. Thinking of self as worthless

12. Feeling reasonably happy 
Appendix L: Work-Related Depression, Anxiety, and Irritation (Caplan, Cobb, French, Harrison, \& Pinneau, 1980)

Please indicate how often you have felt each statement in the past month

4-point scale $1=$ never $4=$ most of the time

Depression

1. I feel sad

2. I feel unhappy

3. I feel $\operatorname{good}(\mathrm{R})$

4. I feel depressed

5. I feel blue

6. I feel cheerful (R)

Irritation

7. I get angry

8. I get aggravated

9. I get irritated or annoyed 
Appendix M: Physical Symptom Inventory (PSI; Spector \& Jex, 1998)

During the past $\mathbf{3 0}$ days did you have any of the following symptoms?

7 point scale $1=$ not at all $7=$ several times a day

During the past 30 days did you have?

1. An upset stomach or nausea

2. A backache

3. Trouble sleeping

4. A skin rash

5. Shortness of breath

6. Chest pain

7. Headache

8. Fever

9. Acid indigestion or heartburn

10. Eye strain

11. Diarrhea

12. Stomach cramps (Not menstrual)

13. Constipation

14. Heart pounding when not exercising

15. An infection

16. Loss of appetite

17. Dizziness

18. Tiredness or fatigue 
Appendix O: Results of Confirmatory Factor Analysis

\begin{tabular}{lccccc} 
Model & DF & $\mathrm{x}^{2}$ & CFI & RMSEA & PCLOSE \\
\hline 3- Factor Aggression Model & 62 & 397.21 & .88 & .13 & .00 \\
$\begin{array}{l}\text { 2- Factor Aggression Model (Conflict and } \\
\text { Abusive Supervision) }\end{array}$ & 63 & 453.86 & .87 & .14 & .00 \\
$\begin{array}{l}\text { 2- Factor Aggression Model (Supervisor and } \\
\text { Co-worker) }\end{array}$ & 64 & 540.08 & .84 & .15 & .00 \\
1- Factor Aggression Model & 65 & 625.24 & .81 & .16 & .00 \\
\hline $\begin{array}{l}\text { 3- Factor Intensity Model } \\
\text { 2- Factor Intensity Model (Conflict and }\end{array}$ & 62 & 232.45 & .81 & .09 & .00 \\
$\begin{array}{l}\text { Abusive Supervision) } \\
\text { 2- Factor Intensity Model (Supervisor and Co- }\end{array}$ & 64 & 241.07 & .81 & .09 & .00 \\
worker) In & 242.86 & .80 & .09 & .00 \\
1- Factor Intensity Model & 65 & 250.20 & .80 & .09 & .00 \\
\hline $\begin{array}{l}\text { 2- Factor Social Support Model } \\
\text { 1- Factor Social Support Model }\end{array}$ & 53 & 227.86 & .93 & .10 & .00 \\
\hline
\end{tabular}

* Note. Although model fit is not good for the aggression and intensity models, the hypothesized 3 factor models fit better than the 2 factor and 1 factor alternatives. 